McNeill, L.C., Shillington, D.J., Carter, G.D.O., and the Expedition 381 Participants

Proceedings of the International Ocean Discovery Program Volume 381

publications.iodp.org

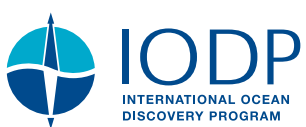

Check for updates

Contents

\section{Expedition 381 methods ${ }^{1}$}

L.C. McNeill, D.J. Shillington, G.D.O. Carter, J.D. Everest, E. Le Ber, R.E.Ll. Collier,

A. Cvetkoska, G. De Gelder, P. Diz, M.-L. Doan, M. Ford, R.L. Gawthorpe,

M. Geraga, J. Gillespie, R. Hemelsdaël, E. Herrero-Bervera, M. Ismaiel, L. Janikian,

K. Kouli, S. Li, M.L. Machlus, M. Maffione, C. Mahoney, G. Michas, C. Miller,

C.W. Nixon, S.A. Oflaz, A.P. Omale, K. Panagiotopoulos, S. Pechlivanidou,

M.P. Phillips, S. Sauer, J. Seguin, S. Sergiou, and N.V. Zakharova²

Keywords: International Ocean Discovery Program, IODP, D/V Fugro Synergy, mission-specific platform, Expedition 381, Site M0078, Site M0079, Site M0080, Corinth rift, Gulf of Corinth, Alkyonides Gulf, Eastern Mediterranean Sea, Aegean Sea, continental rifting, extension, active rift, normal fault, earthquake, horst, fault growth, rift development, synrift stratigraphy, drainage evolution, surface processes, basin paleoenvironment, glacio-eustatic cycles, sea level, semi-isolated basin, marine basin, lacustrine, sediment flux, Quaternary, Pliocene, Miocene, carbon cycling, nutrient preservation, marine isotope stage
1 Introduction and operations

5 Lithostratigraphy

9 Structural geology

13 Micropaleontology

16 Geochemistry

18 Physical properties

25 Paleomagnetism

26 Downhole measurements

30 Core-log-seismic integration

33 References

\section{Introduction and operations}

This chapter documents the primary "shipboard" procedures and methods employed by various operational and scientific groups during the offshore and Onshore Science Party (OSP) phases of International Ocean Discovery Program (IODP) Expedition 381. Methods for postexpedition research conducted on Expedition 381 samples and data will be described in individual scientific contributions published after the expedition. Detailed drilling and engineering operations are described in the Operations section of each site chapter.

\section{Site locations}

At all Expedition 381 sites, GPS coordinates from precruise site surveys were used to position the vessel on site. Once the D/V Fugro Synergy was positioned at a site, a dynamic positioning model was established. The coordinates for the borehole position were calculated from a combination of the corrected GPS position and the position of the transponder on the seabed template relative to the vessel following a settling period.

\section{Platform}

The drilling platform used for Expedition 381 was the Fugro Synergy, a high-end geotechnical drilling vessel (103.7 m long; 9287 tonnes) (Figure F1). As with all European Consortium for Ocean Research Drilling (ECORD) mission-specific platform (MSP) expeditions, a full suite of containerized laboratories and offices were in-
Figure F1. Fugro Synergy, operated by Fugro N.V.

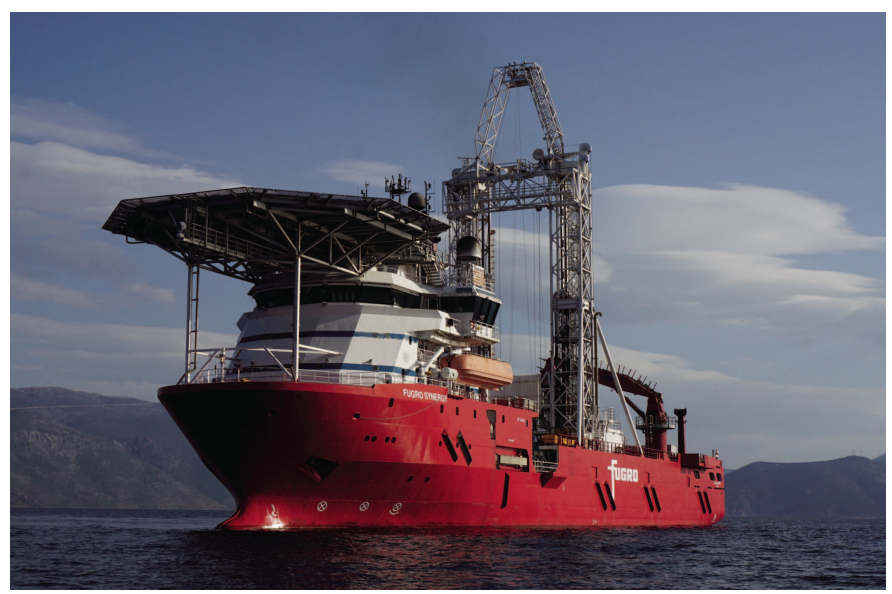

stalled on the Fugro Synergy aft deck area. The layout was designed to enable the most efficient core flow and core processing from core recovered through core curation, multisensor core logging, sampling and description, geochemical analyses, and refrigerated storage (Figure F2). Access to the Gulf of Corinth involved transit under a bridge that was only $57 \mathrm{~m}$ above sea level, which is why this expedition required an MSP. It was therefore necessary to remove the upper section of the drilling derrick during transit and replace it during the final mobilization at the Port of Corinth prior to transit

\footnotetext{
${ }^{1}$ McNeill, L.C., Shillington, D.J., Carter, G.D.O., Everest, J.D., Le Ber, E., Collier, R.E.LI., Cvetkoska, A., De Gelder, G., Diz, P., Doan, M.-L., Ford, M., Gawthorpe, R.L., Geraga, M., Gillespie, J., Hemelsdaël, R., Herrero-Bervera, E., Ismaiel, M., Janikian, L., Kouli, K., Li, S., Machlus, M.L., Maffione, M., Mahoney, C., Michas, G., Miller, C., Nixon, C.W., Oflaz, S.A., Omale, A.P., Panagiotopoulos, K., Pechlivanidou, S., Phillips, M.P., Sauer, S., Seguin, J., Sergiou, S., Zakharova, N.V., 2019. Expedition 381 methods. In McNeill, L.C., Shillington, D.J., Carter, G.D.O., and the Expedition 381 Participants, Corinth Active Rift Development. Proceedings of the International Ocean Discovery Program, 381: College Station, TX (International Ocean Discovery Program). https://doi.org/10.14379/iodp.proc.381.102.2019

2 Expedition 381 Participants' affiliations.

MS 381-102: Published 28 February 2019

This work is distributed under the Creative Commons Attribution 4.0 International (CC BY 4.0) license. (c) BY
} 


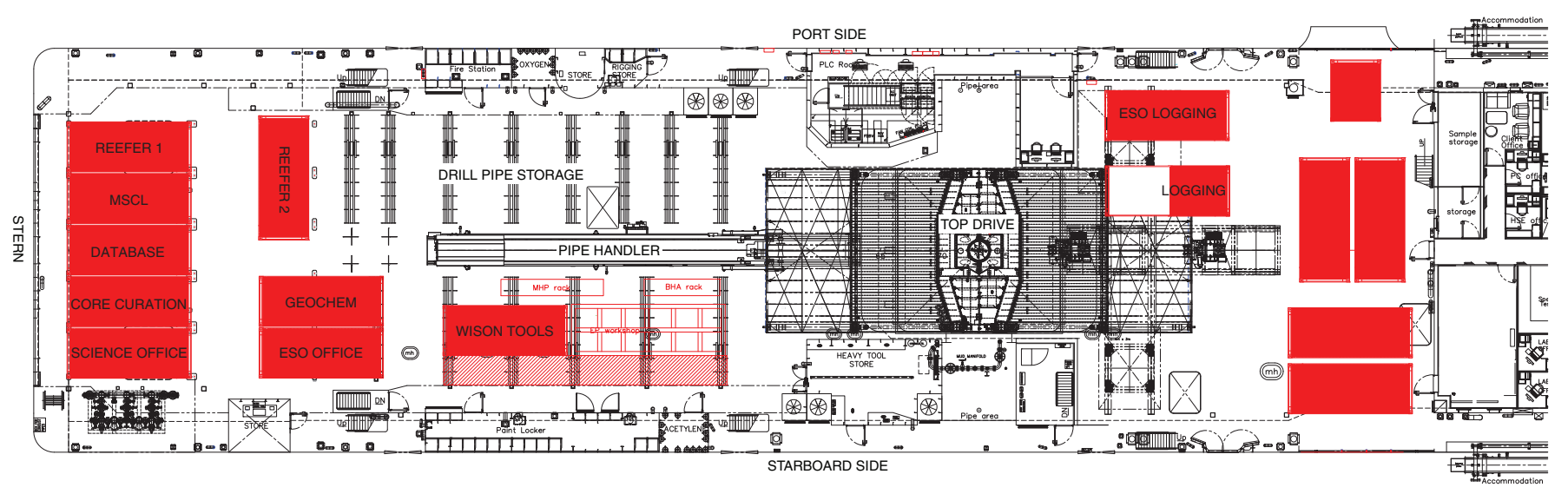

to the first site. The anticipated maximum depth of the boreholes was 750 meters below seafloor (mbsf).

\section{Drilling system}

The system on the Fugro Synergy utilized a Fugro SeaCore R-190 drilling rig that incorporated a National Oilwell Varco TDS 250 top drive. The R-190 drilling rig had a below deck capacity of 150 tonnes and was compensated by a passive Bosch Rexroth system with a $7 \mathrm{~m}$ stroke capability. The derrick had the ability to handle double American Petroleum Institute (API) pipe lengths, which allowed faster tripping times while in the water column. In addition, the $\mathrm{Fu}$ gro Synergy utilized a semiautomated pipe handling system that comprised a pipe deck pipe handler and a "tubular feeding machine" to reduce manual handling and improve efficiency.

The Fugro SEADEVIL (a recent development and addition to the standard seabed template) was utilized while drilling the first borehole to control the feed and hence the bit weight from the seabed. Decoupled from the vessel heave and midwater pipe flex, the fine control of bit weight and penetration rate the SEADEVIL offers was used to provide accurate depth position and improve the quality of samples recovered. This fine control was achieved by clamping the drill string at the seabed (rotary was still driven from the drill floor) and feeding the drill pipe into the formation at the seabed. The driller controlled the system on the surface with data feedback in real time, including a video feed to the driller's control panel. Accurate measurement of the mudline could be achieved and downhole depth could be determined.

Unfortunately, a number of technical problems with the SEADEVIL were experienced while drilling the upper half of Hole M0078A, and it was decided to downgrade it to the standard seabed clamp (SEACLAM) for subsequent holes by removing the feed capability but still allowing clamping of the drill string when required (e.g., during coring [Fugro Wison Extended Piston system and Fugro Corer], cone penetration tests [CPTs], and downhole logging operations). Because of the generally benign weather conditions, this downgrade did not cause any decrease in the quality of the core recovered or in the production rate thereafter.

\section{Wireline coring}

The drill string comprised 51/2 inch full hole API pipe and collars with Fugro's medium common bottom-hole assembly (BHA), into which all coring tools were deployed, and a $216 \mathrm{~mm}\left(8^{1 / 2}\right.$ inch) polycrystalline compact diamond (PCD) coring bit.
Four methods of wireline coring were conducted during the expedition:

- Fugro Wison Extended Piston (WEP) system (designated core type "H"; equivalent to IODP's advanced piston corer [APC] system),

- Fugro Corer system in push mode (designated core type "P"; near equivalent to IODP's APC system),

- Fugro Corer system in percussive mode (designated core type "V"; near equivalent to IODP's APC system), and

- Fugro Extended Marine Core Barrel (FXMCB) system (designated core type "R"; equivalent to IODP's rotary core barrel [RCB] system).

\section{Wison Extended Piston Corer}

The Fugro WEP system is designed to operate primarily in unconsolidated sediment. The system is deployed by wireline to the base of the BHA. The pipe is sealed at the surface using a wireline seal plug (WLSP), allowing the drill string to be pressurized and the core barrel to be extruded from the housing into the formation.

During Expedition 381, the WEP system was only used in the upper $75 \mathrm{~m}$ of Hole M0078A. After each sample was taken, the hole was advanced by drilling to the next sample point, either by recovery or by penetration if the full length of the core barrel had been achieved. Although the sample quality was judged at sea to be high (accepting the limitation of core assessment through the core liner), the disadvantage of this method was a lower force and hence lower penetration rate and the additional time needed to retract the piston into the protective housing. Because the Fugro Corer (see below) appeared to provide an equally high-quality core, the WEP system was not used further.

\section{Fugro Corer (push or percussive mode)}

The Fugro Corer is designed to operate in very soft to hard clay, cemented sand, and weak rock. Like the WEP system, the Fugro Corer operates by pressurizing the drill string with a WLSP. The tool is dropped by free fall into the drill string, with the overshot following behind. The pressurized drill string initiates either a push movement similar to the WEP system or a percussive action. A full stroke has been achieved when pressure drops in the drill string. If a full stroke is not achieved, the pressure is released manually at deck level. The drill string is raised to extract the core barrel from the formation before it is retrieved to the deck using an overshot.

As with the WEP system, the core bit must be advanced before another sample is taken or a new core barrel can be released into the 
drill string. The distance advanced can either be on penetration or full stroke of the barrel if the pressure was seen to drop off during the sampling procedure.

\section{Fugro Extended Marine Core Barrel (rotary corer)}

The FXMCB is a retractable corer that shares some similarities to a standard diamond rotary corer and is designed to core hard and lithified sediments and rock formations.

The FXMCB is advanced by rotary coring, with flushing occurring at the point where the core enters the core barrel. When this corer is used in softer formations with a basket-type catcher to hold in the material, undercutting of the core may result. If the penetration rate is low, some undercutting can also occur in firmer lithologies because material can get caught in the tines of the basket, which has space to rotate around the core as it enters the barrel. The core cutting bit on the FXMCB is retrieved with each core run; thus, the cutting ability can be optimized by exchanging bits for each formation encountered.

A range of core catchers can be used either independently or in combination depending on formation lithologies: the Fugro Corer flapper and multidogged, FXMCB basket (used most extensively) or a core spring (not used).

\section{Numbering of cores and samples}

The cored interval is measured by the drillers in meters below seafloor. The depth below seafloor is determined by subtracting the initial drill pipe measurement to the seafloor from the total drill pipe measurement. For Expedition 381, the cored interval consisted of the entire drilled section (i.e., no drilling without coring occurred). Recovered core is divided into sections with a maximum length of $1.5 \mathrm{~m}$ and numbered sequentially from the top, starting at 1 . By convention, material recovered from the core catcher of a sedimentary core is treated as a separate section labeled "CC" (for core catcher) and placed below the last section recovered in the liner. The core catcher is assigned to the top of the cored interval if no other material is recovered. When recovered core is shorter than the cored interval, the top of the core, by convention, is equated to the top of the cored interval to achieve consistency in reporting depth in core.

A soft to semisoft sediment core or a core of expanding clay expands upon recovery (typically $10 \%-15 \%$ ), so the recovered interval may not match the cored interval and a core may be recorded with greater than $100 \%$ recovery. In addition, a coring gap typically occurs between cores (i.e., some cored interval is lost during recovery). Thus, a discrepancy exists between the drilling meters below seafloor and the curatorial meters below seafloor. For example, the curatorial depth of the base of a core can be deeper than the top of the subsequent core (if recovery is greater than 100\%).

Any sample removed from a core is designated by distance measured in centimeters from the top of the section to the top and bottom of the sample removed. A full identification number for a sample consists of the following information: expedition, site, hole, core number, core type, section number, and interval in centimeters measured from the top of section. For example, a sample identification of "381-M0078A-5P-2, 35-40 cm," represents a sample removed from the interval $35-40 \mathrm{~cm}$ below the top of Section 2, Core 5P (" $\mathrm{P}$ " indicates core type; see Wireline coring), from Hole M0078A during Expedition 381. All IODP core identifiers indicate core type.
The depth of a sample in meters below seafloor is calculated by adding the depth of the sample below the section top and the lengths of all higher sections in the core to the core-top datum measured with the drill string.

\section{Core handling and analysis}

\section{Offshore phase}

As soon as a core was retrieved on deck, it was curated by the ECORD Science Operator (ESO) curators, which involved marking and cutting the core into sections (maximum $1.5 \mathrm{~m}$ length). Each section was sealed at the top and bottom by attaching color-coded plastic caps: blue at the top of a section and white at the bottom. A yellow cap was placed on section ends where a whole-round sample was removed. Core section liners were permanently labeled with an engraving tool. The length of the core section and the core catcher sample were measured to the nearest centimeter and logged into ESO's Expedition Drilling Information System (ExpeditionDIS). No core splitting took place during the offshore phase.

After curation, the core proceeded through a sequence of processing steps. The geochemists were given access to the cores for interstitial water sampling, which normally involved squeezing 5-7 $\mathrm{cm}$ whole rounds or using 1-2 Rhizon syringes per section (maximum spacing of $150 \mathrm{~cm}$ ) (Dickens et al., 2007) at shallow depths where the core material was suitable. Occasionally, samples were taken from these whole rounds for micropaleontological characterization.

The core catcher, or a sample from the core catcher, was given to the micropaleontologists and sedimentologists for initial description. Further palynology samples were taken from a subset of the core catchers; these samples were sent to a member of the science party following the offshore phase to generate shipboard data prior to the OSP.

Beyond these samples, no sampling of the unsplit cores was undertaken during Expedition 381.

The shipboard sedimentologists also described the core sections through the clear plastic liners, although drilling fluid and smeared core sediment made description challenging.

The core sections were allowed to thermally equilibrate for $6 \mathrm{~h}$ before they were run through the Multi-Sensor Core Logger (MSCL) (see Physical properties).

After MSCL measurements and through-liner descriptions were complete, the core was moved to refrigerated storage.

\section{Onshore Science Party}

The OSP was held at the IODP Bremen Core Repository (BCR; Bremen, Germany) from 31 January to 28 February 2018. All cores were measured for thermal conductivity before they were split.

After being taken out of refrigerated storage, cores were split lengthwise into working and archive halves. The splitting technique varied depending on the strength of the cores, which ranged from soupy sediment to rock. The core splitters had at their disposal horizontal and vertical wire cutters, steel plates to keep soupy material intact while the liner was cut, and a diamond cutting saw for indurated core. Wire-cut cores were split from bottom to top, so investigators should be aware of the potential for older material to have been dragged up the core on the split face of each section.

The sedimentologists described the archive halves visually, aided by smear slides and occasional thin sections (see Lithostratigraphy). Digital images of archive halves were made with a digital 
imaging system (see Physical properties). Specific areas of interest on the archive halves were occasionally photographed using a color digital camera.

Prior to sampling, the working half of the core was scanned for discrete color reflectance measurements, and some $P$-wave velocity and shear strength measurements were made.

Each sample was logged into the ExpeditionDIS database (see Data handling, database structure, and access). Samples were generally sealed in plastic bags, labeled, and stored as appropriate. Samples were routinely taken for shipboard measurements and analysis (see Physical properties, Geochemistry, Paleomagnetism, and Micropaleontology):

- Physical properties analysis (moisture and density [MAD] and discrete $P$-wave velocity);

- Geochemical and compositional characterization, including Xray diffraction (XRD), X-ray fluorescence (XRF), total carbon

(TC), and total organic carbon (TOC);

- Paleomagnetic studies; and

- Micropaleontological analysis.

Interstitial water samples taken from cores offshore were analyzed for cations (major and trace elements), anions (chloride, bromide, sulfate, and phosphate), dissolved inorganic carbon (DIC), and phosphate (using spectrophotometry) (see Geochemistry).

Following initial measurements and sampling, both halves of the cores were cling-filmed, placed in labeled plastic D-tubes, sealed, and transferred to refrigerated storage at the BCR.

\section{Downhole logging}

Downhole logging services were contracted and managed by the European Petrophysics Consortium (EPC). Details and results of the expedition logging program are given in Downhole measurements and in the Downhole measurements section of each site chapter.

\section{Depth scales terminology}

Conforming to the IODP Depth Scales Terminology (2011; https://www.iodp.org/policies-and-guidelines/142-iodp-depthscales-terminology-april-2011/file), the following terms were used during Expedition 381:

- $\operatorname{mbsf}=$ meters below seafloor

- DSF = drilling depth below seafloor.

- WSF = wireline log depth below seafloor.

\section{Data handling, database structure, and access}

Data management during the offshore and onshore phases had two overlapping stages. The first stage was the capture of metadata and data during the expedition (offshore and onshore). Central to this stage was the ExpeditionDIS, which stored drilling information, core curation information, core images, sample information, section unit descriptions, smear slide descriptions, and primary measurement data (MSCL, red-green-blue [RGB], $P$-wave velocity, and some geochemistry). Additional data were captured in files stored on a shared file server. The second stage was the longer term postexpedition archiving of Expedition 381 data sets, core material, and samples. This function was performed by the World Data Center (WDC) for Marine Environmental Sciences (PANGAEA/WDCMARE) and the BCR.

The ExpeditionDIS is a flexible and scalable database system originally developed for the International Continental Scientific
Drilling Project (ICDP) and adapted for ESO so that it is compatible with the databases of the other IODP implementing organizations and ICDP. Adaptations were made for the Expedition 381 offshore and onshore workflow requirements. The development and adaptation work on the ExpeditionDIS to fit Expedition 381 requirements was carried out by Smartcube GmbH (Potsdam, Germany). Remote access to the ExpeditionDIS by the science party was provided using the XDIS web interface during both the onshore phase and the moratorium.

All cores, sections, and samples entered into the ExpeditionDIS automatically receive an individual International Geo Sample Number (IGSN; http://www.igsn.org). After the end of the moratorium, all data are transferred from the ExpeditionDIS to CurationDIS, the long-term BCR core curation system; contemporaneously, the IGSNs are registered and can be accessed at http://www.igsn.org (to navigate to a particular IGSN, add the IGSN to the end of this link: e.g., http://www.igsn.org/IBCR0381EXI3001).

The EPC was responsible for capturing and processing MSCL and downhole logging data. Logging data (other than metadata) were not entered into the ExpeditionDIS (see below for logging data archiving details). During the onshore phase, core data (e.g., linescan images and MSCL data) were exported from the ExpeditionDIS into the Corewall Corelyzer application for visualization to aid with core description.

During the offshore and onshore phases of the expedition, integration of the acquired core properties with the available seismic data sets at and in the vicinity of the drill sites through the generation of synthetic seismograms was performed using Schlumberger's Petrel software.

The data captured in the Expedition 381 ExpeditionDIS and the shipboard expedition data stored in the shared file server were transferred to PANGAEA. PANGAEA is a member of the International Council of Scientific Unions WDC system and is used for processing, long-term storage, and publication of georeferenced data related to earth sciences. Until the end of the moratorium period, data access was restricted to the expedition scientists. Following the moratorium, all shipboard expedition data except downhole logging data were published online in PANGAEA (https://www.pangaea.de), and PANGAEA will continue to acquire, archive, and publish new results derived from Expedition 381 samples and data sets. Downhole logging data were archived in the IODP logging database and are accessible through http://mlp.ldeo.columbia.edu/logdb/scientific_ocean_drilling with a link from PANGAEA.

The central portal for all IODP data, including Expedition 381 data, is the Scientific Earth Drilling Information Service (SEDIS; http://sedis.iodp.org). IODP MSP data are also downloadable from http://iodp.pangaea.de.

\section{Core, section, and sample curation using the ExpeditionDIS}

Expedition 381 followed IODP procedures and naming conventions in core, section, and sample handling (see Numbering of cores and samples). The ExpeditionDIS captured the curation metadata, which comprise the following, to IODP standards:

- Expedition information,

- Site information (latitude, longitude, water depth, start date, and end date),

- Hole information (hole naming by letter, latitude, longitude, water depth, start date, and end date), 
- Core data (core number, core type, top depth, bottom depth, number of sections, core catcher where present, curator name, core on deck date and time, and additional remarks),

- Section data (section number, section length, curated length, and curated top depth of section),

- Sample information (repository, requester code, sampler code, expedition, site, hole, core, section, half [working or archive], sample top, sample bottom, sample volume, and additional remarks),

- Calculated core recovery percentage on the basis of the drilled or cored length and the curated recovery, and

- Calculated section recovery on the basis of the section length and curated length.

No correction was made in cases where recovery exceeded $100 \%$ because of core expansion. Top and bottom depths of the section (mbsf scale) were calculated on the basis of the core-top depth. Section and sample label formats follow the standard IODP convention. The labels include barcodes of the section/sample code and the complete section/sample code (Expedition-Site-Hole-Core-Core type-Section-Half-Interval and sample request code). This standardization guarantees data exchange between the repositories and enables information flow between the implementing organizations.

\section{Authorship of chapters}

The separate sections of the site chapters were written by the following expedition participants (see Expedition 381 participants for contact information):

Background and objectives: McNeill, Shillington

Operations: Everest, Carter, Le Ber, Smith, Tulloch

Lithostratigraphy: Gawthorpe, Collier, De Gelder, Ford, Gillespie, Hemelsdaël, Janikian, Li, Nixon, Pechlivanidou, Sergiou

Micropaleontology: Phillips, Cvetkoska, Diz, Geraga, Kouli,

Oflaz, Panagiotopoulos

Structural geology: Ford, Nixon

Geochemistry: Miller, Mahoney, Sauer, Seguin

Physical properties: Le Ber, Doan, Ismaiel, Machlus, Michas, Omale

Paleomagnetism: Maffione, Herrero-Bervera

Downhole logging/measurements: Le Ber

Core-log-seismic integration: Zakharova, Shillington

\section{Lithostratigraphy}

This section summarizes the methods used to describe and document the sedimentology of cores recovered during Expedition 381, with particular emphasis on sedimentary structures and textures. It outlines the offshore and onshore visual core description methods, together with details of sediment classification and descriptive terms used, the methods used to prepare supporting sediment smear slides, and the methods for XRD analysis. For additional methods used to characterize the physical properties and sediment composition, see Geochemistry and Physical properties.

\section{Offshore methodology}

\section{Visual core description}

Shipboard core descriptions were performed after initial core curation and after the cores were passed through the MSCL. Cores were not split offshore, and visual descriptions were made through the transparent plastic core liner, with additional insight from ex- amination of core catcher portions before they were placed in the liner and occasional split whole rounds taken for geochemical pore water analysis approximately every $10 \mathrm{~m}$ (see Geochemistry).

The mud-rich sediment was commonly smeared along the outside of the core (confirmed by core catcher and split whole-round sample observations), obscuring features in the core and significantly reducing the ability to make detailed observations about the sediment and sedimentary structures. Furthermore, added drilling mud was occasionally present between the core and the core liner and, together with water condensation on the interior of the liner, caused problems in observing the core. As a result, the offshore visual core descriptions have a high degree of uncertainty and provided only a general and simplified impression prior to splitting the cores onshore.

Core descriptions were recorded on visual core description (VCD) sheets (Figure F3), which include lithology, grain size, fossils and sedimentary structures, bioturbation, sorting and roundness of grains, color, and structures, where visible and recognizable. On offshore VCD sheets, lithologies of the recovered core intervals are represented by graphic patterns in the Lithology column. Written comments (e.g., core visibility, core disturbance, trends, etc.) could be added to the VCD sheet.

During offshore description, both lithology and grain size were difficult to determine through the core liner, particularly in dominantly fine grained lithologies where smearing was present. Blank regions on VCD sheets represent areas where lithology and grain size were not visible because of drilling mud or smearing along the outside of the core or the inside of the core liner (also recorded in the Description column).

\section{Color}

Visual core descriptions show sediment color and the corresponding hue, value, and chroma data as determined qualitatively using the Munsell soil color charts (Munsell Color Company). The Munsell soil color charts are capable of providing a suitable general color but are subject to lighting conditions and personal judgment on the part of the describer. Most core color during Expedition 381 was assigned to the GLEY 1 and $5 Y$ color charts. For the lower part of Site M0080, the 7.5YR and 10YR color charts were commonly needed.

During offshore description, it was often difficult to clearly assign a suitable color from the Munsell soil color charts to distinguish the range of light gray colors seen in the core. However, given the high degree of smearing of mud and sediment along the core and the fine grain size of the observed sediment in core catcher samples, color was one of the more significant descriptive parameters that could be recorded.

\section{Offshore core catcher and split whole-round analysis}

Because of the problems with mud-rich lithologies and drilling mud smeared along the outside of the core and in the core liner, visual core description through the core liner was restricted. The possibility of artificial mixing of core catcher material also requires that results be treated with caution. Nonetheless, core catcher and whole-round samples taken for pore water geochemistry provided an opportunity for high-quality core observations prior to splitting. Visual description of these sections was made and recorded on the VCD sheets, and a small amount of the sediment was removed for investigation under a reflected light binocular microscope and for preparation of smear slides that were analyzed under a transmitted light microscope (see Smear slide preparation). 
Figure F3. Sample VCD sheet used during offshore phase, Expedition 381.

IODP-MSP (Exp. 381) Visual Section Unit Description

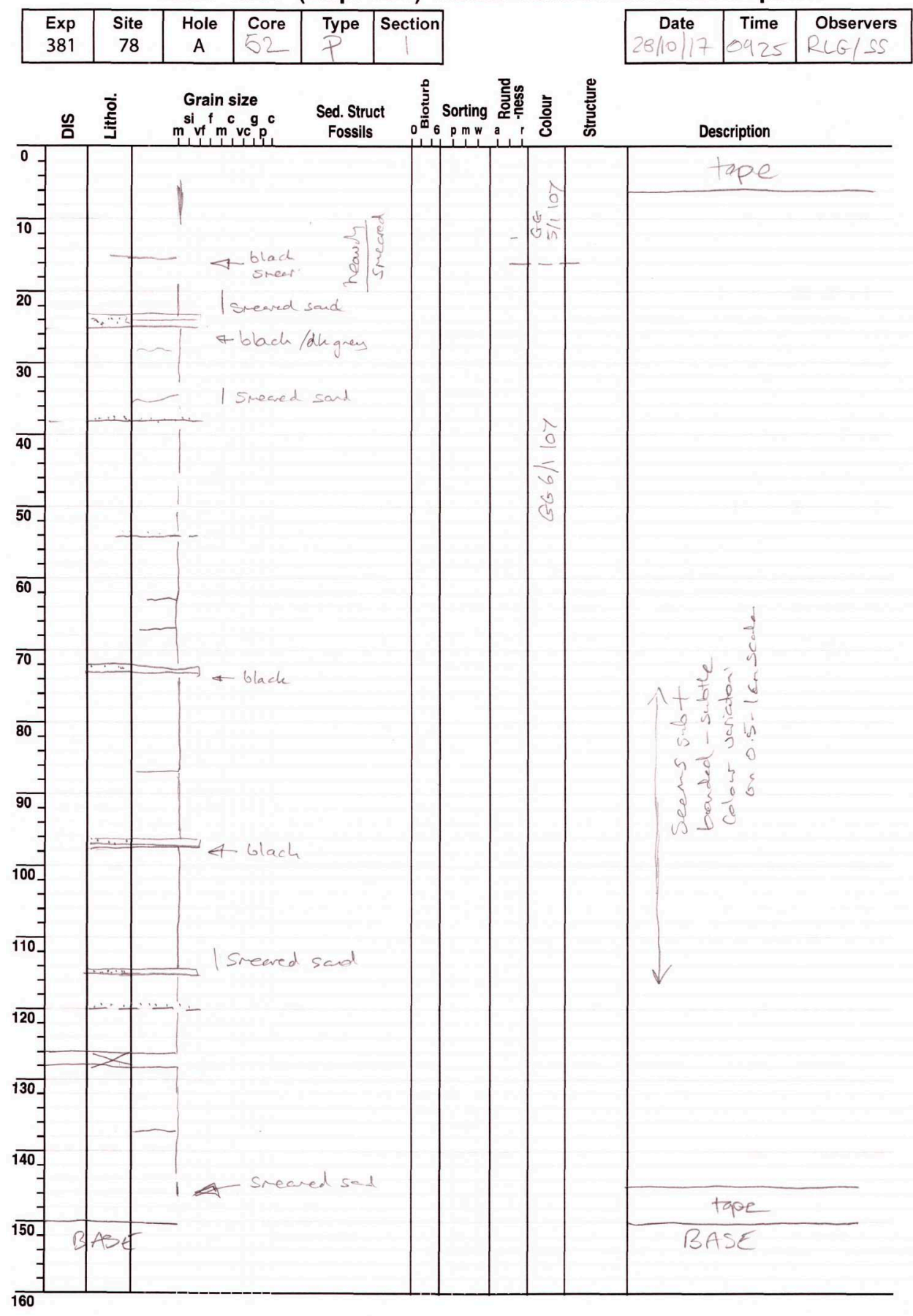

\section{Onshore methodology}

\section{Visual core description}

Visual core description was carried out during the OSP at the $\mathrm{BCR}$ at the Center for Marine Environmental Sciences (MARUM; Germany). Core sections as long as $1.5 \mathrm{~m}$ were placed in top-lit core trays in front of screens displaying the high-resolution linescan core section images through the Corewall Corelyzer visualization tool (http://www.corewall.org). Descriptions were documented on a
VCD sheet for each core section, including the linescan core section image for the onshore phase (Figure F4).

Lithostratigraphic approach, lithology, grain size, and sedimentary structures

Seventeen facies associations were defined and used to describe the sediment and sedimentary rocks across Sites M0078-M0080 (see the Expedition 381 facies associations chapter [McNeill et al., 2019a]). These facies associations were defined based on physical 
Figure F4. Sample VCD sheet used during onshore phase, Expedition 381. Red dot on left side indicates the position of a sample.

IODP-MSP (Exp. 381) VISUAL SECTION UNIT DESCRIPTION

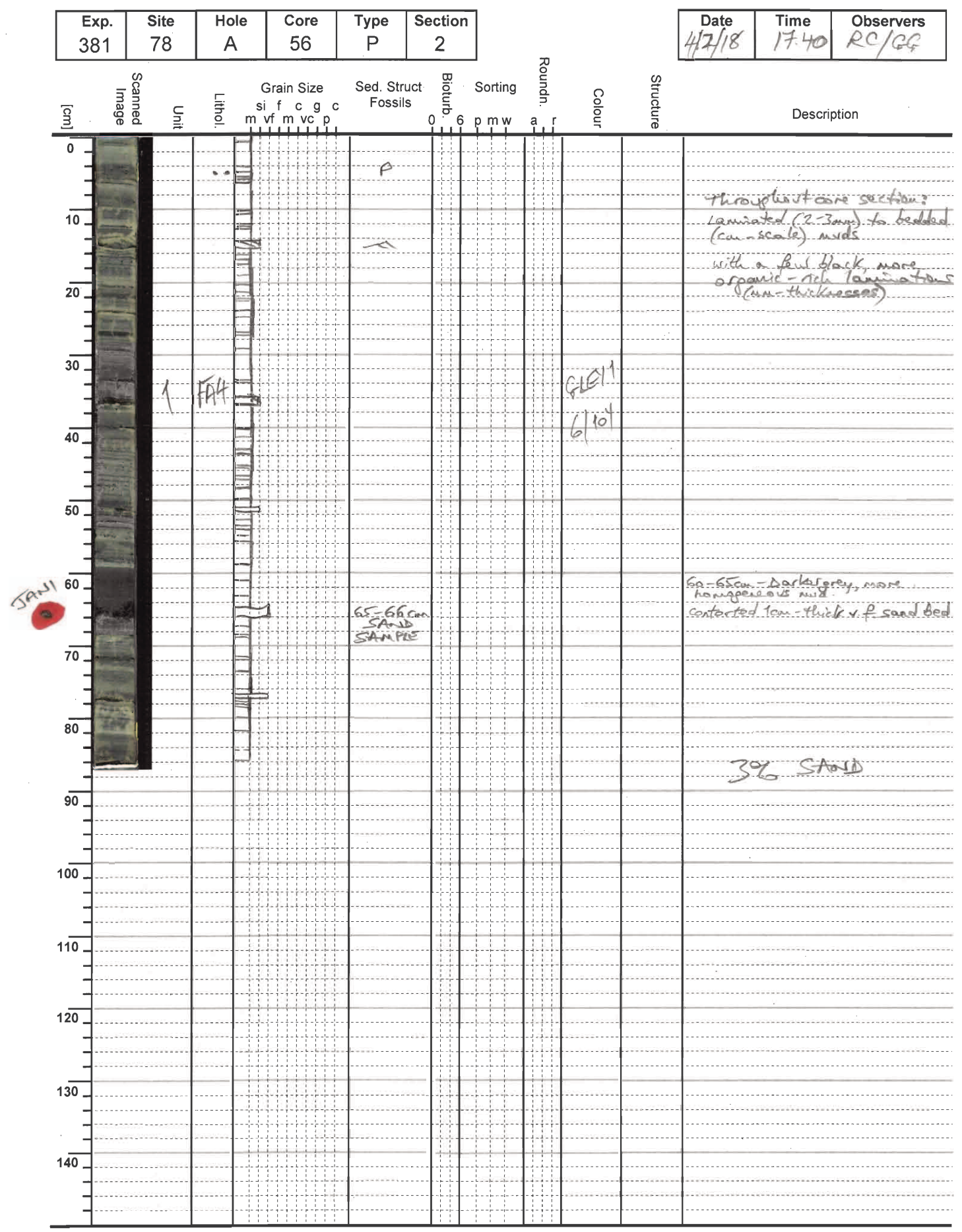

and biogenic features in the sediment, including bedding and lamination style, color, body and trace fossils, and the nature and percentage of sand. The facies associations were recorded on the onshore VCD sheets (Lithology column). Lithostratigraphic units were then defined by a combination of one or more facies associations together with micropaleontological assemblages (see Micropaleontology).
Grain size was recorded according to the Wentworth grain size scale (Wentworth, 1922) in the Grain size column. Distinctions between grain size divisions for mud (clay), silt, very fine sand, fine sand, medium sand, coarse sand, very coarse sand, granules, pebbles, and cobbles (after Wentworth, 1922) were made using grain size comparator cards (Geo Supplies Ltd., Weatherford Laboratories, and Gamma Zeta Chapter, Kent State University). 
Bed thicknesses are commonly indicated in terms of laminated versus bedded material other than homogeneous sediment or sedimentary rock. Laminations refer to dominant layer thicknesses $<1$ $\mathrm{cm}$, whereas bedded material refers to a dominant layer thickness $>1 \mathrm{~cm}$. If the dominant bed thickness is $>10 \mathrm{~cm}$, it is referred to as decimeter-scale bedding or by individually quantified bed thickness values.

Lithification state descriptors follow the definitions used during IODP Expeditions 353 and 362 (Clemens et al., 2016; McNeill et al., 2017a). If a core of siliciclastic sediment cannot be easily deformed by pushing on it with a finger, it is designated as "-stone," as in mudstone, siltstone, and sandstone. Following the same criteria, lithified ash is designated "tuff." However, lithification state is a transient property that may evolve with temperature change or as cores dry out. "Sediment" encountered in cores could generally be dispersed as constituent detrital particles for smear slide preparation. Some but not all of the material designated as "-stone" could be disaggregated sufficiently for smear slide preparation and examination.

Sedimentary structures, such as ripples or soft-sediment deformation, were added to the Sedimentary structures/Fossils column on the onshore VCD sheets. If no sedimentary structures were visible, this column was left blank. Comments on sedimentary structures are also found in the Description column on the VCD sheets. Structures formed by both biogenic and physical processes (including drilling-induced deformation [DID]) are also described in the Description column on the VCD sheet (Figure F4).

\section{Fossils, bioturbation, grain sorting, and roundness}

Body fossils and ichnofabrics, where identifiable, are highlighted in the Sedimentary structures/Fossils column on the onshore VCD sheets. Bioturbation intensity, grain sorting, and roundness were also recorded in their respective columns on the VCD sheets (Figure F4). The degree of bioturbation is a semiquantitative assessment that ranges from 0 (no bioturbation) to 6 (completely bioturbated), following the scheme of Taylor and Goldring (1993). Blank regions represent areas of no visible bioturbation.

Grain roundness and sorting were recorded for sand and coarser grain sizes based on visual estimation in comparison with illustrations of degrees of grain roundness and sorting on grain size cards (Geo Supplies Ltd., Weatherford Laboratories, and Gamma Zeta Chapter, Kent State University).

\section{Color}

Visual core descriptions show sediment color and the corresponding hue, value, and chroma data as determined qualitatively using the Munsell soil color charts (Munsell Color Company). The Munsell soil color charts are capable of providing a suitable general color but are subject to lighting conditions and personal judgment on the part of the describer. Most core color during Expedition 381 was assigned to the GLEY 1 and $5 Y$ color charts. For the lower part of Site M0080, the 7.5YR and 10YR color charts were commonly needed.

Greater confidence can be placed in the color descriptors from the onshore VCD team, who had the benefit of consistent laboratory lighting conditions and freshly split surfaces, than in the offshore assessment of core color. Even so, rapid surface oxidation sometimes altered original mud hues. The cores were also fed through an automated color reflectance tool (see Physical properties).

\section{Description comments}

Additional observations on the lithology, grain size, sedimentary or biogenic characteristics, and structure of the core were written in the Description column on the right-hand side of the VCD sheet. In addition, comments concerning sediment disturbance resulting from the coring process, including the degree of smearing of drilling mud or sediment along the core, were recorded here on both offshore and onshore VCD sheets (Figures F3, F4). Any comments on sedimentary composition based on hand lens observations were also made in the Description column. Observations include the presence of organic-rich layers, presence of pyrite, and percentage of sand. Finally, a summary of the main characteristics of the logged interval was included.

\section{Smear slide preparation}

Smear slide observations are useful for the examination of sediment composition (e.g., testing for the presence of aragonite needles), grain size, and texture in fine-grained sediment (clay, silt, and very fine sand). Smear slides were prepared both offshore and onshore using the following procedures.

For each smear slide, a small amount of sediment was collected using a toothpick and placed directly on a glass slide. A few drops of distilled water were added, and the sediment was spread evenly across the glass slide using a toothpick and dried on a hot plate. Afterward, two drops of optical adhesive (Norland optical adhesive Number 61) were added to mount a $22 \mathrm{~mm} \times 50 \mathrm{~mm}$ coverslip to the glass slide. The slide and mounted cover were then placed under ultraviolet light for about 10 min to dry the adhesive.

Once the mounts were fixed, each slide was observed under an Olympus BX51 polarizing microscope. A high-resolution camera (Olympus DP22) was connected to the microscope to record digital images of the field of view. Slides were examined at 10×, 20×, 40×, and $100 \times$ magnification with eyepiece micrometers, allowing assessment of the grain size distributions of the clay $(<4 \mu \mathrm{m})$, silt $(4-$ $63 \mu \mathrm{m})$, and sand $(>63 \mu \mathrm{m})$ fractions. The grain size proportions were estimated semiquantitatively using a standard visual composition chart (Terry and Chilingar, 1955).

Preliminary petrography of the sediment was also performed on the smear slides using standard optical mineralogy and petrographic techniques. Commonly occurring minerals and biogenic components were identified, as well as important accessory minerals and other lithic grains. Identifiable whole microfossils and fossil fragments, including diatoms, calcareous nannofossils, and foraminifers, were noted. Rock fragments, heavy minerals, and opaque grains were also recorded. The abundance of these components was classified into the following categories:

- $\operatorname{Rare}(<1 \%)$

- Common (1\%-10\%),

- Abundant (10\%-50\%),

- Dominant $(50 \%-80 \%)$, and

- Major (>80\%).

The relative abundance of major compositional components was further characterized by XRD (see $\mathrm{X}$-ray diffraction) and by the absolute weight percent of carbonate determined by coulometric analysis (see Geochemistry).

Sediment grain size distribution was classified according to the scheme of Mazzullo and Graham (1988), and the scheme of Roth- 
well (1989) was used to describe the detrital/biocalcareous/biosiliceous origin. Finally, textural attributes such as sorting and roundness were estimated visually. The classification of the sorting and roundness indexes were based on the scheme of Folk (1980). All data were entered into the Drilling Information System (DIS) using the Smear Slide Input Form template.

\section{X-ray diffraction}

The principal goal of XRD analysis is to estimate relative weight percentages of major minerals and mineral groups such as phyllosilicates, including clay minerals (smectite + illite + kaolinite), quartz, plagioclase (representing feldspar), and calcite, from the areas of relevant peaks.

Approximately $10 \mathrm{~cm}^{3}$ of bulk sediment was freeze-dried and ground to a fine powder using an agate mortar for most of the samples and an impact mortar for indurated samples from Hole M0080A, Units 3 and 4. Subsequently, the material was weighed and three splits were extracted, including one for XRD.

Mineral analysis was conducted on homogenized powder from each of the selected sediment samples using a Philips X'Pert Pro multipurpose diffractometer. These measurements were performed in the Crystallography Laboratory at the Department of Geosciences of the University of Bremen (Germany). The samples were prepared using a Philips backloading system to prevent any kind of preferred orientation, according to Moore and Reynolds (1997). The diffractometer uses a Cu-tube $\mathrm{K} \alpha$ under $45 \mathrm{kV}$ and $40 \mathrm{~mA}$, a fixed divergence slit, a 16-sample changer, a secondary monochromator, and the X'Celerator detector system. The goniometer scanned from $3.5^{\circ}$ to $65^{\circ} 2 \theta$ for each run, with a calculated step size of $0.016^{\circ} 2 \theta$. The measuring time for each sample was $1 \mathrm{~h}$.

Minerals were identified by the position of their main diffraction peaks on the XRD run, whereas semiquantitative estimates were produced in relation to their intensity (relative intensity ratio [RIR]) using the Philips software X'Pert HighScore. The RIR values were calculated as the ratio of the intensity of X-rays diffracted from the most intense reflex of a specific mineral phase to the intensity of the most intense reflex of pure corundum (I/IC), referring to the "matrix flushing method" of Chung (1974). A standard deviation of $\pm 5 \%$ is the general reproducibility of the measurement for mineral groups with $>20 \%$ clay fraction (Moore and Reynolds, 1997). However, for well-crystallized minerals, including heavy minerals and the carbonate series, the standard deviations are smaller (Tucker, 1988).

The method described is semiquantitative, and results should be interpreted with caution. The contrast in peak response between poorly crystalline minerals at low diffraction angles (e.g., clay minerals) and highly crystalline minerals at higher diffraction angles (e.g., quartz and plagioclase) impacts these results. Overall, calculated mineral abundances should be regarded as relative percentages in the four-component system of phyllosilicates + quartz + plagioclase + calcite. The closeness of these estimates to absolute percentages in the total solids depends on the abundance of amorphous solids (e.g., biogenic opal and volcanic glass) and the total of all other minerals that occur in minor or trace quantities.

\section{Core summary}

All VCD sheets were scanned and uploaded to the DIS as PDFs, and the observations of lithology, structures, color, and so on were entered into the DIS for each core, core section, unit, and subunit identified using the Visual Section Unit Description template. Results from smear slide analyses were entered using the Smear Slide
Input Form template. The scanned VCD forms are linked to the Section Unit Description in the DIS.

\section{Structural geology}

The principal objective of the structural geology team during Expedition 381 was to record any deformation features observed in the core. Deformation features can be due to either (1) tectonic deformation or (2) artificial deformation. Natural structures/deformation include brittle and ductile deformation such as fracturing, faulting, and folding/contortion of bedding, whereas artificial structural features can be generated by DID, core handling, core sawing, or syn- or postdrilling volume changes. All structural features identified on archive halves were consistently documented and described to ultimately assess the deformation/stress field history and to gather information that could be used to analyze the gross strength characteristics of the cored section in the Corinth rift. In general, we made detailed structural observations of probable natural structural features following methods used during previous expeditions, and we complemented these methods with detailed observations of artificial structures, in particular DID, following terminology and examples documented by Jutzeler et al. (2014) and Schmitt et al. (2012). Because some deformation features (e.g., fracturing) can result from both natural and artificial processes, a degree of uncertainty often occurs when assigning a deformation feature to "natural" or "artificial." Following the practice of other IODP expeditions (e.g., Expedition 362 [McNeill et al., 2017a]), we therefore denoted a degree of natural/artificial uncertainty for each structure. The methods used for describing, measuring, and recording different deformation features are detailed below.

\section{Natural/Tectonic deformation}

The principal tectonic structures found in Expedition 381 cores were fractures and faults. The orientations of fractures/faults were documented and measured, and for a subset, a sample across the fracture/fault was taken for petrophysical analysis. Methodologies for recording and describing structures were developed and modified during previous scientific ocean drilling expeditions, including Integrated Ocean Drilling Program Expeditions 334 and 344 and IODP Expeditions 352 and 362 (Expedition 334 Scientists, 2012; Harris et al., 2013; Reagan et al., 2015; McNeill et al., 2017a). Additionally, Blenkinsop and Doyle (2010) also provided information on measuring planar structures in core.

\section{Description and measurement of structures}

During the visual core description process, each structure observed on the archive half of the split core was recorded on the VCD sheets. The presence and character of structures were noted in the DIS database using a structural geology template that adopts a descriptive hierarchy (Table T1). We first identified the structure type (e.g., fault, fracture, fold, vein, stylolite, etc.). A second descriptor specifies the sense of displacement (e.g., normal, reverse, strike-slip, or indeterminate). A third descriptor classifies the 2-D geometry of the structure (e.g., planar, curved, etc.). Finally, we also identified the presence of fracture mineralization and/or fault rock. Key parameters and measurements for each fracture were recorded on a separate Excel spreadsheet, including the depth extent and character of fracture terminations in the core (i.e., top and base), orientation (in the core framework, see below), slip sense and amount of apparent offset and/or aperture, and whether samples were taken. An example of a fault in Hole M0079A is shown in Figure F5. 
Table T1. Terminology used to describe natural/tectonic structures and drilling-induced deformation in Expedition 381 cores. Download table in CSV format.

\begin{tabular}{llll}
\hline Tectonic structures & \multicolumn{1}{c}{ Geometry/Fill } & \multicolumn{1}{c}{ Drilling disturbance } & $\begin{array}{c}\text { Origin uncertainty } \\
\text { (range =1-0) }\end{array}$ \\
\hline Fault type: & Structural geometry: & Undisturbed & 1 (tectonic) \\
Fault (indeterminate) & Planar & Slight & (drilling induced) \\
Normal & Curved & Moderate & \\
Reverse & En echelon & High & \\
Strike-slip & Constraining bend & Severe (bedding destroyed) & \\
Fault observation: & Releasing bend & Arching bedding \\
Slickenside/Slickenline & Lens & Lensing & \\
Mineralization & Feature fill observation: & Sediment flow along core liner & \\
Fault rock & Quartz & Axial fluid flow & \\
Fold type: & Calcite & Disturbed/Mingled bedding & \\
Kink & Clay/Marl gouge & Soupy & \\
Synsedimentary & Brecciated & Tilted panels & \\
Monocline & Carbonate & Biscuit & \\
Drag & Pyrite & Shear fractures & \\
Fracture type: & & Open fractures & \\
Stylolitic & & Brecciation & \\
Joint & & Void & \\
Open mode & & Drilling disturbance intensity: & \\
Shear & & Slight & \\
& & Moderate & \\
& & High & \\
& & Severe (bedding destroyed) & \\
& &
\end{tabular}

To differentiate between natural and drilling-induced deformation and structures, we used an uncertainty value for each identified structure ranging from 0 to 1 , where 0 and 1 indicate that a structure is unlikely or likely, respectively, to have formed naturally. Each structure is initially considered to have a 0.5 uncertainty value before further observations are used to shift the uncertainty value toward a more natural $(>0.5)$ or drilling-induced $(<0.5)$ end-member classification. In practice, confidence values range from 0.1 to 0.9 to maintain some possibility that any individual structure may have a component of natural or drilling-induced deformation.

\section{Fracture orientation analysis}

We followed the procedure used during Expedition 362 (McNeill et al., 2017a) for the analysis of fracture orientation in an unoriented core. We used this approach for fracture/fault analysis only in cores unaffected by biscuiting (found mainly, but not uniquely, in rotary cores) because this phenomenon destroys any consistency of orientation in a core and any possibility of fracture orientation restoration to a geographic framework. We used a protractor and a clinometer for orientation measurements (Figure F6).

The orientations of the planar and linear features in the cores were determined relative to the core axis, which represents the vertical axis in the core reference frame. On the archive half, the pole to the core surface represents $000^{\circ}\left(360^{\circ}\right)$, which lies in the plane perpendicular to the core axis (Figure F7). To determine the orientation of a planar structural element, apparent dips were measured in two independent sections in the core reference frame. These two apparent dips were then converted using an Excel spreadsheet (see 362_Structure_Calculations.xlsx in STRUCTURE in the Expedition 362 Supplementary material [McNeill et al., 2017b]) to a plane represented by a dip angle, a strike, and a dip direction (Figure F8). The first apparent dip is represented by the intersection of the planar feature with the split face of the archive half and is quantified by measuring azimuth and plunge in the core reference frame $\left(\alpha_{1}\right.$ and $\beta_{1}$, respectively; Figure F9). The azimuth is either $090^{\circ}$ or $270^{\circ}$, and the plunge ranges from $0^{\circ}$ to $90^{\circ}$. A second apparent dip is represented by the intersection of the planar feature and a cut or frac-
Figure F5. Example of small fault with normal displacement (381-M0079A125R-3).

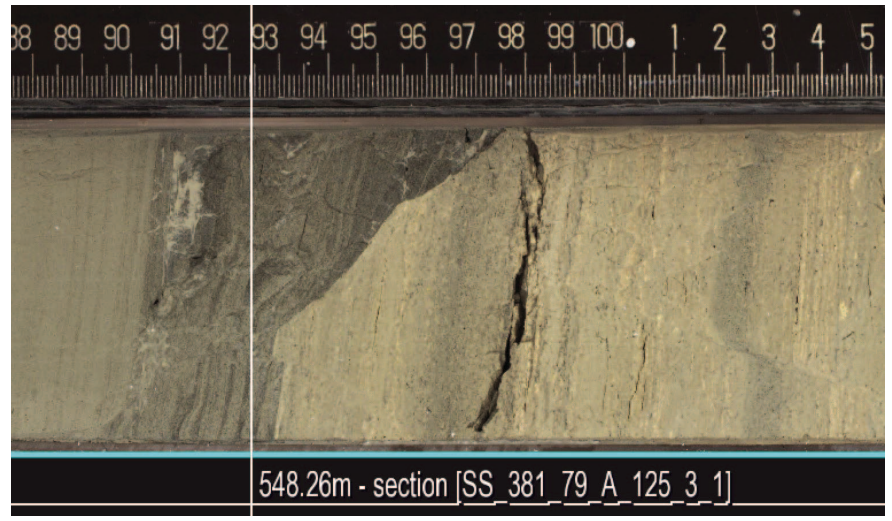

Figure F6. Protractor used to measure apparent dips, azimuths, and plunges of planar and linear features in split cores, Expedition 381.

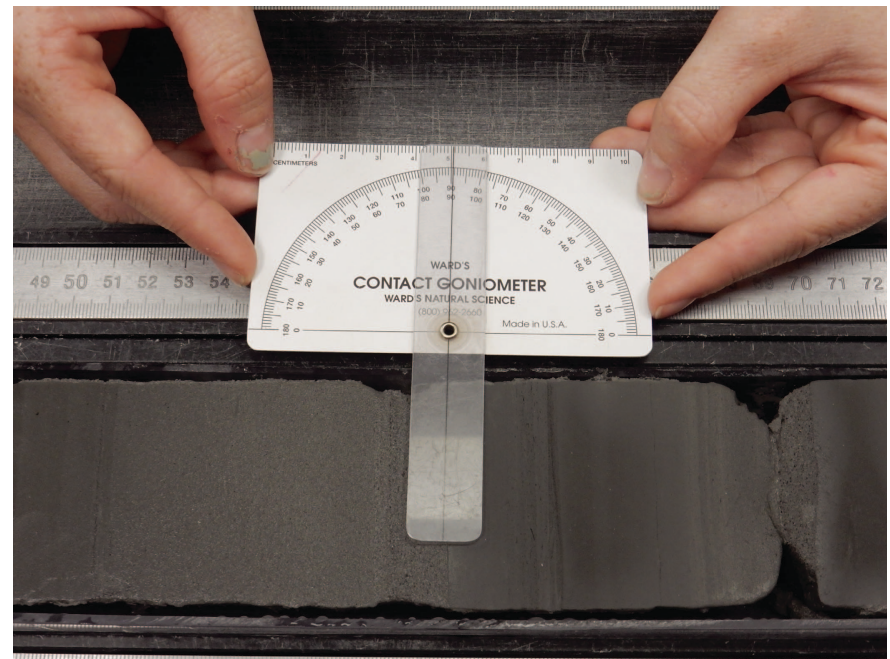


Figure F7. Core reference frame and $x-, y-$, and $z$-coordinates used in orientation data calculations. Modified from McNeill et al. (2017a).

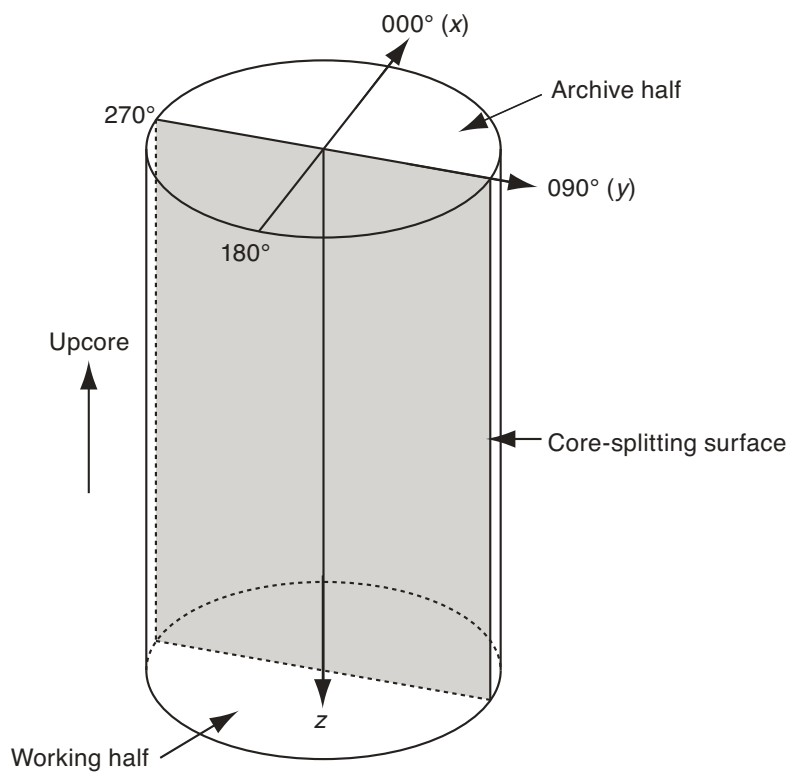

tured surface at a high angle to the split face of the working half. In most cases, this surface lies either parallel or perpendicular to the working core axis. When parallel, the apparent dip trace trends $000^{\circ}$ or $180^{\circ}$ and plunges from $0^{\circ}$ to $90^{\circ}\left(\beta_{2}\right.$; Figure F9); when perpendicular, the trend ranges either from $000^{\circ}$ to $90^{\circ}$ or from $270^{\circ}$ to $360^{\circ}$ and plunges $0^{\circ}$. Fault orientations were measured differently in the lithostratigraphic Unit 3 and 4 consolidated rocks at Site M0080. Here, the working half tended to break cleanly along fault planes so that blocks of core could be temporarily lifted out, thus exposing the fault surfaces in 3-D and allowing a more robust orientation analysis of the surface and measurement of any slickenlines (Figure F10).

\section{Calculation of plane orientation}

The two apparent dips of the planar structures, measured as azimuths (measured clockwise from north, looking down) and plunges of two different observation surfaces in the core reference frame, were converted into a true dip, dip direction, and strike of the plane (e.g., Figure F8A). A coordinate system was defined in such a way that the positive $x$-, $y$-, and $z$-directions coincide with north, east, and vertically downward, respectively. If the azimuths and plunges of the two apparent dips are given as $\left(\alpha_{1}, \beta_{1}\right)$ and $\left(\alpha_{2}\right.$, $\beta_{2}$ ), respectively, as in Figure $\mathbf{F} 9$, then the unit vectors representing these two lines $\left(v_{1}\right.$ and $\left.v_{2}\right)$ are

$$
v_{1}=\left(\begin{array}{c}
l_{1} \\
m_{1} \\
n_{1}
\end{array}\right)=\left(\begin{array}{c}
\cos \alpha_{1} \cos \beta_{1} \\
\sin \alpha_{1} \cos \beta_{1} \\
\sin \beta_{1}
\end{array}\right)
$$

and

$$
v_{2}=\left(\begin{array}{c}
l_{2} \\
m_{2} \\
n_{2}
\end{array}\right)=\left(\begin{array}{c}
\cos \alpha_{2} \cos \beta_{2} \\
\sin \alpha_{2} \cos \beta_{2} \\
\sin \beta_{2}
\end{array}\right) .
$$

Figure F8. Lower hemisphere equal area stereographic projections showing the procedure for converting 2-D measured data to 3-D data, modified from McNeill et al. (2017a). A. Plane orientation determined using two apparent dips (black dots), one on the core surface and the other on the cutting (splitcore) surface. B. With paleomagnetic correction.
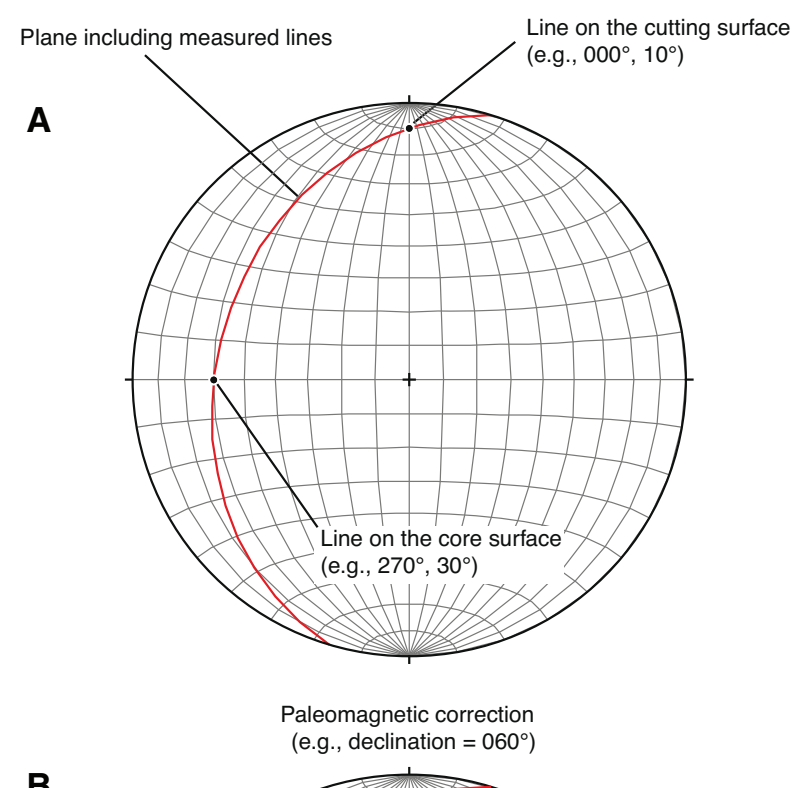

B

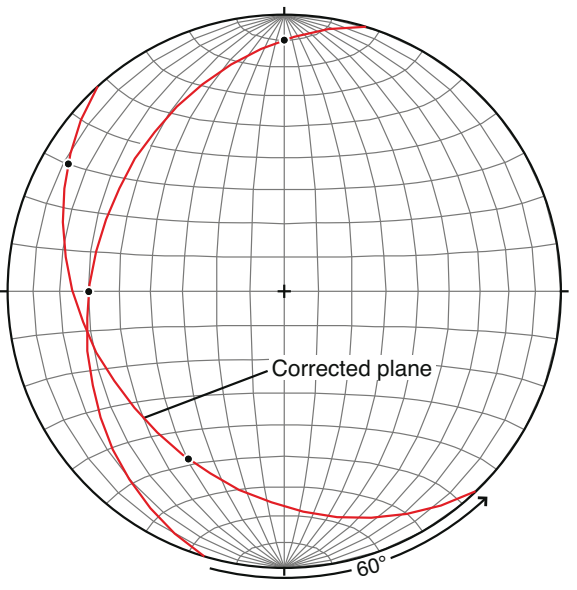

The unit vector normal to the plane $\left(v_{\mathrm{n}}\right)$ (Figure F9) is then defined as

$$
v_{\mathrm{n}}=\left(\begin{array}{c}
l_{\mathrm{n}} \\
m_{\mathrm{n}} \\
n_{\mathrm{n}}
\end{array}\right)=\frac{v_{1} \times v_{2}}{\left|v_{1} \times v_{2}\right|},
$$

where

$$
v_{1} \times v_{2}=\left(\begin{array}{c}
\left|\begin{array}{c}
m_{1} m_{2} \\
n_{1} n_{2}
\end{array}\right| \\
\mid n_{1} n_{2} \\
l_{1} l_{2} \mid \\
\left|\begin{array}{c}
l_{1} l_{2} \\
m_{1} m_{2}
\end{array}\right|
\end{array}\right)=\left(\begin{array}{c}
m_{1} n_{2}-m_{2} n_{1} \\
n_{1} l_{2}-n_{2} l_{1} \\
l_{1} m_{2}-l_{2} m_{1}
\end{array}\right) \text {. }
$$


Figure F9. Calculation of plane orientation (shaded) from two apparent dips. Intersections of plane with split-core surface and a section perpendicular to split-core surface and parallel to core axis are shown. $\left(a_{1}, \beta_{1}\right)$ and $\left(\alpha_{2}, \beta_{2}\right)$ are the azimuths and plunges of the traces of the plane on these two sections, $v_{1}$ and $v_{2}$ are unit vectors parallel to the traces of the plane on these two sections, and $v_{n}$ is the unit vector normal to the plane (its pole). Modified from McNeill et al. (2017a).

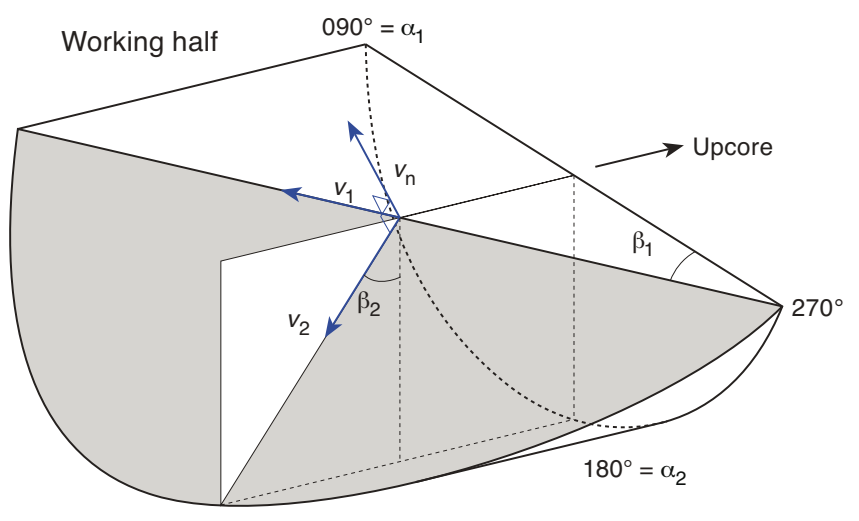

The azimuth $\left(\alpha_{n}\right)$ and plunge $\left(\beta_{n}\right)$ of $\nu_{n}$ are given by the following:

$$
\alpha_{\mathrm{n}}=\tan ^{-1}\left(\frac{m_{\mathrm{n}}}{l_{\mathrm{n}}}\right), \beta_{\mathrm{n}}=\sin ^{-1} n_{\mathrm{n}}
$$

The dip direction $\left(\alpha_{d}\right)$ and dip angle $(\beta)$ of this plane are $\alpha_{n}$ and $90^{\circ}+\beta_{n}$, respectively, when $\beta_{n}<0^{\circ}$. They are $\alpha_{n} \pm 180^{\circ}$ and $90^{\circ}-\beta_{n}$, respectively, when $\beta_{\mathrm{n}} \geq 0^{\circ}$. Using the right-hand rule, the strike of this plane $\left(\alpha_{\mathrm{s}}\right)$ is then given by $\alpha_{\mathrm{d}}-90^{\circ}$.

During postexpedition analysis, paleomagnetic data can be used to restore orientation data to the true geographic reference frame (Figure F8B).

\section{Drilling-induced deformation}

Cores may be significantly disturbed and deformed as a result of the coring and core handling process (Jutzeler et al., 2014). We therefore included observations on drilling disturbance in the structural geology workflow. Our motivation was to document DID if required for follow-up studies and to evaluate its potential impact on other studies (e.g., paleomagnetic measurement) and sampling strategies (e.g., avoiding contamination or injected layers of mobile material). These features can also be calibrated against drilling parameters to indicate rock strength. Drilling- and coring-induced structures are initiated by stresses related to drilling operations and/or removal of overburden pressure. Different drilling methods induce systematically different deformation in the core (Jutzeler et al., 2014). These disturbances are described in each site chapter and graphically indicated on the VCDs. Parts of core sections were sometimes pushed back into liners (material that had extruded out of the core), thus generating deformation. Core handling-induced structures are initiated by stresses related to splitting, bending, and impact after cores are brought on board (Kulander et al., 1990).

Three parameters were recorded for describing DID features: type (Figure F11), intensity (slight, moderate, high, or severe [bedding destroyed]), and origin uncertainty (described above). DID types are described below and in Table T1.
Figure F10. Examples of tectonic faults observed in Hole M0080A cores. A. Normal faults (138R-3). Lower fault has a $2 \mathrm{~cm}$ thick black fault gouge. B. Two sampled fault planes from Unit 3 with slickenlines on polished mirror surfaces indicating dip-slip (ss2) and oblique-slip (ss1) (113R-2). C. One sampled fault surface (blackened) from Unit 4 with slickenlines indicating oblique-slip (ss3) (133R-2).
A

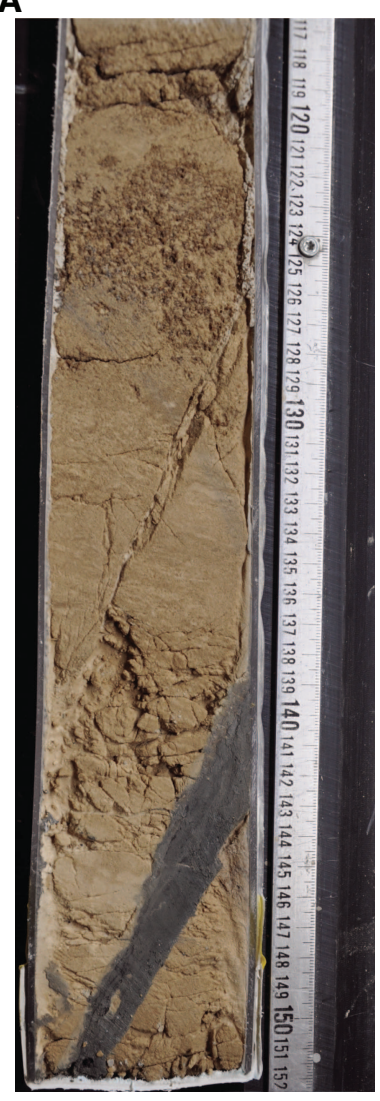

B

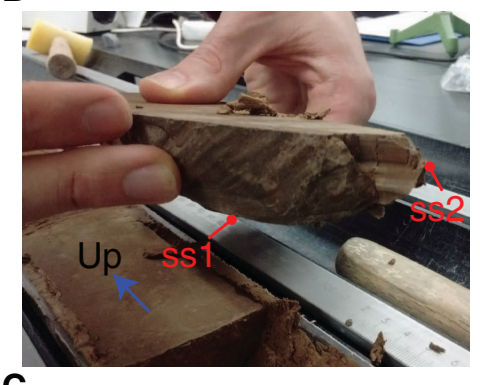

C

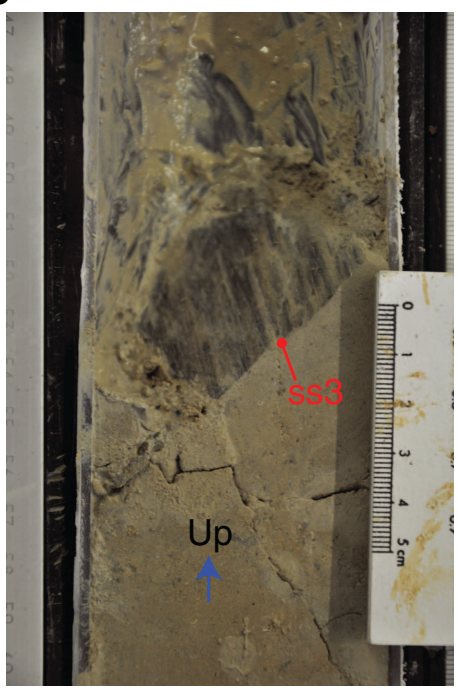

\section{Arching bedding}

Upward arching of bedding is often described as bowing up or folding and is probably caused by suction of the material into the core barrel (Skinner and McCave, 2003). Downward-arching structures can also occasionally occur. Lensing of coarse material and sediment flow/smearing are often associated with arching of bedding (Figure F11A).

\section{Lensing}

If present, coarse sediment can be dragged into the core of an arch, often due to extreme arching and "pull-in" of beds along the base of the coarser bed (Figure F11A).

\section{Sediment flow along core liner}

Sediment flow or smearing along the core liner is the result of coring-induced shear of sediment (often mixed with drilling fluid) along the margins of the core liner (either up or down) (Figure F11A).

\section{Axial fluid flow (injection/escape)}

Divergent upward arching of beds around a central flow axis records upward fluid or sediment escape. The flow can reach the top of a core or end in a chaotically disrupted bed (Figure F11C). 
Figure F11. Examples of DID, Hole M0078A. A. Upward arching of bedding and lensing of coarse beds (dark material) in the cores of arches (73V-2). B. Biscuits with flow along core liner and inflow of darker sediment and/or drilling fluids between biscuits (44P-1). C. Upward flow of sediment along the center of a core associated with upward drag of bedding on either side. The flow channel terminates in a chaotic disturbed bed above (7H-1). D. Drilling-induced small faults and tilting of beds in fault blocks (105R-1).
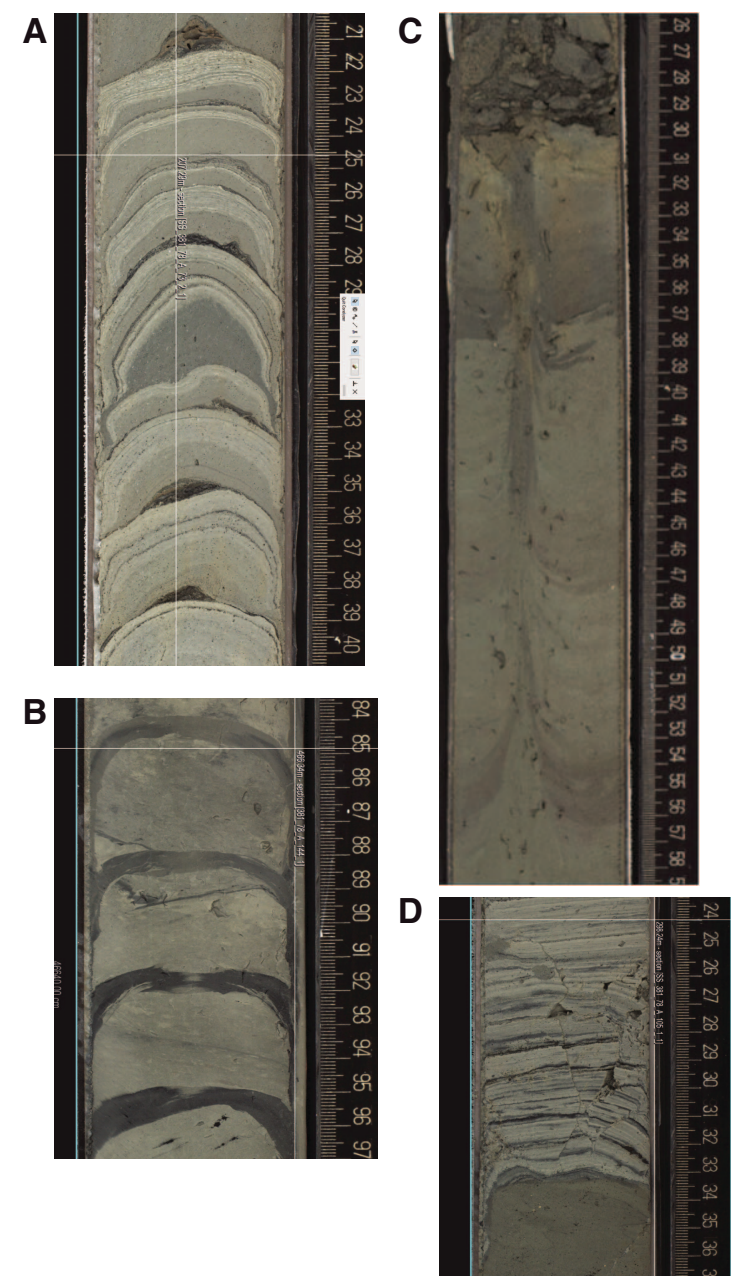

\section{Disturbed/Mingled bedding}

Disturbed to mingled bedding can be caused by suction of material into the core barrel or dewatering or injection of mobile sediment or fluid from below (Figure F11C).

\section{Soupy texture}

The primary structure is destroyed as the sediment is completely liquefied, and sediment does not fill the core liner.

\section{Tilted panels} ing:

Three different processes can generate tilted panels during drill-

- Core can be broken into panels of variable thickness that are variably tilted because of injection of mobile sediment and/or drilling mud/seawater.

- Tilted panels can occur in discs during biscuiting.

- Tilting of blocks between DID faults is also common (Figure F11D).

\section{Biscuiting}

Biscuiting is one of the most common forms of damage in rotary coring (Figure F11B). It describes the breaking up of the core into "biscuits" or discs with convex tops and/or concave/convex bases. The discs have relatively constant thickness and spacing (that varies with facies/strength or potentially changing drilling parameters). Biscuiting is the result of vertical tensile stress acting on the rock during progress of the drill bit, followed by blocks rotating with respect to each other in the core barrel. Biscuiting can be associated with flow or smearing of sediment and drilling fluids along the core liner and variable inflow from core margins. Mobile sediment and/or drilling mud can be injected between the discs to form "pseudobeds" or "rinds" of variable thickness. In the case of Expedition 381 cores, the rinds are sometimes markedly darker relative to the discs, suggesting either exploitation of weaker lithologies or preferential mobilization of organic-rich sediment (e.g., dark layers, Figure F11B). The biscuits themselves can undergo attrition, smearing, or faulting of their margins. Small thrusts can form on the top of discs because of inflow from the core margins. The discs may have a central "tail" descending from their base. Bedding in the discs can also be tilted.

\section{Shear fractures}

Shear fractures, faults, and shear bands can develop either along the edges of the core or in the center of the core (Figure F11D). Conjugate normal faults can develop symmetrically around the core axis. Small faults, both inverse and normal, can be associated with arching beds and smearing along core margins (Figure F11A, F11B).

\section{Open fractures (transverse to bedding)}

Open fractures can form along preexisting in situ tectonic structures or sedimentary layering. An open fracture in a core may be a primary tectonic structure, a drilling-induced fracture, or a drillinginduced fracture superimposed on a primary structure and/or preexisting mechanical anisotropy. Examples of preexisting mechanical anisotropies include natural fractures, faults, microfractures, bedding planes, and solution cleavage (Kulander et al., 1990).

\section{Brecciation}

Brecciation can occur between discs during biscuiting of welllithified rocks. Limited brecciation can also occur along DID shear fractures.

Voids

Voids are irregular "holes" in the core attributed to DID.

\section{Micropaleontology}

Micropaleontological investigations carried out during the offshore phase focused primarily on calcareous nannofossils, marine and nonmarine diatoms, and planktonic and benthic foraminifers. Preliminary geologic age determinations were based on calcareous nannofossils. Additionally, select core catcher samples were sent to the National and Kapodistrian University of Athens (Greece) during and soon after the offshore phase for preliminary palynological analyses in advance of the OSP. Preliminary environmental interpretations were determined through a combination of the assemblages observed and qualitative abundances of all microfossil groups. 
During the OSP phase, the cores were split and additional samples were taken to augment the initial interpretations made from the core catcher samples collected offshore with analysis of calcareous nannofossils, marine and nonmarine diatoms, planktonic and benthic foraminifers, and palynomorphs.

\section{Foraminifers}

For foraminifer analysis, the same methods were applied during the onshore and offshore phases of the expedition. During the offshore phase, planktonic and benthic foraminifers from core catcher samples were examined; during the OSP, core samples were examined. Core catcher samples (between 10 and $15 \mathrm{~cm}^{3}$ ) and onshore core samples $\left(10 \mathrm{~cm}^{3}\right)$ were first sieved with tap water over a $63 \mu \mathrm{m}$ mesh sieve. The residue was dried on filter paper in a low-temperature oven at $\sim 45^{\circ} \mathrm{C}$. If samples were indurated, they were first soaked in $\mathrm{H}_{2} \mathrm{O}_{2}(10 \%)$ to further disaggregate the sediment before sieving. To minimize contamination of foraminifers between samples, the sieves were placed in an ultrasonic bath for several minutes and thoroughly checked between each sample.

For both the offshore and onshore phases, species identifications for benthic and planktonic foraminifers were made on the $>125 \mu \mathrm{m}$ size fraction, which was examined under a binocular microscope. The $63-125 \mu \mathrm{m}$ size fraction was examined if benthic foraminifers were absent or very low numbers were observed in the larger size fractions. Where possible, at least 100 specimens were identified and counted to determine benthic foraminiferal relative abundances of the dominant taxa (Fatela and Taborda, 2002). In cases where abundance was lower than 100 individuals, all foraminiferal samples were identified and counted. The genera of benthic foraminifers were assigned following the World Register of Marine Species (WoRMS) database (WoRMS Editorial Board, 2018).

Planktonic foraminifer species identification was based on Kennett and Srinivasan (1983), Bolli and Saunders (1985), and Hemleben et al. (1989). The species Globoturborotalita rubescens and Globoturborotalita tenella were counted together because of the similarity in their ecological characteristics (Capotondi et al., 1999). The species Globigerinoides sacculifer also includes Globigerinoides trilobus according to Hemleben et al. (1989). Left- and right-coiling specimens of Neogloboquadrina pachyderma were counted separately. Samples containing $\leq 5$ foraminifers are considered to provide very limited environmental information.

Relative abundance of benthic and planktonic foraminifer species in a sample was estimated according to the following criteria in samples containing more than 100 individuals:

- $\mathrm{T}=$ trace $(<5 \%$ of the $>125$ or $>63 \mu \mathrm{m}$ size fraction $)$.

- $\mathrm{F}=$ few $(<5 \%-9 \%$ of the $>125$ or $>63 \mu \mathrm{m}$ size fraction).

- $\mathrm{C}=$ common $(10 \%-24 \%$ of the $>125$ or $>63 \mu \mathrm{m}$ size fraction).

- $A=$ abundant $(25 \%-39 \%$ of the $>125$ or $>63 \mu \mathrm{m}$ size fraction).

- VA = very abundant $(40 \%-74 \%$ of the $>125$ or $>63 \mu \mathrm{m}$ size fraction).

- $\mathrm{D}=$ dominant $(>75 \%$ of the $>125$ or $>63 \mu \mathrm{m}$ size fraction).

\section{Calcareous nannofossils}

Calcareous nannofossil examination was conducted on core catcher samples collected offshore and core samples collected during the OSP. Smear slides were prepared for nannofossil observation using a standard technique of mixing the sample material with Milli-Q water using a toothpick to produce and evenly distribute a slurry onto a $24 \mathrm{~mm} \times 24 \mathrm{~mm}$ glass coverslip. The slurry on the coverslip was then dried on a hot plate and adhered onto a glass mi- croscope slide with Norland optical adhesive Number 61. Finally, the glue was cured under a UV light for approximately $10 \mathrm{~min}$.

Nannofossils were examined using an Olympus BX51 optical microscope, and specimen photographs were taken with an Olympus DP22 microscope camera. Species identifications, relative abundance, and preservation were determined at $1000 \times$ magnification under both plane- and cross-polarized light across one whole traverse of the coverslip.

Relative abundances of calcareous nannofossil species were developed to best suit the observed assemblages with the following criteria:

- $A=$ abundant ( $>50$ specimens of a given species per field of view [FOV] at $1000 \times$ magnification).

- $\mathrm{C}=$ common (16-50 specimens of a given species per FOV at $1000 \times)$.

- $F=$ few $(2-15$ specimens of a given species per FOV at $1000 \times)$.

- $\mathrm{R}=$ rare $(0-1$ specimens of a given species per FOV at $1000 \times)$.

- $\mathrm{VR}=$ very rare $(<5$ specimens of a given species per traverse at $1000 \times)$.

A qualitative measurement of calcareous nannofossil preservation follows these criteria:

- $\mathrm{E}=$ excellent (no evidence of dissolution or overgrowth; all specimens identifiable to the species level; coccospheres preserved and observed).

- $\mathrm{G}$ = good (little to no evidence of dissolution or overgrowth; all specimens identifiable to the species level).

- $M=$ moderate (evidence of dissolution or overgrowth; primary morphological characteristics partially altered, rendering some specimens unidentifiable at the species level).

- $\mathrm{P}=$ poor (specimens severely altered by dissolution, overgrowth, or fragmentation, rendering most specimens unidentifiable at the species level and in some cases at the genus level).

The biozonation of Backman et al. (2012), developed for Miocene through Pleistocene calcareous nannofossils from low to middle latitudes, was applied to the calcareous nannofossils to determine geologic age. This biozonation was further calibrated with the most recent geologic timescale of Ogg et al. (2016). The website http://www.mikrotax.org was consulted as necessary to aid in calcareous nannofossil identification.

\section{Offshore diatoms}

Marine and nonmarine diatom examination was conducted on core catcher samples or the base-of-core sample offshore-whichever was available. Because of limited laboratory capabilities on the MSP and limited time, diatoms were not prepared for examination using conventional methods. Diatoms were ultimately observed in smear slides prepared for calcareous nannofossil examination and in sieved sample material prepared for foraminifer examination. When necessary for species identification, diatoms were picked from the sieved material, injected into a droplet of Milli-Q water on a glass $24 \mathrm{~mm} \times 24 \mathrm{~mm}$ coverslip, and otherwise prepared as a smear slide (see Calcareous nannofossils) for examination under an optical light microscope. These unconventional techniques proved sufficient for initial offshore "shipboard" characterization.

Diatoms were examined using an Olympus BX51 optical microscope, and specimen photographs were taken with an Olympus DP22 microscope camera. Species identifications, relative abundance, and preservation were typically determined at 1000× magnification under plane-polarized light across one whole traverse of the 
coverslip. For diatoms from the large size fraction, identification and photography was done at $400 \times$ magnification.

Relative abundances of marine and nonmarine diatom species were developed to best suit the observed assemblages with the following criteria:

- $\mathrm{A}=$ abundant $(>20$ specimens of a given species per traverse at $400 \times$ magnification; for specimens from the small size fraction, relative abundance was determined at $1000 \times$ magnification).

- $\mathrm{C}=$ common (11-20 specimens of a given species per traverse at $400 \times)$.

- $F=$ few (3-10 specimens of a given species per traverse at $400 \times$ ).

- $\mathrm{R}=$ rare (2 specimens of a given species per traverse at $400 \times$ ).

- $\mathrm{VR}=$ very rare (1 specimen of a given species per traverse at $400 \times)$.

- $\mathrm{X}=$ present (reserved for other siliceous microfossils and reworked specimens).

A qualitative measurement of diatom preservation follows these criteria:

- $\mathrm{E}$ = excellent (no evidence of dissolution or breakage; all specimens identifiable to the species level; frustules preserved and observed).

- $\mathrm{G}$ = good (little to no evidence of dissolution or breakage; whole valves preserved, and all specimens identifiable to the species level).

- $M=$ moderate (evidence of dissolution and breakage; primary morphological characteristics partially altered, rendering some specimens unidentifiable at the species level).

- $\mathrm{P}=$ poor (specimens severely altered by dissolution and breakage, rendering most specimens unidentifiable at the species level and in some cases at the genus level).

Marine diatoms were not used to constrain geologic age here, but both marine and nonmarine diatom assemblages were applied to interpret depositional environment.

References utilized to aid in taxonomy include Witon and Witkowski (2003), Houk et al. (2010), and Hajós (1973).

\section{Onshore diatoms}

Diatom data were generated from additional analyses of core catcher samples and samples selected from specific intervals throughout each hole. Smear slides were prepared by mixing and evenly distributing the sample material with Milli-Q water using a toothpick onto a $24 \mathrm{~mm} \times 40 \mathrm{~mm}$ glass coverslip. After drying, the coverslip was adhered onto a glass microscope slide with Norland optical adhesive Number 61 and cured under a UV light for approximately $10 \mathrm{~min}$. Diatom assemblages were analyzed under oil immersion at 1000x magnification with an Olympus BX51 microscope. Photomicrographs were taken with an Olympus DP20 camera. Whenever possible, diatoms were identified to species level; morphological splits according to valve shape and/or shape of the central area were applied for some of the taxa. Diatom identification followed Economou-Amilli (1987, 1991), John and Economou-Amilli (1990), Krammer and Lange-Bertalot (1991), Houk et al. (2010), and Cvetkoska et al. (2014).

For each slide, diatom valves were counted along one traverse of the coverslip (as many as 100 valves). Data are presented as counts per taxon and total counts per sample. Diatom taxa were assigned to different categories based on their salinity, habitat, nutrient, and $\mathrm{pH}$ preferences. The relative proportion of each category from the total counts was used to aid environmental information. The statis- tical software packages Tilia and TGView v. 2.0.2. (Grimm, 2004) were used to display the diatom stratigraphy.

\section{Palynomorphs}

A total of 28 core catcher samples of $1-4.5 \mathrm{~g}$ of dry sediment were processed for palynological analysis during the offshore phase and between the offshore and onshore phases in the palynology laboratory of the National and Kapodistrian University of Athens. The following processing steps were applied:

1. Treatment with $37 \% \mathrm{HCl}$, with spike added (Lycopodium tablets);

2. Treatment with $39 \% \mathrm{HF}$ ( 2 days);

3. Treatment with $37 \% \mathrm{HCl}$;

4. Sieving through a $10 \mu \mathrm{m}$ mesh; and

5. Mounting the residue on slides using glycerin.

Centrifuging was applied between steps to speed up the process.

During the OSP, additional core catcher and core samples of $3-$ $4 \mathrm{~g}$ of dry sediment were processed. The following processing steps were applied:

1. Treatment with $37 \% \mathrm{HCl}$ (1 day), with spike added (Lycopodium tablets);

2. Neutralizing with $40 \% \mathrm{KOH}$ (1 day), decant;

3. Treatment with $40 \% \mathrm{HF}$ ( 2 days);

4. Neutralizing with $40 \% \mathrm{KOH}$ (1 day), decant;

5. Treatment with $10 \% \mathrm{HCl}$, neutralizing with $10 \% \mathrm{KOH}$ (1 day), decant; and

6. Mounting the residue on slides using glycerin.

\section{Terrestrial and marine palynomorphs}

Palynomorphs were identified and counted on a Zeiss Axioskop microscope using 200×, 400×, and 1000× magnification, and phase contrast was applied when necessary. Pollen grains, dinoflagellate cysts, foraminifer test linings, freshwater algae coenobia (e.g., Botryococcus and Pediastrum) and spores, fern spores, fungal remains, and microscopic charred particles were counted.

A mean of 130 pollen grains were counted per sample. Pollen identification follows Beug (2004), and the pollen atlases of Reille $(1992,1998)$ were also consulted.

A mean of 190 dinoflagellate cysts were counted in the same slides used for pollen analysis to achieve a direct land-sea correlation. Dinoflagellate cysts (dinocysts) were identified to genus or species level using the atlases of Zonneveld and Pospelova (2015) and Mudie et al. (2017), and some species were identified with the help of shore-based scientist F. Marret (pers. comm., 2018). Dinoflagellate cysts are categorized in four groups:

- Cysts of freshwater species Gonyaulax apiculata (Evitt et al., 1985; Kouli et al., 2001);

- Cysts of Pyxidinopsis psilata, Spiniferites cruciformis, and Lingulodinium machaerophorum with low processes indicating brackish conditions (Mertens et al., 2012; Mudie et al., 2017);

- Cysts of marine species Bitectatodinium tepikiense, Impagidinium aculeatum, Impagidinium patulum, L. machaerophorum, Operculodinium centrocarpum, Nematosphaeropsis labyrinthus, Polysphaeridium zoharyi, Pyxidinopsis reticulata, Selenopemphix quanta, Spiniferites elongatus, Spiniferites membranosus, Spiniferites pachydermus, Tectatodinium psilatum, Tuberculodinium vancampoae, and Tectatodinium sp.; and - Unidentified dinocysts. 
Foraminiferal test linings were divided into two groups (planispiral and trochospiral).

Pollen percentages were calculated on the Pollen Sum (terrestrial pollen grains), excluding pines, to ensure compatibility with other marine pollen archives. Percentages of pollen and other palynomorphs are reported using the following scheme:

- Dominant (>60\%),

- Abundant (60\%-40\%),

- Common (40\%-15\%),

- Few $(15 \%-3 \%)$, and

- Rare $(<3 \%)$.

In addition, palynomorph concentrations per gram of sediment were calculated against an exotic marker (Lycopodium spores) that was added during the chemical treatment of the samples. The terrestrial and aquatic environmental indicators are subsequently integrated per sample to evaluate terrigenous input and to distinguish between marine, brackish, and freshwater depositional environments when possible.

\section{Microfossil assemblage characterization}

Microfossil assemblages observed during shipboard characterization proved complex. Abundance and diversity of individual microfossil groups and of the collective microfossil assemblage shift significantly between depositional environments. To characterize the total microfossil assemblage, each microfossil group was first examined individually and given a simple environmental assignment based on presence and abundance (e.g., marine assemblage, nonmarine assemblage, or undetermined). Then, criteria describing the whole microfossil assemblage were created based on combined qualitative and quantitative data collected for each microfossil group:

- Fully marine (sample contains only marine microfossils in moderate to high abundances),

- Mixed assemblage (sample contains both marine and nonmarine microfossils in variable but generally low abundances),

- Nonmarine (sample contains only nonmarine microfossils in moderate to high abundances), and

- Undetermined (microfossils are either absent or present in abundances too low to reliably determine depositional environment; abundance minimum varies by microfossil group).

\section{Geochemistry}

\section{Offshore interstitial water sampling and analysis}

\section{Pore water sampling}

Pore water was collected from sediment cores immediately after recovery using either Rhizon samplers or whole-round squeezing. Rhizon sampling was preferred over whole-round squeezing in shallow sediment to increase depth resolution. Generally, pore water samples were retrieved from every core section in the upper 10 mbsf and at 9-10 m intervals thereafter.

Rhizon samplers (CSS-F 5 cm; Rhizosphere Research Products, Netherlands) are narrow elongated cylindrical microporous filters ( $0.2 \mu \mathrm{m}$ pore size; $5 \mathrm{~cm}$ long; $130 \mu \mathrm{L}$ volume) with a stiff plastic core (Seeberg-Elverfeldt et al., 2005; Dickens et al., 2007; Miller et al., 2017). Before use, each Rhizon was soaked in ultrapure water (Elga Purelab Classic UV) for approximately $30 \mathrm{~min}$. A $3.8 \mathrm{~mm}$ hole was drilled into the plastic core liner using a spacer on the drill bit to avoid penetrating the sediment, and the Rhizon filament was in- serted into the sediment. Negative pressure was applied by attaching a 12 or $24 \mathrm{~mL}$ all-plastic pulled-back syringe to the Rhizon sampler. The sediment cores remained capped throughout this process to minimize ambient gas penetration. Rhizon samplers remained in the cores for 3-6 h until approximately $10 \mathrm{~mL}$ of pore water was collected. Usually, two Rhizons were used per core section, spaced $10 \mathrm{~cm}$ apart to obtain sufficient pore water from a single interval while minimizing overlap.

When Rhizon samplers were no longer effective at removing pore water, typically at $10-20 \mathrm{mbsf}, 5-7 \mathrm{~cm}$ long whole-round sections were cut, and the sediment was squeezed in a Teflon-lined titanium squeezer of piston-cylinder design (described in detail at http://www.marum.de/en/Research/Acquisition.html). Whole rounds were removed from the bottom of the second core section to minimize potential seawater contamination or mud fluid penetration from core ends. Before squeezing, 4-5 $\mathrm{mm}$ of sediment was scraped off the edges to remove drilling mud from the outer surface. The sediment in the squeezer was contained by a circular titanium screen at the base of the cylinder overlain by nylon mesh and a paper filter (Whatman 1; $55 \mathrm{~mm}$ ) through which the water was pushed through an online filter (Sartorius; $0.2 \mu \mathrm{m} ; 25 \mathrm{~mm}$; nylon) and into a $24 \mathrm{~mL}$ all-plastic syringe. All parts of the squeezer that may come in contact with the sediment or pore water are made of polytetrafluoroethylene (PTFE), titanium (Grade 2), or polyamide plastic (Delrin). The hydraulic press applied as much as 10 tons/inch ${ }^{2}$, equivalent to $137,900 \mathrm{kPa}$, on the sediment; however, pressure was slowly increased (over 3-6 h) to allow the sediment to adjust to increasing compression. The recovered interstitial water volume ranged from 1 to $18 \mathrm{~mL}$, varying with depth and lithology. If the sampling yield was too low, limited measurements were performed, indicated by data gaps in the tables and figures. After 3-4 $\mathrm{mL}$ of pore water was collected, a $1 \mathrm{~mL}$ aliquot was transferred directly into a $1.5 \mathrm{~mL}$ glass vial with a screw cap prefilled with $0.4 \mathrm{~mL}$ of $2 \% \mathrm{Zn}$ acetate for $\mathrm{H}_{2} \mathrm{~S}$ analyses. After squeezing was finished, the extracted pore water was transferred to a $20 \mathrm{~mL}$ polypropylene vial. When multiple Rhizon samples were taken from one core section within $10 \mathrm{~cm}$ of each other, samples were combined in a single vial. The sample was subsequently split into as many as ten fractions (depending on collected volume) for the following analyses:

- Alkalinity and $\mathrm{pH}(0.5 \mathrm{~mL})$,

- Ammonium $\left(\mathrm{NH}_{4}{ }^{+} ; 0.5 \mathrm{~mL}\right)$,

- Anions (1-3 mL),

- Cations (1-3 mL acidified to $1 \%$ concentrated trace metal grade $\left.\mathrm{HNO}_{3}\right)$

- Salinity $(0.5 \mathrm{~mL})$,

- $\delta^{13} \mathrm{C}$ of DIC preserved with $\mathrm{HgCl}_{2}$ and no headspace in a glass crimp vial $(1.8 \mathrm{~mL})$

- ${ }^{87} \mathrm{Sr} /{ }^{86} \mathrm{Sr}$ ratio acidified to $1 \%$ concentrated trace metal grade $\mathrm{HNO}_{3}(1.8 \mathrm{~mL})$,

- $\delta^{18} \mathrm{O}$ of water in a glass crimp vial without headspace $(1.8 \mathrm{~mL})$,

- Phosphate $\left(\mathrm{PO}_{4}{ }^{3-}\right)$ acidified to $1 \%$ concentrated trace metal grade $\mathrm{HCl}(1.8 \mathrm{~mL})$ in a $6 \mathrm{~mL}$ high-density polyethylene (HDP) pony vial, and

- DIC in $2 \mathrm{~mL}$ glass screw vials $(1 \mathrm{~mL})$.

During offshore operations, additional pore water reference samples were collected from the drilling mud in the mud tank (mud front), drilling mud liner (drilling mud residues from the core liner after core arrival on deck), tap water (extra tap water line for the geochemistry container from the ship's potable water system with 
an upstream filter cartridge), and laboratory water (ultrapurified water). The drilling coordinator collected drilling mud samples from the core liner at the rig floor in $50 \mathrm{~mL}$ polypropylene centrifuge tubes; the geochemists collected tap and laboratory water samples in the geochemistry container. These samples were filtered as quickly as practicable with Rhizons and treated exactly as pore water samples (i.e., split and analyzed to fulfill IODP-required measurements). The remaining drilling mud after pore water removal was collected in a $20 \mathrm{~mL}$ polypropylene vial and archived. Geochemical characterization of drilling mud fluid was continuously compared (approximately every $50 \mathrm{~m}$ ) with sediment pore water results to highlight potential mud fluid intrusion into pore water samples.

\section{Pore water analysis}

Pore waters from sediment core samples and reference samples were analyzed offshore for alkalinity, $\mathrm{NH}_{4}{ }^{+}, \mathrm{pH}$, and salinity. All analyses were performed within $72 \mathrm{~h}$ of collection. Pore water $\mathrm{pH}$ was measured using an ion-specific electrode (Mettler Toledo) with a 2-point calibration on $0.5 \mathrm{~mL}$ of pore water, which was then used for alkalinity measurement by single-point titration to $\mathrm{pH} 3.95$ with 0.01 or $0.05 \mathrm{M} \mathrm{HCl}$ according to standard procedures (Grasshoff et al., 1983). $\mathrm{NH}_{4}{ }^{+}$was measured by conductivity after separation as ammonia $\left(\mathrm{NH}_{3}\right)$ through a PTFE membrane in a flow-through system. In this technique, modified after Hall and Aller (1992), $\mathrm{NH}_{3}$ is stripped from a $100 \mu \mathrm{L}$ sample by an alkaline carrier solution $(0.2 \mathrm{M}$ $\mathrm{Na}$ citrate in $10 \mathrm{mM} \mathrm{NaOH}$ ), passed through a $200 \mathrm{~mm} \times 5 \mathrm{~mm}$ PTFE membrane, and redissolved as $\mathrm{NH}_{4}{ }^{+}$in an acidic solution (1 $\mathrm{mM} \mathrm{HCl}) . \mathrm{NH}_{4}{ }^{+}$ions were then measured as the resulting conductivity signal in the acidic carrier in a microflow-through cell. Salinity was determined by optical refraction (Krüss Optronic digital refractometer DR301-95) and calibrated with International Association for the Physical Sciences of the Oceans (IAPSO) seawater standards by OSIL with salinity values of 9.989, 29.968, 34.993, and 38.022 and with deionized ultrapurified laboratory water as a standard for zero salinity. All residual pore water collected for alkalinity, $\mathrm{pH}$, and salinity analyses was stored and archived at $4^{\circ} \mathrm{C}$. Pore water splits for anions, cations, and $\mathrm{PO}_{4}{ }^{3-}$ were stored at $4{ }^{\circ} \mathrm{C}$ for further analysis during the OSP. The methods are described below.

\section{Methane sampling}

Methane $\left(\mathrm{CH}_{4}\right)$ headspace samples were collected from the same cores as pore water samples. Typically, samples for headspace $\mathrm{CH}_{4}$ were taken at the bottom of the first section immediately after cutting the section on the catwalk. Two $3-4 \mathrm{~cm}^{3}$ sediment samples were collected with cut-off disposable syringes from the freshly exposed end of the section. The samples were extruded into a $20 \mathrm{~mL}$ glass vial filled with $8 \mathrm{~mL}$ of $1 \mathrm{M} \mathrm{NaOH}$ solution, immediately crimp-sealed with a gas-tight septum, and stored upside down at $4^{\circ} \mathrm{C}$ prior to analysis. Two additional methane samples were collected at a $100 \mathrm{~m}$ resolution for clumped isotope analysis (for personal postexpedition research).

\section{Seawater sampling}

During drilling operations, surface seawater samples were collected at midship using $10 \mathrm{~L}$ buckets on a rope. At Sites M0079 and M0080, sufficient seawater was retrieved to fill one low-density polyethylene (LDP) $1 \mathrm{~L}$ bottle acidified with $5 \mathrm{~mL}$ of concentrated trace metal grade $\mathrm{HNO}_{3}$, one LDP $1 \mathrm{~L}$ bottle unpreserved, and one $20 \mathrm{~mL}$ polypropylene vial. At Site M0078, one $20 \mathrm{~mL}$ polypropylene vial was filled with seawater. The seawater in the $20 \mathrm{~mL}$ vials was filtered with Rhizons and treated as pore water samples (i.e., split and analyzed to fulfill IODP-required measurements). Two additional seawater samples for neodymium analyses were collected at Sites M0079 and M0080 by filtering $10 \mathrm{~L}$ of seawater through qualitative filter paper into acid-washed HDP containers (for personal postexpedition research). Neodymium samples were acid preserved with $20 \mathrm{~mL}$ of concentrated trace metal grade $\mathrm{HNO}_{3}$.

Additionally, four seawater samples were collected during transit from Site M0079 to Site M0080 and one was collected during transit from Site M0080 to the Port of Corinth. At predetermined locations, the drillship slowed to $\sim 1 \mathrm{kt}$, and seawater was retrieved from a $10 \mathrm{~L}$ bucket tied to a rope. Seawater samples were split into four $125 \mathrm{~mL}$ HDP amber bottles and one $20 \mathrm{~mL}$ polypropylene vial. Two amber bottle splits and the $20 \mathrm{~mL}$ vial were unpreserved, one bottle was acidified with $1.25 \mathrm{~mL}$ of concentrated trace metal grade $\mathrm{HNO}_{3}$, and one bottle was acidified with $1.25 \mathrm{~mL}$ of concentrated trace metal grade $\mathrm{HCl}$. Additionally, $20 \mathrm{~mL}$ of seawater was filtered directly from the bucket with a Rhizon and treated as pore water samples (i.e., split and analyzed to fulfill IODP-required measurements).

\section{Onshore science party chemical analyses Pore water analysis}

Pore water splits collected and preserved offshore were analyzed for anions, cations, $\mathrm{PO}_{4}{ }^{3-}$, and DIC during the OSP at the University of Bremen. The anions bromide $\left(\mathrm{Br}^{-}\right)$, chloride $\left(\mathrm{Cl}^{-}\right)$, and sulfate $\left(\mathrm{SO}_{4}{ }^{2-}\right)$ were measured using a Metrohm 882 compact ion chromatograph. A 40-fold dilution of IAPSO seawater and standards prepared from commercial single anion standards was used for calibration. Measurement precisions were $\pm 2.6 \%$ for $\mathrm{Cl}^{-}, \pm 2.7 \%$ for $\mathrm{Br}^{-}$, and $\pm 0.95 \%$ for $\mathrm{SO}_{4}{ }^{2-}(1 \sigma)$. Detection limits are listed in Table T2.

Filtered $(0.2 \mu \mathrm{m})$ and acidified $(10 \mu \mathrm{L}$ of concentrated $\mathrm{HNO}_{3} / \mathrm{mL}$ ) pore water splits were analyzed for cations and trace metals. All samples were diluted 10 -fold with $1 \% \mathrm{HNO}_{3}$ and analyzed for Al, B, Ba, Ca, Fe, K, Mg, Mn, Na, P, S, Si, Sr, and Zn using a Varian Vista Pro charge-coupled device (CCD) inductively coupled plasma-optical emission spectrometer (ICP-OES) equipped with a sea-spray nebulizer and a cyclon spray chamber. Trace elements ( $\mathrm{Al}$, $\mathrm{As}, \mathrm{Ba}, \mathrm{Be}, \mathrm{Co}, \mathrm{Cr}, \mathrm{Cu}, \mathrm{Fe}, \mathrm{Li}, \mathrm{Mn}, \mathrm{Mo}, \mathrm{Ni}, \mathrm{P}, \mathrm{Ti}, \mathrm{V}, \mathrm{Zn}$, and $\mathrm{Zr}$ ) were analyzed on the same set of 10 -fold diluted samples as the major elements using an Agilent Technologies 700 Series ICP-OES equipped with a K-style conical nebulizer. Standardization was performed against multielement solutions prepared from commercial standards with either a $1 \% \mathrm{HNO}_{3}$ matrix adjusted to a $\mathrm{NaCl}$ concentration similar to the matrix in the samples (for trace element samples with salinity $>5$ ) or $1 \% \mathrm{HNO}_{3}$ only (all other samples). Calibration standards for major and trace elements were prepared using IAPSO seawater and National Institute of Standards and Technology Certified Reference Material (NIST CRM). Measurement precision was $\pm 3 \%$ for major elements and $\pm 5 \%$ for trace elements. A drift correction was applied to each major and trace element by linear interpolation between the drift-monitoring solutions.

$\mathrm{PO}_{4}{ }^{3-}$ splits were analyzed following Gieskes et al. (1991). Two reagents were added to the pore water sample to react with $\mathrm{PO}_{4}{ }^{3-}$. Reagent A consisted of ammonium molybdate, concentrated sulfuric acid, and potassium antimonyl tartrate hydrate. Reagent $B$ was created by dissolving ascorbic acid in milli-Q water. A $50 \mu \mathrm{L}$ aliquot of each reagent was added to $1 \mathrm{~mL}$ of sample and allowed to react for $10 \mathrm{~min}$ in the dark. The absorbance at a wavelength of $880 \mathrm{~nm}$ was determined using a DR 5000 UV-Vis spectrophotometer. The 
Table T2. Analytical limit of detection (LOD) for each element for all data types, Expedition 381. DIC = dissolved inorganic carbon, IC = ion chromatography, ICP = inductively coupled plasma, XRF = X-ray fluorescence. Download table in CSV format.

\begin{tabular}{|c|c|c|c|c|c|c|}
\hline $\begin{array}{r}\text { Analytical method: } \\
\text { LOD: }\end{array}$ & $\begin{array}{c}\mathrm{DIC} \\
\mathrm{mM} / \mathrm{L}\end{array}$ & $\begin{array}{c}\mathrm{IC} \\
\mu \mathrm{M} / \mathrm{L}\end{array}$ & $\begin{array}{c}\text { ICP-axial } \\
\mu \mathrm{M} / \mathrm{L}\end{array}$ & $\begin{array}{c}\text { ICP-radial } \\
\mu \mathrm{M} / \mathrm{L}\end{array}$ & $\begin{array}{c}\text { Photometric } \\
\qquad \mathrm{M} / \mathrm{L}\end{array}$ & $\begin{array}{c}\mathrm{XRF} \\
\mathrm{mg} / \mathrm{kg}\end{array}$ \\
\hline \multicolumn{7}{|l|}{ Element } \\
\hline $\mathrm{Al}$ & & & 0.37 & 1.85 & & 5000 \\
\hline As & & & 3.71 & & & 10 \\
\hline B & & & & 4.62 & & \\
\hline $\mathrm{Ba}$ & & & 0.01 & 0.15 & & 50 \\
\hline $\mathrm{Be}$ & & & 0.11 & & & 50 \\
\hline $\mathrm{Br}$ & & 1.25 & & & & 10 \\
\hline$C$ & 0.1 & & & & & \\
\hline $\mathrm{Ca}$ & & & & $<0.25$ & & 5000 \\
\hline $\mathrm{Cl}$ & & 14.10 & & & & 500 \\
\hline Co & & & 0.17 & & & \\
\hline $\mathrm{Cr}$ & & & 0.19 & & & 20 \\
\hline $\mathrm{Cu}$ & & & 0.31 & & & 10 \\
\hline $\mathrm{F}$ & & 5.26 & & & & \\
\hline $\mathrm{Fe}$ & & & 0.04 & 0.36 & & 1000 \\
\hline $\mathrm{K}$ & & & & 12.79 & & 1000 \\
\hline $\mathrm{Li}$ & & & 7.20 & & & \\
\hline $\mathrm{Mg}$ & & & & 0.41 & & 1500 \\
\hline $\mathrm{Mn}$ & & & 0.02 & 0.18 & & 50 \\
\hline Mo & & & 0.10 & & & \\
\hline $\mathrm{Na}$ & & & & 4.35 & & 5000 \\
\hline $\mathrm{Ni}$ & & & 0.17 & & & 200 \\
\hline$P$ & & & 3.20 & 16.14 & & 200 \\
\hline $\mathrm{Pb}$ & & & & & & 200 \\
\hline $\mathrm{PO}_{4}^{3-}$ & & & & & 0.21 & \\
\hline $\mathrm{Rb}$ & & & & & & 5 \\
\hline$S$ & & & & 62.37 & & 1500 \\
\hline $\mathrm{SO}_{4}^{2-}$ & & 20.82 & & & & \\
\hline $\mathrm{Si}$ & & & & 17.80 & & $<1$ \\
\hline $\mathrm{Sr}$ & & & & 0.11 & & 20 \\
\hline $\mathrm{Ti}$ & & & 0.10 & & & 250 \\
\hline V & & & 0.20 & & & 20 \\
\hline $\mathrm{Zn}$ & & & 0.15 & 1.53 & & 10 \\
\hline $\mathrm{Zr}$ & & & 0.22 & & & 10 \\
\hline
\end{tabular}

absorbance was used to calculate $\mathrm{PO}_{4}{ }^{3-}$ concentration using a fivepoint calibration curve based on standards from 0 to $1.5 \mathrm{mg} / \mathrm{L}$ $\mathrm{PO}_{4}{ }^{3-}$. Calibration linearity exceeded $99 \%$. Additionally, unacidified pore water samples were analyzed in this same manner to look for evidence of sorption of $\mathrm{PO}_{4}{ }^{3-}$ to $\mathrm{Fe}$ (oxyhydr)oxides in sample vials. No statistically significant difference was observed between preserved and unpreserved pore water samples.

Preserved pore water splits were analyzed for DIC by catalytic combustion/nondispersive infrared (NDIR) measurement using an Analytik Jena Multi N/C 2100S. The sample aliquots were diluted by a factor of 1,2 , or 4 depending on their estimated $\mathrm{HCO}_{3}{ }^{-}$content based on shipboard alkalinity results. Reproducibility was $<7 \%$ in all samples with an average of $1.64 \%$.

\section{Bulk geochemical analysis of sediments}

Samples of approximately $10 \mathrm{~cm}^{3}$ of bulk sediment were freezedried and ground to a fine powder using a pestle and an agate mortar. Indurated samples from the lower section of Hole M0080A were ground with an impact mortar. Subsequently, the material was weighed, and three splits were extracted from each ground sample for TOC/TC, XRD, and XRF analysis. The remaining sample was stored in a glass vial and archived. The XRD methodology is reported in Lithostratigraphy.

\section{Total carbon, total organic carbon, and total inorganic carbon analysis}

For TOC measurement, $1 \mathrm{~g}$ of each ground sample was weighed into a glass vial. TC and TOC were measured using a LECO CS-300 carbon-sulfur analyzer. Approximately $65 \mathrm{mg}$ of the homogenized sample was weighed in a ceramic cup and heated in a furnace. The evolved $\mathrm{CO}_{2}$ and $\mathrm{SO}_{2}$ were then measured with a NDIR detector to provide a measure of the sedimentary TC content. To determine the TOC content, sediments were decalcified using $12.5 \% \mathrm{HCl}$ to remove carbonate species and analyzed as described above. Total inorganic carbon (TIC) was determined by subtracting TOC from TC. All data are reported in weight percent (wt\%) dry sample with TOC analytical precision $<2.62 \%$ (average $=0.83 \%$ ) and TC analytical precision $<4.02 \%$ (average $=0.77 \%$ ) based on replicate standard analysis.

\section{X-ray fluorescence}

For measuring the elemental composition of discrete sediment samples via energy dispersive XRF (ED-XRF), $4 \mathrm{~g}( \pm 0.2 \mathrm{~g})$ of freezedried, ground, homogenized sediment was weighed into plastic cuvettes with a Mylar foil bottom covered with polypropylene film. The sample in the cuvette was then compacted twice manually, applying a force of approximately $25 \mathrm{~kg} / \mathrm{cm}^{2}$ on a plastic piston to obtain a smooth surface with limited void space, consistent density, and sufficient sample thickness. Elemental concentrations of freezedried and manually ground discrete samples were measured by EDXRF spectroscopy using a PANalytical Epsilon 3-XL benchtop EDXRF spectrometer at the MARUM sediment geochemistry laboratory. The ED-XRF uses a calibration for geological material based on a series of certified standard reference materials and house standards. Results were fine-tuned during postprocessing based on the recovery of remeasured standards after the first set of 140 samples and again after the remaining samples. Results are rounded to three significant digits. Detection limits are listed in Table T2. The following elements were measured with a precision of $<1 \%$ : $\mathrm{Al}, \mathrm{Ca}, \mathrm{Fe}$, $\mathrm{K}, \mathrm{Mn}, \mathrm{Rb}, \mathrm{Si}, \mathrm{Sr}$, and $\mathrm{Zr}$. Mg and Ni precision was $1.52 \%$ and $3.16 \%$, respectively. The elements $\mathrm{Cr}, \mathrm{Cu}, \mathrm{Na}$, and $\mathrm{Ti}$ were quantified, but the accuracy of these measurements may not be reliable for reasons ranging from a low atomic weight (e.g., $\mathrm{Na}$ ) to overlaps of spectra (e.g., Cl) and very low concentrations. These values should be checked with more suitable methods. Results for $\mathrm{As}, \mathrm{Ba}, \mathrm{Br}, \mathrm{Cl}, \mathrm{P}$, $\mathrm{Pb}, \mathrm{S}, \mathrm{V}$, and $\mathrm{Zn}$ indicate concentrations were too low to be reliable.

\section{Physical properties}

The primary objective of the physical properties program was to collect high-resolution physical properties data that would enable the following:

- Characterization of lithologic units and formation physical properties,

- Facilitation of hole-to-hole and site-to-site correlation,

- Retrieval and construction of complete composite stratigraphic sections together with lithologic and sedimentological descriptions for each hole, and

- Provision of data for construction of synthetic seismograms and investigation of the characteristics of major seismic reflectors.

Offshore, (1) handheld penetrometer measurements were collected every $\sim 20 \mathrm{~m}$ when cores arrived on deck for strength measurements and (2) high-resolution, nondestructive measurements 
were collected on whole-round cores using a Geotek MSCL. The MSCL has five sensor types to measure gamma density, transverse compressional wave $(P$-wave) velocity, noncontact electrical resistivity (NCR), magnetic susceptibility, and natural gamma radiation (NGR). Note that "gamma density" refers to the bulk density of the core as derived from the collimation of gamma rays across the core.

Onshore prior to the OSP, thermal conductivity was measured every $\sim 10 \mathrm{~m}$ on whole-round cores using a needle probe. During the OSP, petrophysical measurements included digital linescan imaging, color reflectance, MSCL $P$-wave velocity, and shear strength on split cores, as well as discrete $P$-wave velocity and MAD on core samples. Discrete $P$-wave velocity and MAD measurements were conducted at an approximate resolution of one per core section from the working halves, which allowed independent determination of bulk density, dry density, grain density, water content, porosity, and void ratio, all of which were used to calibrate the high-resolution, nondestructive measurements collected offshore on wholeround cores with the MSCL. Shear strength data were collected with a fall cone (approximately every section or $1.5 \mathrm{~m}$ ) and a shear vane (every core, where possible) on the working halves.

Physical properties data handling and plotting (see Physical properties in each site chapter) was done using Python (Matplotlib, NumPy, and pandas), Matlab, and Excel.

\section{Offshore physical properties measurements}

Core logging was performed to obtain physical properties using a Geotek MSCL with five sensors for measuring gamma density, $P$ wave velocity, NCR, magnetic susceptibility, and NGR. The physical properties measured by these instruments were used offshore together with geochemistry, sedimentology, and paleontology data for preliminary interpretations of lithology, composition, and paleoenvironment; synthetic seismogram generation; and correlation between the borehole sites.

After arriving on deck, cores equilibrated for at least $6 \mathrm{~h}$ to bring them to a relatively constant temperature and facilitate consistent measurements of physical properties, which are sensitive to temperature.

Physical properties measurements are affected by core quality. Sections of the core that do not fill the core liner and/or have cracks can have anomalous measurements. Prior to measurement, the MSCL operators took note of the core quality and lithology with emphasis on cracks, gaps, voids, incomplete filling of the core liner, and fluid contents. When processing data, data points from lowquality core intervals were removed (although all raw data are archived).

At the start of the expedition, the MSCL sensors were fully calibrated, and calibration checks were performed approximately every $6 \mathrm{~h}$ to check instrument drift for all sensors except the NGR sensor, which was checked biweekly for any drift in the calibration. A full calibration was also performed whenever the system was restarted. Following full calibration, processing parameters were obtained for each instrument; during the expedition, physical properties measured from each core were processed with the parameters generated from the most recent full calibration as described in detail in the following sections.

The core physical properties were measured at predetermined optimal instrument-based spatial and temporal sampling intervals. Gamma density, $P$-wave velocity, NCR, and magnetic susceptibility were measured every $2 \mathrm{~cm}$, and NGR measurements were obtained every $10 \mathrm{~cm}$.

\section{Gamma ray densiometry}

The gamma ray attenuation (GRA) densiometry technique was used to obtain bulk density measurements by passing mediumenergy gamma rays from a ${ }^{137} \mathrm{Cs}$ source with a principal energy of $0.662 \mathrm{MeV}$ through a whole-round core. These medium-energy gamma rays pass through the core and are attenuated mainly by Compton scattering. The degree of scattering and consequent attenuation is a function of the electron density of the material, which is also related to bulk density. Most elements of rock-forming minerals have similar Compton mass attenuation (Blum, 1997). The relationship between electron density and bulk density is given by

$$
\rho_{\mathrm{b}}=\rho_{\mathrm{e}} N_{\mathrm{AV}}(Z / \mathrm{A})
$$

where

$\rho_{\mathrm{b}}=$ bulk density,

$\rho_{\mathrm{e}}=$ electron density,

$N_{\mathrm{AV}}=$ Avogadro number,

$Z=$ atomic number of elements in the material, and

$\mathrm{A}=$ atomic mass of the material.

Further derivation (see Blum, 1997) results in

$$
\rho_{\mathrm{b}}=\ln \left(Y_{\mathrm{t}} / Y_{\mathrm{i}}\right) / \mu d
$$

where

$Y_{\mathrm{t}}=$ transmitted gamma ray energy,

$Y_{\mathrm{i}}=$ incident gamma ray energy $(0.662 \mathrm{MeV})$,

$\mu=$ Compton gamma ray mass attenuation coefficient $(\sim 0.10$

$\mathrm{cm}^{2} / \mathrm{g}$ for medium-energy gamma rays and for most common rock-forming minerals), and

$d=$ sample (scatterer) thickness, which is the core thickness.

The standard sampling interval was set at $2 \mathrm{~cm}$, and count time was set to $10 \mathrm{~s}$. The resolution with this setup is $0.5 \mathrm{~cm}$. Initial full calibration was performed using a standard core liner containing a stepped aluminum calibration piece centered inside the liner, which was filled with distilled water ("wet calibration"). Gamma counts were taken for $60 \mathrm{~s}$ through each of the five aluminum steps of known thicknesses $(6,5,4,3$, and $2 \mathrm{~cm})$. In addition, the gamma count of the liner filled with only distilled water was recorded. All data were handled using the processing parameters from these wet calibrations. Calibration checks were made by logging the distilled water calibration piece approximately every $6 \mathrm{~h}$ during the core logging process.

\section{$\boldsymbol{P}$-wave velocity}

$P$-wave velocity (measured in $\mathrm{m} / \mathrm{s}$ ) is the rate at which compressional waves pass through a medium. Transverse $P$-wave velocity was measured using two $P$-wave transducers (a transmitter and a receiver) aligned perpendicular to the core axis with $P$-waves passing through the core horizontally. A compressional wave pulse centered on a frequency of $230 \mathrm{kHz}$ was transmitted through the core. Signal processing software picks the first arrival of the wave at the receiver. The processing routine also corrects for the thickness of the liner. The $P$-wave transducers also function as displacement transducers, monitoring the small variations of the outside diameter of the liner over which the traveltime was measured. These variations are also used in processing the gamma density and magnetic susceptibility in addition to the velocity data. $P$-wave velocity is affected by the 
quality of the core; incomplete filling of the liner reduces the ability to obtain reliable $P$-wave data.

Standard measurement spacing was set at $2 \mathrm{~cm}$, and measurements were instantaneous. Initial calibration was performed using a core liner filled with distilled water, measured at a known temperature. Calibration checks were made by logging the distilled water calibration piece approximately every $6 \mathrm{~h}$ during the core logging process.

\section{Noncontact electrical resistivity}

NCR is based on conductivity (inversely proportional to resistivity) measurements from the core. A transmitter coil induces a highfrequency magnetic field, which in turn generates electrical currents that are proportional to the core's conductivity. During the resistivity measurements, readings obtained from the core by one set of coils were compared with readings taken in air by a second set of coils. The very small magnetic fields regenerated by these electrical currents were measured by a receiver coil and normalized with the separate set of identical coils operating in air. The spatial resolution of this method was $\sim 2 \mathrm{~cm}$, which was set as the measurement interval. The measurement time was $5 \mathrm{~s}$. Prior to initial measurement of each core, the resistivity sensor was zeroed.

Initial calibration was performed using six standard core liner sections containing water of known but varying salinity. Six standards were made up to $\mathrm{NaCl}$ concentrations of 35, 17.5, 8.75, 3.5, 1.75 , and $0.35 \mathrm{~g} / \mathrm{L}$. Calibration checks were performed approximately every $6 \mathrm{~h}$ by relogging the $8.75 \mathrm{~g} / \mathrm{L}$ saline standard.

\section{Magnetic susceptibility}

Magnetic susceptibility ( $\mathrm{k}$ ) is a dimensionless measure of the degree to which a material can be magnetized by an external magnetic field:

$$
\kappa=M / H,
$$

where $M$ is the magnetization induced in the material and $H$ is the strength of the external field.

Magnetic susceptibility varies in response to the type and concentration of magnetic grains, making it useful for identifying compositional variations. Whole-round core magnetic susceptibility was measured on the MSCL using a Bartington MS2 meter coupled to a MS2C sensor coil. The loop sensor has an internal diameter of $90 \mathrm{~mm}$.

A standard loop was used during the expedition, operating at a frequency of $565 \mathrm{~Hz}$. The MS2 system operates on two fixed sensitivity levels, $\times 0.1$ and $\times 1$, corresponding to $10 \mathrm{~s}$ and $1 \mathrm{~s}$ sampling integration periods, respectively, with the $10 \mathrm{~s}(\times 0.1)$ setting used. Magnetic susceptibility measurements were made at a sampling interval of $2 \mathrm{~cm}$. The sensor automatically zeros and takes a free-air reading at the start and end of each run to account for instrument drift by subtraction of a linear interpolation between readings. Magnetic susceptibility data were recorded as corrected volumespecific units $\left(\times 10^{-5} \mathrm{SI}\right)$. The accuracy of the magnetic susceptibility sensor was checked using a calibration standard made of impregnated resin, and calibration checks were carried out approximately every $6 \mathrm{~h}$ to check the consistency of the sensor.

\section{Natural gamma radiation}

NGR is emitted from rock primarily as a result of the radioactive decay of ${ }^{40} \mathrm{~K}$ and the decay of isotopes in the ${ }^{238} \mathrm{U}$ and ${ }^{232} \mathrm{Th}$ series (primeval emitters). Measurement of natural gamma rays from the recovered core provides an indication of the concentration of these elements. The principle behind NGR is that the primeval emitters are in secular equilibrium (Blum, 1997). The sensor comprises three $\mathrm{NaI}(\mathrm{Tl})$ detectors housed in 6 inch diameter lead shields. Emitted gamma rays hit the $\mathrm{NaI}(\mathrm{Tl})$ crystals, which produces a pulse of light. This pulse of light then strikes the photomultiplier tube, producing a small electrical current to give a voltage pulse, which is related to the energy of the gamma emission. Three detectors are used to increase the recorded signal level because natural rocks and sediment have very low natural radioactivity, so combining data collected with multiple detectors improves the data quality. Natural gamma total counts refer to the integration of all emission counts over the gamma ray energy range between 0 and $3 \mathrm{MeV}$, with a spatial resolution of $10 \mathrm{~cm}$ and a count time of $30 \mathrm{~s}$. A background measurement was acquired when at sea, before logging the first core. This background was subtracted from the natural gamma readings of the cores. No calibration was made on this sensor. Instead, a calibration check was performed weekly by placing a calibration standard of potassium sulfate and making sure that the potassium peak does not deviate by more than $5 \%$.

\section{Quality assurance/Quality control}

During the offshore phase of the expedition, quality assurance (QA)/quality control (QC) was performed by repeating measurements on the best quality section of every 10 cores. QA/QC involved core quality description using the hard copy and electronic MSCL log sheets prepared during the original core logging and processing the repeat measurements with the same processing parameters as the original measurement to check for consistency.

\section{Handheld penetrometer strength measurements}

Sediment strength in the cores was measured using a handheld penetrometer approximately every $20 \mathrm{~m}$. The handheld penetrometer method involves penetrating the core section with a penetrometer graduated from 1 to 10 that consists of a cone and spring of known area and force, respectively, and recording the reading, the value of which corresponds to the penetration resistance. A conversion factor is then applied to convert the readings from the penetrometer to penetration resistance (in $\mathrm{kg} / \mathrm{cm}^{2}$ ). Depending on the material strength, two cones of 0.25 and $0.5 \mathrm{~cm}^{2}$ and three springs of $50 \mathrm{~N}, 100 \mathrm{~N}$, and $150 \mathrm{~N}$ were used.

\section{Onshore physical properties measurements}

Onshore physical properties measurements include data collected before and during the OSP and are described below in the order in which they were performed. Thermal conductivity was measured on whole-round cores prior to the OSP. Line scanning and color reflectance measurements were conducted on split-core sections immediately after splitting to record accurate colors prior to core desiccation and oxidation. Digital images of archive halves were made with a digital imaging system. Discrete color reflectance and $P$-wave measurements of working halves were made with an MSCL. Shear strength measurements were performed on the working half prior to sampling. $P$-wave and MAD measurements were conducted on discrete samples taken from the working-half cores.

\section{Thermal conductivity}

Thermal conductivity was measured with the TeKa TK04 system using the needle-probe method in full-space configuration for soft sediment (Von Herzen and Maxwell, 1959). The needle probe contains a heater wire and a calibrated thermistor, which is assumed 
to be a perfect conductor because it is significantly more conductive than the sediment being measured. Prior to the OSP, cores were measured at $4^{\circ}-6^{\circ} \mathrm{C}$ in the refrigerated core repository at MARUM.

Thermal conductivity of sediment in whole cores was measured by inserting the needle probe into the sediment through a small hole drilled into the core liner parallel to the working-half/archivehalf surface (splitting surface) to ensure minimum disturbance to either core half. Generally, thermal conductivity $(k)$ is calculated from the following:

$$
k(\mathrm{t})=(q / 4 \pi) \times\left\{\left[\ln \left(t_{2}\right)-\ln \left(t_{1}\right)\right] /\left[T\left(t_{2}\right)-T\left(t_{1}\right)\right]\right\},
$$

where

$$
\begin{aligned}
& T=\text { temperature }(\mathrm{K}), \\
& q=\text { heating power }(\mathrm{W} / \mathrm{m}) \text {, and } \\
& t_{1}, t_{2}=\text { time interval (normally } 80 \mathrm{~s} \text { ) along the heating curve }(\mathrm{s}) \text {. }
\end{aligned}
$$

The optimal choice of $t_{1}$ and $t_{2}$ is difficult to determine; commonly, thermal conductivity is calculated from the maximum interval $\left(t_{1}\right.$ and $\left.t_{2}\right)$ along the heating curve where $k(\mathrm{t})$ is constant. In the early stages of heating, the source temperature is affected by the contact resistance between the source and the full space, and in later stages it is affected by the finite length of the heating source (theoretically assumed to be infinite). The special approximation method (SAM) employed by the TK04 software is used to develop a best fit to the heating curve for all of the time intervals, where

$$
\begin{gathered}
20 \leq t_{1} \leq 40, \\
45 \leq t_{2} \leq 80 \text {, and } \\
t_{2}-t_{1}>25 .
\end{gathered}
$$

A good measurement results in a match of several hundred time intervals along the heating curve. The best solution (output thermal conductivity) is that which most closely corresponds to the theoretical curve. Numerous measuring cycles were automatically performed at each sampling location.

Thermal conductivity measurements were taken every $\sim 10 \mathrm{~m}$, preferably from Section 2 . If core quality in Section 2 was not appropriate, the nearest good quality section to it was selected. The quality of thermal conductivity measurements was monitored as measurements were taken. Multiple measurements were taken at the selected depth. Where possible, a minimum of three good quality measurements were chosen to calculate the mean thermal conductivity, and a variance of less than $\pm 1 \%$ was sought.

Data quality was evaluated by the operator. Low-quality measurements resulted from boundary effects and reflections (especially where there was not good contact between the core and the probe [because of cracking]). These measurements were removed prior to calculation of a mean thermal conductivity and standard deviation. Sometimes the SAM employed by the TK04 software could not calculate a best fit to the heating curve because of boundary effects or a lack of contact between needle and sediment, in which case no data are produced.

\section{Formation temperature and heat flow}

Thermal conductivity and measured formation temperature (see Downhole measurements) were used to calculate geothermal gradient and heat flow. The geothermal gradient can be estimated from the slope of a plot of temperature against depth, and the inter- cept of this plot can be taken as the temperature at the seafloor $\left(T_{0}\right.$, where $z=0 \mathrm{~m}$ ).

Heat flow is calculated using the Bullard method (Bullard, 1939), which is useful when thermal conductivity varies over a depth interval where the geothermal gradient is established (e.g., Pribnow et al., 2000). It assumes a linear relationship between the temperature and thermal resistance of the sediment:

$$
T(z)=T_{0}+q \times \Omega(z)
$$

where

$$
\begin{aligned}
& z=\text { depth (mbsf), } \\
& T_{0}=\text { temperature at } z=0, \text { and } \\
& q=\text { heat flow. }
\end{aligned}
$$

Thermal resistance $(\Omega[z])$ is defined as

$$
\Omega(z)=\int_{0}^{z} \frac{d z}{\lambda(z)} \approx \sum_{i=1}^{I} \frac{z_{\mathrm{i}}-z_{\mathrm{i}-1}}{\lambda_{\mathrm{i}}},
$$

where

$z_{\mathrm{i}}=$ bottom depth of the $i$ th horizontal layer,

$z_{\mathrm{i}-1}=$ top depth of the $i$ th horizontal layer,

$\lambda_{\mathrm{i}}=$ thermal conductivity, and

$I=$ number of horizontal layers between the seafloor $(z=0)$ and depth $z$.

A plot of temperature versus thermal resistance (a Bullard plot) allows estimation of (1) surface temperature $\left(T_{0}\right)$ from the intercept with $z=0$ and (2) heat flow from the slope of a line fitted to the data. Data in a Bullard plot form a line when conditions between the seafloor and depth $z$ include (1) conductive cooling, (2) steady state, and (3) no heat source/sink.

If thermal conductivity increases linearly with depth, thermal conductivity is represented as

$$
\lambda(z)=\lambda_{0}+\Gamma \times z
$$

where $\lambda_{0}$ is the estimated surface thermal conductivity and $\Gamma$ is the slope.

When establishing the fitting line, thermal conductivity corrected to in situ pressure and temperature conditions is used, as described above.

Then, thermal resistance is solved as

$$
\Omega_{\mathrm{i}}=\left[\ln \left(\lambda_{0}+\Gamma \times z_{\mathrm{i}}\right)-\ln \left(\lambda_{0}\right)\right] / \Gamma
$$

where $\Omega_{\mathrm{i}}$ is the thermal resistance of the $i$ th horizontal layer.

\section{Digital imaging}

Digital linescan images of the split cores were obtained during the OSP using the Avaatech Superslit XRF core scanner. The XRF scanner has an option for linescan camera and linear light source. The line scanner produces high-resolution color images and also outputs accurate color data in RGB and Commission Internationale d'Eclairage (CIE) L (lightness), a (green to red chromaticity), and b (blue to yellow chromaticity) units ( $\left.\mathrm{L}^{*} \mathrm{a}^{*} \mathrm{~b}^{*}\right)$ using individual CCD pixel calibration. The linescan program uses the Stemmer Common Vision Blox (CVB) platform to acquire and process color images. 
The camera system contains a 3-CCD camera using $3 \times 2048$ pixels with a beam splitter and a manually controlled Pentax $50 \mathrm{~mm}$ lens. The image resolution is $\sim 150 \mathrm{pixel} / \mathrm{cm}(70 \mu \mathrm{m} / \mathrm{cm})$ in the cross-core and downcore directions. With an exposure time of 5 $\mathrm{ms}$, a scan speed of $125 \mathrm{~mm} / \mathrm{s}$ was achieved. Added to this time is the initialization time and camera repositioning after a scan. The image coverage is $\sim 13.5 \mathrm{~cm}$ cross core and a maximum of $153 \mathrm{~cm}$ in the downcore direction.

Every split core was imaged with a color/gray chart beside it, and this scan is available as the original file. Three output files were generated for each core section: a high-resolution bitmap file (BMP), a compressed image file (JPEG), and a numeric text file (TXT). Numeric data are in RGB units. The linescan system was calibrated every $24 \mathrm{~h}$ with black and white calibration. All split cores were measured using aperture setting $f / 9.5$ (a fixed value between 11 and 8). Additional apertures were used when necessary but were always run in addition to the standard aperture used on all cores. Consistency of equipment settings was chosen over custom settings to ensure uniformity of the data set. Software features necessitated the length of linescan images at a couple of centimeters longer than the curated core length. Bitmap picture files were modified to match the length of the cores after the image was taken. Where a whole-round sample had been removed from the core, a foam placer was inserted in its place. The operator verified that the full core section had been imaged during the scan before the data were accepted.

\section{MSCL $\boldsymbol{P}$-wave velocity on split cores}

$P$-wave velocity was measured on split cores on the Geotek splitcore MSCL track at an $8 \mathrm{~cm}$ sampling interval. Acquiring $P$-wave data on split cores is not part of the normal core flow; this step was added in an attempt to obtain $P$-wave information because reliable $P$-wave data could not be acquired offshore with the whole-round MSCL. Every fifth core was measured because there was insufficient time to acquire $P$-wave data on all cores during the OSP. The $P$-wave transducers are located on the same MSCL track as color reflectance, and the plastic-wrapped split core goes through the $P$ wave transducers first. It is necessary to wet the samples to facilitate transmission of the compressional waves, but they must be dry before going through the color reflectance sensor. To address this issue, distilled water was sprayed on the plastic film covering the split surface prior to $P$-wave measurements, and a drying system was installed to dry the surface of the split core before it advanced to the color reflectance sensor. These steps made MSCL operations take longer; hence, the measurement of $P$-wave velocity only every fifth core.

The $P$-wave system has two transducers: a transmitter and a receiver. The transmitter transducer generates an ultrasonic compressional pulse at about $500 \mathrm{kHz}$. The transmitted pulse propagates through the core, is detected by the receiver, and is amplified by the automatic gain control (AGC). Traveltime is automatically detected on the received waveform, where the software picks the first negative excursion of the pulse.

The system automatically corrects the traveltime for delays in transmitting and receiving the signal (resulting from the transducers and electric circuit), delays in the peak detection, and delays due to transit time through the liner.

\section{Diffuse color reflectance spectrophotometry}

During the onshore phase, the working halves of split cores were measured at an $8 \mathrm{~cm}$ sampling interval using a Minolta spectro- photometer (Model CM-2600D) installed on a Geotek split-core MSCL system. White calibration of the spectrophotometer was carried out once per day, and a calibration for zero was performed once per day when starting up the machine. Vertical adjustment of the spectrophotometer and pusher adjustment to the reference point were performed before every run. The split calibration piece (stepped aluminum) for gamma density was used as the reference height of the spectrophotometer. Prior to measurement, the core surface was covered with clear plastic wrap to maintain a clean spectrometer window.

Spectrophotometric analysis produced three types of data:

- $\mathrm{L}^{*}, \mathrm{a}^{*}$, and $\mathrm{b}^{*}$ values, where $\mathrm{L}^{*}$ is a total reflectance index ranging from $0 \%$ to $100 \%$, $\mathrm{a}^{*}$ is green $(<0)$ to red $(>0)$ chromaticity, and $\mathrm{b}^{*}$ is blue $(<0)$ to yellow $(>0)$ chromaticity;

- Munsell color values; and

- Intensity values for 31 contiguous $10 \mathrm{~nm}$ wide bands across the 400-700 nm interval of the visible light spectrum.

Measurement quality is affected by the degree and uniformity of sediment fill in the split liner, by cracks or other core disturbance, and by the smoothness of the clear plastic wrap over the core surface (e.g., no air bubbles). Plastic film covering the samples was dried following the $P$-wave measurement before the spectrophotometry measurement so as to not deteriorate the spectrometer window.

Comments for every section (e.g., cracks, holes, and voids in sediment and quality of the sediment surface) were appended to the spectrophotometer data to allow for better evaluation of data quality. Badly disturbed core sections and core sections shorter than 5 $\mathrm{cm}$ were not measured. Core sections with significantly high fluid content were omitted because of the risk of sensor damage. Color reflectance spectrophotometry data can be used to determine lithology changes and abundance of compounds.

\section{Shear strength}

Undrained shear stress $\left(S_{\mathrm{u}}\right)$ was measured on the working half after core description to avoid any disruption of key intervals identified by the VCD team. Two instruments were used: the fall cone on every section or every $1.5 \mathrm{~m}$ and the shear vane apparatus on every core, preferably on the second section. For both methods, the measurement was taken as close as possible to the center of the core along the $y$-axis.

\section{Fall cone testing}

The fall cone measures the penetration of a standard cone as it free falls a set distance and embeds itself in the sediment. During testing, the cone (pointing downward) is lowered so that it just touches and marks the surface of the split core before it is locked in place with the dial gauge reading noted. The cone is then released and penetrates the surface of the sample. The system is left unlocked for $5 \mathrm{~s}$ to allow the cone to complete its penetration.

During Expedition 381, a single cone with an apex angle of $30^{\circ}$ and a mass of $82.97 \mathrm{~g}$ was used.

Undrained shear strength is determined using an empirical formula determined by Hansbo (1957):

$$
S_{\mathrm{u}}=K \times M \times g / d^{2},
$$

where

$S_{\mathrm{u}}=$ undrained shear strength $(\mathrm{kPa})$,

$K=$ empirical factor related to the cone angle and sediment type, 
$M=$ weight of the cone $(\mathrm{g})$,

$g=$ gravity acceleration $\left(\mathrm{m} / \mathrm{s}^{2}\right)$, and

$d=$ penetration distance of cone $(\mathrm{mm})$.

The $K$ factor is dependent on the apex angle of the cone. A $K$ factor of 0.85 was used based on common $K$ factors in the literature (Wood, 1985; Zreik et al., 1995).

The accuracy of the measurement is very dependent on correctly determining the position of the cone above the split surface of the core. The error induced by the initial location of the cone is at least $0.2 \mathrm{~mm}$. In addition, the analog dial used to read the cone position before and after the release leads to a typical error of $0.05 \mathrm{~mm}$. Hence, the maximum resolution of the measurement of the penetration distance of the cone is estimated to be $0.3 \mathrm{~mm}$. More cohesive and stiff sediment, where cone penetration is less than $2 \mathrm{~mm}$, can result in as much as a $15 \%$ error. In addition, the formula of Hansbo (1957) may be inadequate for silty sediment (present in many Expedition 381 cores).

In this condition, the values recovered are considered to be relative qualitative measurements; they are compensated by the high number of measurements that can be performed because each measurement is very quick and only results in minimal disturbance of the core. In the experiments performed during Expedition 381, the cone leaves a $2 \mathrm{~mm}$ diameter mark at most.

\section{Shear vane testing}

Shear vane testing is a more quantitative way to estimate the undrained shear strength of cohesive sediment. The shear vane apparatus consists of four vanes perpendicular to each other that are inserted in the sediment to their full length while attempting to minimize disturbance to the sediment.

A Wykeham Farrance automated apparatus was used during Expedition 381. A motor loads a helical torsion spring by rotating its upper end, inducing a deflection on its upper end $\left(\theta_{u}\right)$ that is accompanied by the rotation of an inner dial. The bottom of the spring is united to the vane; therefore, the bottom deflection $\left(\theta_{b}\right)$ also records the angular displacement of the sediment. It can be directly read from an outer dial (fixed) as it is set on the frame of the apparatus. Hence, the same pointer coupled to the vane reads (1) the angular displacement $\left(\theta_{\mathrm{b}}\right)$ of the sediment on the fixed outer dial attached to the frame of the apparatus and (2) the actual angular twist on the loading spring $\left(\theta_{\mathrm{u}}-\theta_{\mathrm{b}}\right)$ from the inner dial that rotates with the motor. Because the loading spring is elastic with a stiffness $(B)$, the torque $(T)$ actually applied is calculated as $T=B \times\left(\theta_{\mathrm{u}}-\theta_{\mathrm{b}}\right)$. Four springs of different stiffness are available, and the most compliant ones are more appropriate for softer sediment because they allow a lower loading rate and more resolution for strength determination.

Undrained shear strength is calculated as

$$
S_{\mathrm{u}}=T_{\max } / K,
$$

where

$S_{\mathrm{u}}=$ undrained shear strength $(\mathrm{kPa})$,

$T_{\max }=$ maximum torque measured $(\mathrm{Nm})$, and

$K=$ geometrical factor $\left(\mathrm{m}^{3}\right)$ that depends on the diameter $(D)$ and height $(H)$ of the vane:

$$
K=\pi \times D^{2} \times H / 2+\pi \times D^{3} / 6,
$$

where $D$ is the diameter of the vane $(\mathrm{m})$ and $H$ is the height of the vane $(\mathrm{m})$. The vane used for Expedition 381 was $12.7 \mathrm{~mm}$ in height and width.
A number of assumptions are made in calculating the shear strength:

- The sediment is not disturbed during the insertion of the vane.

- Isotropic strength conditions exist in the sediment.

- The remolded zone around the vane is very small.

- There is no progressive failure so that the maximum applied torque overcomes the shear strength along the cylindrical surface.

During the insertion, the blades were oriented along the $y$-and $z$-axes of the split surface. Whenever possible, a video recording of the dials was made to allow later recovery of the time history of deformation and torque and a picture of the final state of the core was taken to characterize the zone tested and the type of mechanical failure.

If the failure of the sediment is accommodated by a circular crack, the vane is turned on a full rotation and the remolded strength is recorded. Because this measurement takes much longer (10 to $>45$ min depending on the sediment) than the cone fall test, the shear vane test was performed only once on every core.

\section{$\boldsymbol{P}$-wave velocity from discrete samples}

$P$-wave velocity was derived from the traveltime of seismic waves passing through a sample of known thickness. $P$-wave velocity varies with the lithology, porosity, and bulk density of the material; the state of stress, such as lithostatic pressure; and the fabric or degree of fracturing. In marine sediment and rocks, $P$-wave velocity values are also controlled by the degree of consolidation and lithification, by fracturing, and by the occurrence and abundance of free gas and gas hydrates. $P$-wave velocity is used together with density measurements to calculate acoustic impedance or reflection coefficients. Velocity measurements can also be used to estimate the depth of reflectors observed in seismic profiles and to construct synthetic seismograms.

Discrete samples were taken from the working halves of split cores at an average of one per section (approximately every $1.5 \mathrm{~m}$ ) in semiconsolidated or consolidated sediment and adjacent to the MAD samples. Relatively shallow sections or other unconsolidated samples were typically not measured because of the lack of the requisite consolidation and tendency to crumble or squash when placed between the transducers.

Measurements were performed with a Geotek $P$-wave logger for discrete samples (PWL-D), which consists of a mechanical section containing the transducers (between which the sample to be measured is placed), an electronic panel, and a laptop. Acoustic coupling is through solid neoprene surfaces (pads on the transducers) and is improved by applying downward pressure on the sample between transducers and by wetting the neoprene with distilled water. A laser distance transducer measures the thickness of the sample. The PWL-D system can measure velocity on cubic or cylindrical, consolidated, semiconsolidated, or lithified core specimens.

The basic velocity $(v)$ equation is

$$
v=d / t
$$

where $d$ is the distance traveled through the material $(\mathrm{m})$ and $t$ is traveltime (s).

The PWL-D was calibrated using a standard of known length and $P$-wave velocity provided by Geotek. At the start of each set of samples measured, a calibration check was performed using the same standard. 
Traveltimes are corrected for delays related to the latency of transducers and electronics $\left(t_{\text {delay }}\right)$ and to the peak detection procedure $\left(t_{\text {pulse }}\right)$. Delays were determined during calibration with zero distance. For routine measurements on discrete samples with the PWL-D system, the equation for the velocity is

$$
v_{\text {sample }}=\left(10,000 \times d_{\text {sample }}\right) /(\text { TOT }-\mathrm{PTO}) \text {, }
$$

where

$v_{\text {sample }}=$ velocity through the sample $(\mathrm{m} / \mathrm{s})$,

$d_{\text {sample }}=$ measured thickness of the sample $(\mathrm{mm})$,

TOT $=$ measured total traveltime $(\mu \mathrm{s})$, and

$\mathrm{PTO}=$ delay correction $(\mu \mathrm{s})$.

A pulse is sent to the transmitter sensor, which generates an ultrasonic compressional pulse at $\sim 230 \mathrm{kHz}$ that propagates through the sample and is received by the receiver sensor. The received signal is processed through an analog-to-digital converter before appearing in the software display. The signal is digitized at a sampling frequency of $12.5 \mathrm{MHz}$.

In the software, a threshold detector determines the first positive or negative excursion on the received pulse and can be adjusted by the operator. The traveltime is determined by measuring the time to the first zero crossing after the threshold has been exceeded. In this way, the traveltime measured is approximately one-half of the wavelength after the start of the pulse but is measured without any errors caused by signal amplitude. A delay can be used to define the point at which the software should start its threshold detection. The delay should be set before the arrival of the signal.

Sample quality strongly affects the ability to acquire $P$-wave velocity data. It was important during Expedition 381 to prepare the sample correctly to get good contact between the transducers. Sample strategy varied throughout the OSP. Where possible, a $\sim 6 \mathrm{~cm}^{3}$ plug sample was extracted from the core with a truncated plastic syringe. Samples were extracted from the syringe for measurement. As sediment stiffness increased with depth, wedge samples were extracted with a spatula; sampling stopped where sediment was too brittle. With the $6 \mathrm{~cm}^{3}$ plugs, preparation consisted of cutting the uneven end of the sample to ensure there were two flat, parallel surfaces to aid good acoustic coupling with the transducers, wetting the pads of the transducers, and applying downward pressure. Plug sediment tended to either squash or crack, and wedge samples tended to crack under the pressure applied by the transducers. Samples were first measured along the $x$-axis of the core; if no signal was detected, samples were rotated along the $y$ - or $z$-axis. Where a waveform could be detected by the software, $P$-wave measurements were performed three times.

$P$-wave velocity is also sensitive to temperature (Leroy, 1969) and increases with increasing temperature. Temperature was recorded during every measurement and was found to be uniform, so no temperature corrections were applied. The data files are in comma-separated value (CSV) format, containing a header with the core and sample identifier followed by measured data and calculated velocity. The waveform is recorded in two columns containing the time base and voltage changes.

\section{Moisture and density}

MAD properties (bulk density, dry density, grain density, water content, porosity, and void ratio) were derived from measurements of the wet and dry masses of core samples and their dry volumes. Discrete samples $\left(\sim 6 \mathrm{~cm}^{3}\right.$ plugs) were acquired at an approximate resolution of one per core section (approximately every $1.5 \mathrm{~m}$ ) from the working halves of split cores adjacent to the $P$-wave samples.

Where possible, samples were extracted from the working half with a truncated plastic syringe. Where sediment was too stiff and brittle, samples were extracted with a spatula. These wet samples were transferred into previously weighed $10 \mathrm{~mL}$ glass beakers, and the wet mass $\left(M_{\text {wet }}\right)$ was determined to a precision of $0.001 \mathrm{~g}$ using an electronic scale. Samples were then dried in a convection oven at $60^{\circ} \pm 5^{\circ} \mathrm{C}$ for a period of $24 \mathrm{~h}$ followed by cooling to room temperature in a desiccator for at least $1 \mathrm{~h}$. Dry sediment was successively weighed to determine dry mass $\left(M_{\mathrm{dry}}\right)$. The volume of dried sample was immediately analyzed using a Quantachrome pentapycnometer (helium-displacement pycnometer) with a precision of $0.02 \mathrm{~cm}^{3}$. This equipment allowed the simultaneous analysis of four samples and one standard (calibration spheres). Volume measurements were repeated three times for each cell, insuring a $<0.02 \%$ standard deviation, with a purge (cleaning of the cell from air and moisture) time of $1 \mathrm{~min}$. Volume measurements were averaged per sample $\left(V_{\mathrm{dry}}\right)$. Calibration spheres were successively cycled between different pycnometer cells for each run to check for accuracy, instrument drift, and systematic error.

The mass of the evaporated water $\left(M_{\text {water }}\right)$ is given by

$$
M_{\text {water }}=M_{\text {wet }}-M_{\text {dry }} \text {. }
$$

The volume of pore water $\left(V_{\mathrm{pw}}\right)$ is given by

$$
V_{\mathrm{pw}}=M_{\mathrm{pw}} / \rho_{\mathrm{w}}
$$

where $M_{\mathrm{pw}}$ is the mass of the pore water and $\rho_{\mathrm{w}}$ is the pore water density $\left(1.024 \mathrm{~g} / \mathrm{cm}^{3}\right)$.

Salt precipitated in sample pores during the drying process is included in $M_{\mathrm{dry}}$ and $V_{\mathrm{dry}}$ values, resulting in the following approximations:

- The mass of pore water $\left(M_{\mathrm{pw}}\right)$ is given by the mass of the evaporated water $\left(M_{\text {water }}=M_{\mathrm{pw}}\right)$

- The mass of solids, including salt $\left(M_{\text {solid }}\right)$, is given by the dried mass of the sample $\left(M_{\mathrm{dry}}=M_{\text {solid }}\right)$.

- The volume of solids, including salt $\left(V_{\text {solid }}\right)$, is given by the measured dry volume from the pycnometer $\left(V_{\mathrm{dry}}=V_{\text {solid }}\right)$.

The mass of the evaporated water $\left(V_{\text {wet }}\right)$ is given by

$$
V_{\text {wet }}=V_{\text {solid }}+V_{\text {pw }}
$$

For all sediment samples, water content $(w)$ is expressed as the ratio of the mass of pore water to the wet sediment (total) mass:

$$
w=M_{\mathrm{pw}} / M_{\text {wet }}
$$

Wet bulk density $(w)$, dry bulk density $(d)$, sediment grain density $(g)$, and porosity $(\phi)$ are calculated from the previous equations (density is given in $\mathrm{g} / \mathrm{cm}^{3}$ ):

$$
\begin{gathered}
w=M_{\text {wet }} / V_{\text {wet }}, \\
d=M_{\text {solid }} / V_{\text {wet}}, \\
g=M_{\text {solid }} / V_{\text {solid }} \text {, and } \\
\phi=V_{\text {pw }} / V_{\text {wet }} .
\end{gathered}
$$


Expedition 381 samples were selected from intervals that appeared undisturbed. However, it was not possible to ensure that all were completely uncontaminated by fluid introduced during the core collection, splitting, and sampling process.

\section{Paleomagnetism}

The main objectives of the OSP paleomagnetic work were to (1) establish a magnetic susceptibility profile for each site based on discrete samples of known volume and mass; (2) establish, if possible, relative paleointensity profiles that could be compared with global master curves (e.g., Channell et al., 2002, 2008, 2009, 2014, 2016; Valet and Meynadier, 1993; Valet et al., 2005) for absolute dating of the core; and (3) reconstruct the downhole variation of magnetic polarity and build magnetostratigraphic logs to compare with the reference geomagnetic instability timescale (GITS) of Singer (2014) and provide absolute dating of the core in combination with biostratigraphic data.

\section{Fundamental magnetic properties, magnetic susceptibility, and natural remanent magnetization}

Depending on their composition, materials can display three fundamental magnetic responses to the application of an external magnetic field. The weakest response, which is inherent to all materials, consists of the development of a nonpermanent, induced magnetization that is parallel but opposite in direction to that of the applied field. This property is known as diamagnetism and is the response typically exhibited by water, organic compounds, most plastics, and some minerals, such as quartz and calcite. A stronger, nonpermanent, induced magnetization that is parallel to and in the same direction as the applied field (known as paramagnetism) is exhibited by minerals that are paramagnetic, such as iron oxides (e.g., lepidocrocite), iron sulfides (e.g., pyrite and marcasite), ferromagnesian minerals (e.g., biotite and pyroxene), iron carbonates (e.g., siderite), and most clay minerals found in claystone and mudstone. Another example of paramagnetic material is the hydrated iron phosphate mineral vivianite, which is commonly found as an authigenic phase in organic-rich, freshwater lake sediment. Induced magnetization in paramagnetic materials disappears as soon as the applied field is removed. Finally, some materials may develop a strong, permanent magnetization that is parallel to and in the same direction as the applied magnetic field and is preserved when the applied field is removed. This property is known as ferromagnetism and can be observed in ferromagnetic materials, such as pure iron. Similar ionic ordering gives rise to ferrimagnetism and antiferromagnetism, which are important in paleomagnetism because of the capability of ferromagnets and ferrimagnetic and canted antiferromagnets to retain a memory of the magnetic field they were once exposed to. This memory is called magnetic remanence. Common natural minerals that behave as ferrimagnets at temperatures and pressures normally experienced close to the Earth's surface include magnetite, titanomagnetite, maghemite, hematite, monoclinic pyrrhotite, and greigite.

Magnetic susceptibility is a parameter that defines how easily a material can be magnetized. It is routinely measured at room temperature and pressure. Temperature-dependent measurements of magnetic susceptibility detect changes in crystallographic structure that cause magnetic transitions and can be diagnostic of specific minerals (e.g., the Verwey transition in magnetite). Volume-normalized magnetic susceptibility $(k)$ is a dimensionless parameter given by the ratio of the intensity of magnetization $(M)$ induced in a sample by an externally applied field $(H)$ to the intensity of that field (i.e., $k=M / H$ ). Magnetic susceptibility is expressed in SI units and can span many orders of magnitude from positive (in paramagnetic and ferromagnetic materials) to negative (in diamagnetic materials) values. Magnetic susceptibility may also be expressed per unit mass $(\mathrm{x})$, and the SI units are cubic meters per kilogram $\left(\mathrm{m}^{3} / \mathrm{kg}\right)$.

Ferrimagnetic minerals have magnetic susceptibility values that are many orders of magnitude higher than those of paramagnetic and diamagnetic minerals. Thus, even if the concentration of naturally occurring ferrimagnetic minerals is typically less than $1 \%$ in sedimentary rocks, they can dominate the magnetic susceptibility signal and yield a strong permanent magnetization known as natural remanent magnetization (NRM).

In natural sediment, NRM is commonly acquired in two fundamental ways. One way is through the acquisition of a (post)depositional remanent magnetization (PDRM). PDRMs require that when mineral grains fall out of a calm fluid suspension, the Earth's ambient magnetic field exerts a torque on them, and they align along the direction of the field. The grains are subsequently buried together with nonmagnetic grains and are locked into position close to or just below the sediment/water interface and at a depth that can be dependent on the degree of consolidation and intensity of bioturbation. PDRMs are frequently carried by primary ferrimagnetic and antiferromagnetic iron oxides that originate from the erosion of magmatic and metamorphic rocks. This process is the primary magnetization mechanism expected for the Corinth rift sediments. A second way of acquiring a permanent magnetization is through the formation of secondary authigenic and diagenetic magnetic minerals that are capable of recording the geomagnetic field intensity and direction at the time of their formation. These minerals progressively grow to a critical volume beyond which a permanent magnetization is locked. This volume threshold is mineral specific but is often exceeded in the submicrometer grain size window. Given the high variability of sedimentary environments in the Gulf of Corinth (e.g., marine to nonmarine) and the possible change in oxidizing conditions at the sediment/water interface, some of these secondary magnetic minerals, such as iron sulfides, may be present in this sedimentary record.

Magnetic minerals in sedimentary rocks may come from the erosion of magmatic rocks, which typically contain magnetite. However, primary productivity and the subsequent degradation of organic matter can cause the reductive dissolution of iron oxides and the diagenesis/authigenesis of iron sulfides. These processes can either decrease or increase magnetic mineral concentration. For example, Sohlenius (1996) showed that authigenic greigite formed through the downward diffusion of sulfide from relatively organic rich sediment. Reinholdsson et al. (2013) subsequently discovered that laminated sapropels were magnetically enhanced because of the presence of magnetosomal greigite, which are single-domain grains produced by magnetotactic bacteria in the water column, just under the anoxic-oxic transition zone.

\section{Paleomagnetic sampling and measurements}

During the OSP in Bremen, standard paleomagnetic and magnetic susceptibility measurements were performed on discrete samples from working-half sections. Discrete samples were collected using plastic cubic boxes (external dimensions of $2 \mathrm{~cm} \times 2 \mathrm{~cm} \times 2$ $\mathrm{cm}$ and an internal volume of $6.86 \mathrm{~cm}^{3}$ ) pushed into the unconsolidated sediment. Orientation of the cubic samples is shown in Figure F12. In the lower part of Hole M0080A, where sediment is partially 
Figure F12. Position and orientation of cubic discrete samples collected from core working halves for paleomagnetic analysis during OSP, Expedition 381.

A

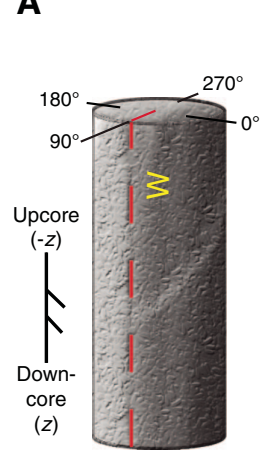

B

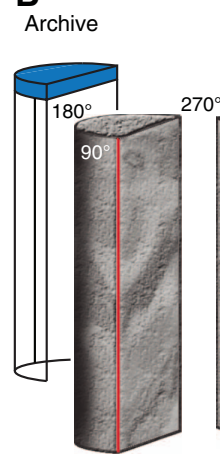

C

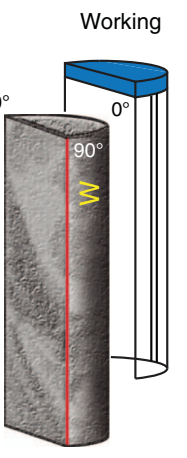

Paleomagnetic sample

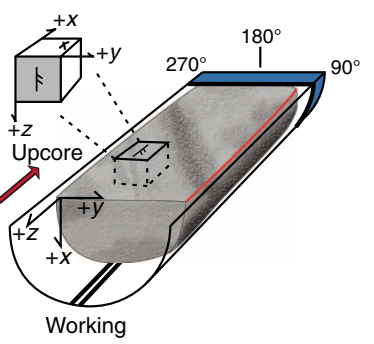

Line with two ticks is upcore $(-z)$

Otherwise ensure $\mathrm{y}$ arrow points to $090^{\circ}$ and $\mathrm{x}$ arrow toward $0^{\circ}$ lithified, standard $24 \mathrm{~mm}$ diameter cylindrical samples were drilled perpendicular to the section half surface and subsequently trimmed to obtain $22 \mathrm{~mm}$ long standard paleomagnetic specimens. In general, one sample per $1.5 \mathrm{~m}$ core section was measured; no samples were collected from core sections shorter than $40 \mathrm{~cm}$. This sampling strategy was applied to the core from all four holes (M0078A, M0078B, M0079A, and M0080A).

\section{Magnetic susceptibility and wet weight measurements}

Magnetic susceptibility of cubic samples was measured using a KLY 2 (AGICO) Kappabridge that operates at a frequency of $920 \mathrm{~Hz}$ and a magnetic induction of $0.4 \mathrm{mT}$ (equivalent to a field intensity of $300 \mathrm{~A} / \mathrm{m}$ ) with a noise level of $2 \times 10^{-10} \mathrm{~m}^{3} / \mathrm{kg}$. The Kappabridge was periodically calibrated using a standard with a known bulk susceptibility of $1165 \times 10^{-6}$ SI. The wet weight of the samples was established with a DISPE TP-200 electronic balance with a precision of 1 $\times 10^{-5} \mathrm{~kg}$. The weight and magnetic susceptibility of the empty plastic cubes were measured at the beginning of operations and were then subtracted from the obtained weight and susceptibility values of each sample.

\section{Thermomagnetic experiments (Curie temperature determinations)}

Continuous and partial thermomagnetic cycles of low-field magnetic susceptibility versus temperature dependence and $k-T$ curves were determined on 19 samples recovered during the offshore phase. The experiments were performed at the petrofabrics and paleomagnetics laboratory of the Hawaii Institute of Geophysics and Planetology-School of Ocean and Earth Science and Technology (HIGP-SOEST) at the University of Hawaii (USA) prior to the OSP. A CS4 furnace coupled to an MFK1-FA multifunction Kappabridge operating at a low field of $200 \mathrm{~A} / \mathrm{m}$ and frequency of $976 \mathrm{~Hz}$ was used. Susceptibility was measured from room temperature to a maximum of $700^{\circ} \mathrm{C}$ with a heating and cooling rate of $9^{\circ} \mathrm{C} / \mathrm{min}$ and in air.

\section{NRM measurements and alternating field demagnetization}

NRM direction and intensity of discrete samples were measured using the 2G-Enterprises horizontal pass-through superconducting rock magnetometer (SRM 755-4000) at the University of Bremen.
Samples collected during the OSP were measured in batches of eight or less using the automatized pass-through conveyor.

After NRM was measured, samples were sequentially demagnetized by 13 increasing alternating field (AF) steps: 5, 10, 15, 20, 25, $30,40,50,60,70,80,90$, and $100 \mathrm{mT}$. Magnetic remanence was measured between each demagnetizing step. Orthogonal plots and visualization of the demagnetization spectra were produced and analyzed using the PuffinPlot software (Lurcock and Wilson, 2012). Because the azimuthal orientations of core samples are not constrained, the calculated magnetic directions are reported relative to the core coordinate system (Figure F12) but still expressed as declination and inclination.

\section{Magnetostratigraphy}

Sites M0078-M0080 are located at an average latitude of $38^{\circ} 8.45 \mathrm{~N}$; hence, reversals of Earth's magnetic field can be easily identified by distinct changes in inclination of the remanence vectors. Assuming a geocentric axial dipole geometry, the expected inclination of the magnetic field at the three sites is $57.5^{\circ}$. Given the expected young age of the sediment and a lack of major latitudinal motion of the European plate in the last $\sim 2 \mathrm{My}$, we assume a constant inclination of $57.5^{\circ}$ throughout the recovered sedimentary sequences. A magnetostratigraphy (log showing the downcore variation of magnetic polarity [positive = normal polarity; negative $=$ reversed polarity]) was produced for each hole based on the remanence directions computed from the OSP data and compared with the GITS (Singer, 2014) with the aid of biostratigraphic datums (where available) to provide absolute dating of specific intervals. Magnetic polarity interval (i.e., chron) terminology is from Cande and Kent (1995).

\section{Downhole measurements}

Downhole logs are used to determine physical, chemical, and structural properties of the formation penetrated by a borehole. The data can be continuous with depth and are measured in situ; they can be interpreted in terms of the stratigraphy, lithology, mineralogy, and physical properties of the penetrated formation. Where core recovery is incomplete or disturbed, log data may provide the only way to characterize the borehole.

Downhole logs measure formation properties on a scale that is intermediate between those obtained from laboratory measurements on core samples and those from geophysical surveys. The 
logs are useful in calibrating the interpretation of geophysical survey data (e.g., through the generation of synthetic seismograms) and provide an understanding of physical and chemical properties on different scales.

In addition to downhole logging, downhole temperature CPTs were conducted during Expedition 381 to measure in situ formation strength and temperature.

\section{Downhole temperature cone penetration tests}

Downhole temperature CPTs (Figure F13) were performed every $\sim 100 \mathrm{~m}$ in each hole if sediment properties allowed (typically to $\sim 300-400$ mbsf). The maximum depth selected for temperature CPT measurement in each hole was based on the assessment of formation stiffness by handheld penetrometer measurements of cores and drilling parameters and on the results of preceding, shallower temperature CPT measurements in that hole. Data were collected with a Fugro WEP system temperature probe. The maximum ratings for this probe are $0-100 \mathrm{kN}$ for penetration tests and $-10^{\circ}$ to $64^{\circ} \mathrm{C}$ for temperature. The probe was calibrated in the range of $0-50$ $\mathrm{kN}$ and $0^{\circ}-30^{\circ} \mathrm{C}$ for Expedition 381 measurements. Calibrations in these ranges gave uncertainties of $0.0003 \times$ applied force $+0.015 \mathrm{kN}$ and $0.10^{\circ} \mathrm{C}$.

The WEP system temperature probe consists of a cone penetrometer tool and a temperature sensor located in the cone (Figure F13). The probe was sent downhole through the drill string and pushed into sediment at the bottom of the hole by the drilling fluid, using the pump to measure penetration resistance. The target penetration depth was $0.5 \mathrm{~m}$, although actual penetration varied between measurements (from 0.15 to $1.41 \mathrm{~m}$ ). Once the probe penetrated the sediment, temperature was measured until equilibrium was reached (4-30 min). Data acquisition was monitored in real time. Data were sent onshore to Fugro for full processing, which yielded results on in situ temperature $\left({ }^{\circ} \mathrm{C}\right)$, cone resistance $\left(q_{\mathrm{c}}\right)$ $(\mathrm{MPa})$, and sleeve friction $\left(f_{\mathrm{s}}\right)(\mathrm{MPa})$.

Cone resistance from the temperature CPT data can be used to calculate the formation strength $\left(S_{\mathrm{u}}\right)$ (Briaud, 2013) for comparison with results obtained from the handheld penetrometer, fall cone, and shear vane measurements on cores (see Physical properties):

$$
S_{\mathrm{u}}=q_{\mathrm{c}}-\sigma_{\mathrm{vo}} / N_{\mathrm{k}}
$$

where

$$
\begin{aligned}
& q_{\mathrm{c}}=\text { cone resistance }, \\
& \sigma_{\mathrm{vo}}=\text { overburden stress, and } \\
& N_{\mathrm{k}}=\text { cone factor. }
\end{aligned}
$$

The temperature CPT data were combined with the thermal conductivity measurements (see Physical properties) obtained from whole-core samples to obtain heat flow values. Heat flow was calculated according to the Bullard method (Bullard, 1939) to be consistent with the synthesis of heat flow data by Pribnow et al. (2000) (see Formation temperature and heat flow).

\section{Downhole logging}

The set and type of logging tools were selected based on the scientific objectives for the expedition and the physical limitations imposed by the drilling system. Super-slimline tools were contracted from the University of Montpellier (France), part of the EPC. Although stackable slimline tools were available at the beginning of the project, the loss of a tool string in Hole M0078A reduced tool
Figure F13. Fugro probe for temperature CPT, Expedition 381.

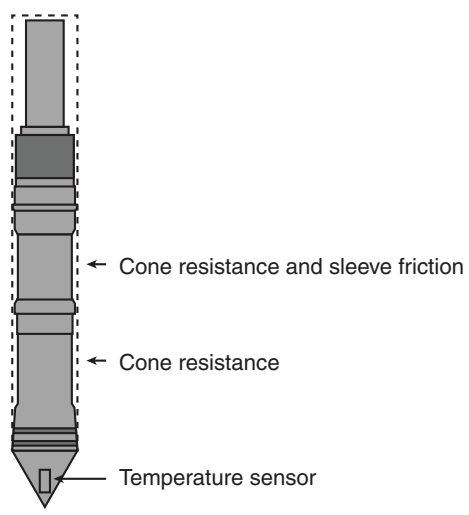

selection, and only standalone tools were used at subsequent sites. The data collected in other holes are not continuous because of difficulties encountered when sending the tools downhole. Because of the total depths of the holes and the nature of the sediment, a staged approach to logging was adopted to limit time in the open hole and maximize chances for acquiring logging data throughout the hole. The stages were determined by assessing the drilling data, physical properties collected on cores, and core descriptions. The bit depth was never set shallower than 50 mbsf to ensure a suitable and stable conduit for tool deployment. During downhole logging, spectral gamma ray data were acquired through pipe and in the open hole where possible. Other tools were deployed in the open hole (when borehole conditions allowed) to characterize the formation, including magnetic susceptibility, conductivity and/or resistivity, and compressional velocity tools (Figure F14). Logging data are provided on the WSF depth scale.

\section{Logging procedure}

After coring operations were completed, a slug of mixed bentonite and barite was pumped downhole, after which the hole was displaced with lighter bentonite drilling mud (8.8-9 lb/gal). Before logging in the open hole, the borehole was reamed for each logging stage: every pipe removed was moved up, down, and up while rotating the drill string. Typically, the logging setup (logging winches [Geovista GV550 and Robertson RG2000] and super-slimline tools) allows for a maximum speed for tool deployment (descent) of 25-30 $\mathrm{m} / \mathrm{min}$ in seawater. However, the combination of the borehole mud properties and the lightweight tools meant that descent speeds had to be reduced to $\sim 10 \mathrm{~m} / \mathrm{min}$. In addition, a $15 \mathrm{~kg}, 147 \mathrm{~cm}$ long sinker bar was added to the tools for effective downward progression of the tools on deployment. On reaching the target depth (or a shallower depth in the case of a borehole obstruction), the tools were pulled up at a constant speed for data acquisition, ranging from 2 to $30 \mathrm{~m} / \mathrm{min}$ depending on the tool.

Data acquired during the expedition were all collected with standalone logging tools following the loss of a set of stackable tools at Site M0078. Each tool deployment is termed a logging "run." A logging run commenced with zeroing the tool to a reference point (zero logger) that corresponded to the top of the drill pipe located in the rooster box. The height of this reference point changed at each stage (Figure F15). Once the tool descended into the hole, the heave compensation system of the ship limited vertical movement of the rooster box and logging sheave to less than $10 \mathrm{~cm}$. Each new uphole or downhole data acquisition during a run is called a "pass." Each logging pass was recorded and stored digitally. 
Figure F14. Logged intervals, Holes M0079A and M0080A.
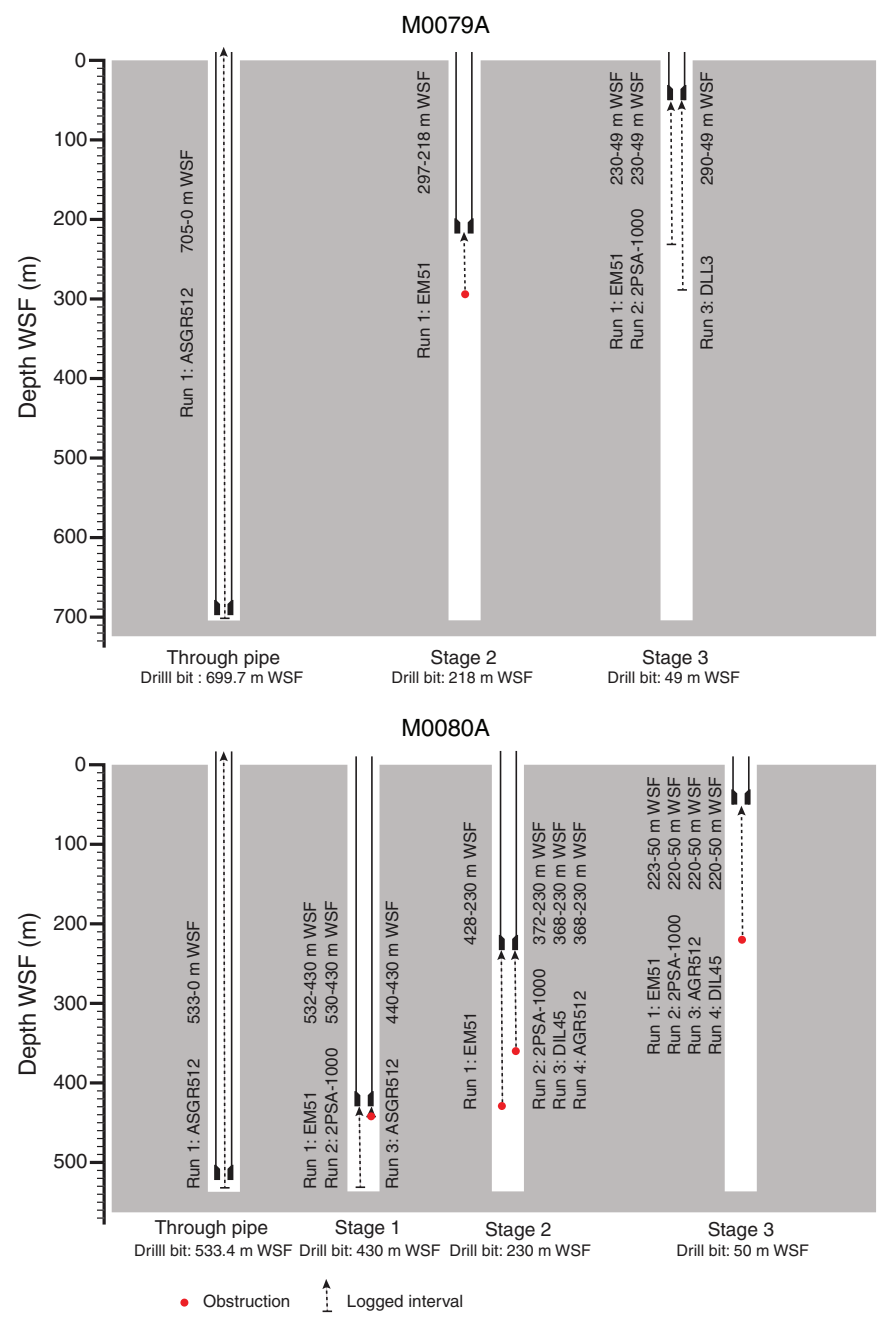

Figure F15. Depth setup during downhole logging operations, Holes M0079A and M0080A. TP $=$ through pipe.

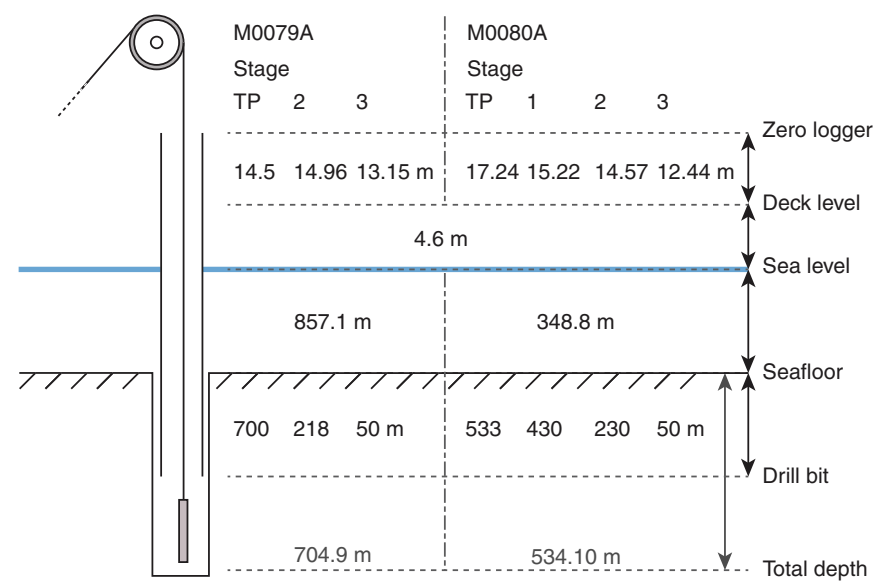

\section{Data monitoring and processing}

During logging, data flow was monitored in real time for both QC and security (e.g., to inform the drilling team of tool location in the hole/pipe) using the Advanced Logging Technology (ALT) and Geovista acquisition boxes and ALT Logger and Geovista software,
Table T3. Downhole tool-specific vertical shifts, Expedition 381. TP $=$ through pipe. ASGR512 = spectral gamma ray, EM51 = magnetic susceptibility and conductivity, 2PSA-1000 = sonic, DLL3 = dual laterolog resistivity, DIL45 = dual induction. Download table in CSV format.

\begin{tabular}{|c|c|c|c|c|c|c|c|}
\hline $\begin{array}{l}\text { Logging } \\
\text { interval }\end{array}$ & Stage & Run & Tool & $\begin{array}{l}\text { Zero logger } \\
\text { to sea level } \\
(\mathrm{m})\end{array}$ & $\begin{array}{l}\text { Sea level } \\
\text { to seafloor } \\
(\mathrm{m})\end{array}$ & $\begin{array}{l}\text { Zero } \\
\text { tool in } \\
(\mathrm{m})\end{array}$ & $\begin{array}{c}\text { Zero } \\
\text { tool out } \\
\text { (m) }\end{array}$ \\
\hline \multicolumn{8}{|c|}{ Hole M0079A } \\
\hline TP & TP & 1 & ASGR512 & 19.1 & 857.1 & 1.24 & -9.47 \\
\hline Upper2 & 2 & 1 & EM51 & 19.56 & 857.1 & 1.9 & 0.4 \\
\hline Upper1 & 3 & 1 & EM51 & 17.75 & 857.1 & 1.9 & 1.18 \\
\hline Upper1 & 3 & 2 & 2PSA- 1000 & 17.75 & 857.1 & 3.4 & 3.3 \\
\hline Upper1 & 3 & 3 & DLL3 & 17.75 & 857.1 & 2.4 & 1.33 \\
\hline \multicolumn{8}{|c|}{ Hole M0080A } \\
\hline TP & TP & 1 & ASGR512 & 21.84 & 348.8 & 1.24 & 4.03 \\
\hline Lower & 1 & 1 & EM51 & 19.82 & 348.8 & 1.9 & 1.32 \\
\hline Lower & 1 & 2 & 2PSA-1000 & 19.82 & 348.8 & 3.4 & 3.64 \\
\hline Lower & 1 & 3 & ASGR512 & 19.82 & 348.8 & 1.24 & 1.01 \\
\hline Middle & 2 & 1 & EM51 & 19.17 & 348.8 & 1.9 & 1.42 \\
\hline Middle & 2 & 2 & 2PSA- 1000 & 19.17 & 348.8 & 3.4 & 3.51 \\
\hline Middle & 2 & 3 & DIL45 & 19.17 & 348.8 & 2.27 & 1.97 \\
\hline Middle & 2 & 4 & ASGR512 & 19.17 & 348.8 & 1.24 & 0.71 \\
\hline Upper & 3 & 1 & EM51 & 17.04 & 348.8 & 1.9 & 1.57 \\
\hline Upper & 3 & 2 & 2PSA-1000 & 17.04 & 348.8 & 3.4 & 3.27 \\
\hline Upper & 3 & 3 & ASGR512 & 17.04 & 348.8 & 1.24 & 0.99 \\
\hline Upper & 3 & 4 & DIL45 & 17.04 & 348.8 & 2.27 & 2.24 \\
\hline
\end{tabular}

depending on the tool and winch used. After logging was completed, the data were processed with WellCad (v5.2) software, and the depth scale of each run was shifted such that all logs are referenced in the WSF depth scale. Depth corrections (Table T3) include the following:

- Zero logger (pipe entrance in the rooster box) to zero driller (rig floor) offset,

- Rig floor to seafloor,

- Offset between the initial and final zero of the tool, and

- Depth matching to distinctive features, where appropriate, including gamma ray logs crossing the seafloor or tools passing from the open hole into the pipe.

\section{Logging tool description and acquisition parameters}

Schematics of the tool strings used during Expedition 381 are shown in Figure F16. Additional information can be found on the manufacturers' websites (http://www.alt.lu, http://www.antaresgeo.de, http://www.mountsopris.com, and http://www.geovista.co.uk). Detailed information on their geological applications can also be found in Schlumberger (1989) and Serra (1984, 1986). For Holes M0079A and M0080A, each tool was deployed with a 15 $\mathrm{kg}$ sinker bar placed above the tool to facilitate its descent.

Spectral natural gamma ray probe (ASGR512)

The naturally occurring radioactive elements $\mathrm{K}, \mathrm{U}$, and Th emit gamma rays with characteristic energies that can be identified by the ASGR512 (ANTARES Datensysteme GmbH; spectral gamma ray) tool. These data are thus sensitive to variations in lithology, including composition. $\mathrm{K}$ decays into two stable isotopes ( $\mathrm{Ar}$ and $\mathrm{Ca}$ ), and a characteristic energy of $1.46 \mathrm{MeV}$ is released. $\mathrm{U}$ and Th decay into unstable daughter elements that produce characteristic energy at 1.76 and $2.62 \mathrm{MeV}$, respectively. The most prominent gamma rays in the $U$ series originate from the decay of ${ }^{214} \mathrm{Bi}$, and those in the Th series originate from the decay of ${ }^{208} \mathrm{Tl}$. It is thus possible to compute the quantity (concentration) of parent ${ }^{238} \mathrm{U}$ and ${ }^{232} \mathrm{Th}$ in the decay series by counting gamma rays from ${ }^{214} \mathrm{Bi}$ and ${ }^{208} \mathrm{Tl}$, respectively. 
Figure F16. Standalone slimline logging tools, Expedition 381.

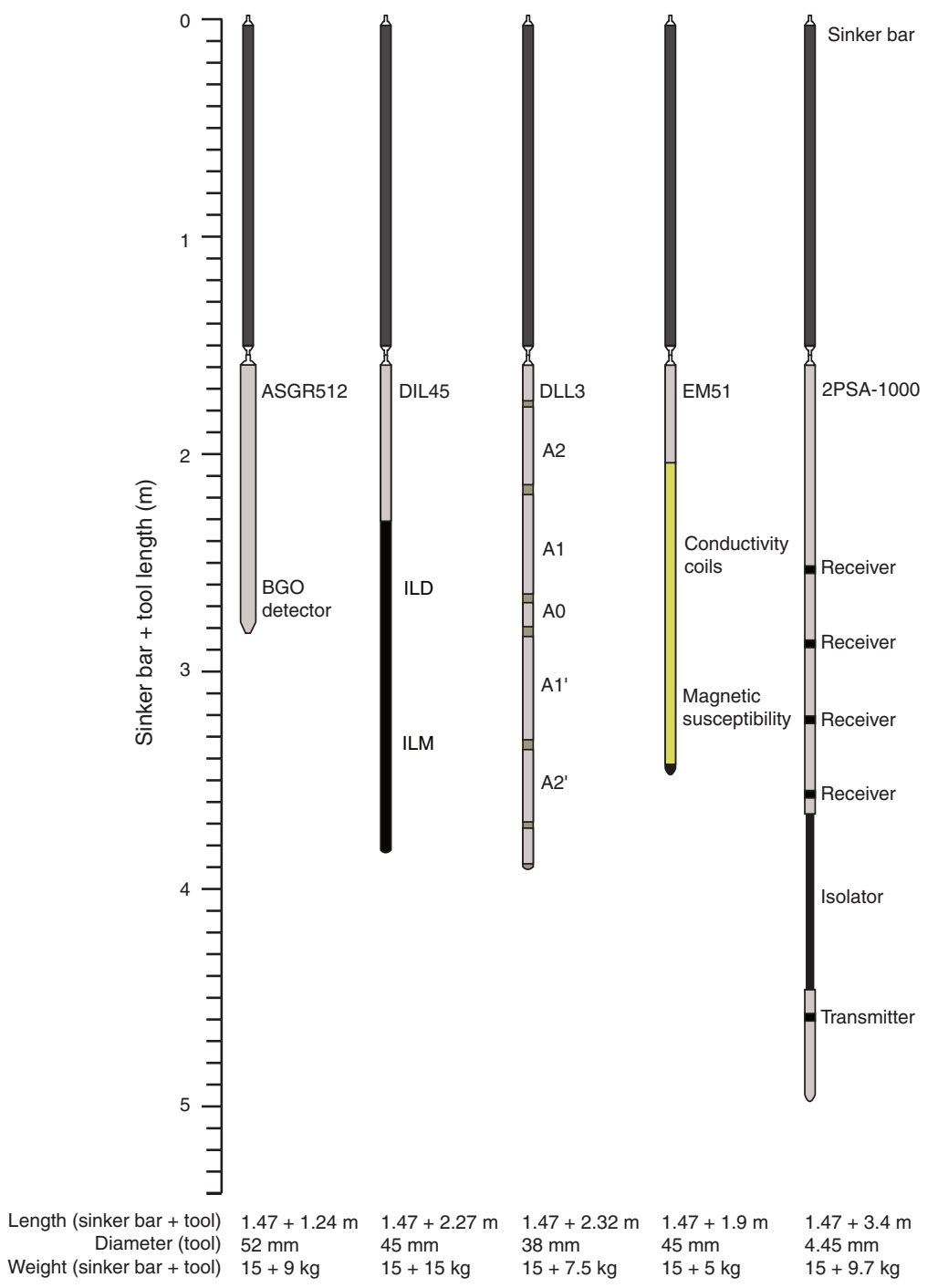

The ASGR detector for gamma rays is a bismuth germanate (BGO) scintillation crystal optically coupled to a photomultiplier. The BGO detector has an absorption potential eight times greater than the NaI crystal. Owing to the majority of the spectral discrimination being performed in the high-energy range, instruments equipped with $\mathrm{BGO}$ detectors prove to be the most reliable for use in slimline tools. The instrument was master-calibrated by the manufacturer. On site, sensor stability and functionality was verified using a volume of pure potassium.

As logging proceeds, gamma rays are sorted according to their emitted energy spectrum (the tool acquires 512 spectral channel data) and the number of counts in each of three preselected energy intervals are recorded. These intervals are centered on the peak values of ${ }^{40} \mathrm{~K}$, ${ }^{214} \mathrm{Bi}$, and ${ }^{208} \mathrm{Tl}$. Tool output includes $\mathrm{K}$, U, and Th in Becquerel per kilogram $(\mathrm{Bq} / \mathrm{kg})$ and total gamma ray counts in counts per second (counts/s). The vertical resolution of the tool is $\sim 15 \mathrm{~cm}$, and the downhole measurement interval is $5 \mathrm{~cm}$, acquired at $1.5-2$ $\mathrm{m} / \mathrm{min}$.

Induction resistivity probe (DIL45)

The ALT DIL45 (http://www.alt.lu; dual induction log; $45 \mathrm{~mm}$ diameter) tool measures electrical conductivity, with variations in electrical conductivity corresponding primarily to variations in lithology (composition and texture), formation porosity and saturation, and interstitial fluid properties (salinity).

An oscillator sends an alternating current of constant amplitude and frequency through an emitting coil, generating an alternating electromagnetic field that induces Foucault currents in the formation. The Foucault currents are proportional to the formation conductivity and generate their own electromagnetic fields. When passing through a receiving coil (solenoid), these secondary magnetic fields induce electromotive forces that are proportional to the flow running through the coil. The output of the DIL45 tool comprises two conductivity logs: a medium induction log (ILM) (0.57 $\mathrm{m})$ and a deep induction $\log$ (ILD) $(0.83 \mathrm{~m})$ in mmho. Measured conductivity can be converted into electrical resistivity. Prior to the expedition, the instrument was calibrated with a loop coil. The measurement window ranges from $5 \mathrm{mmho} / \mathrm{m}$ to $5 \mathrm{mho} / \mathrm{m}$ with a resolution of $0.5 \mathrm{mmho}$. The downhole measurement interval was $0.05 \mathrm{~m}$, measured at $20-25 \mathrm{~m} / \mathrm{min}$.

Dual laterolog electric probe (DLL3)

The DLL3 (dual laterolog resistivity) tool measures electrical resistivity in the formation, which reflects lithology (composition and 
texture), formation porosity and saturation, and interstitial fluid properties. The DLL3 tool provides both deep $(>1 \mathrm{~m})$ and shallow $(<0.5 \mathrm{~m})$ measurements. It has a central electrode (A0) from which a measured current is sent. This current is focused by means of a bucking current that flows from four guard electrodes (A1, $\mathrm{A} 1^{\prime}, \mathrm{A} 2$, and A2'; Figure F16). The electrical potential of the guard electrodes is held equal to the potential of the A0 electrode to force the electrical current to be perpendicular to the tool axis and to flow a greater distance into the formation. The measured current is proportional to formation resistivity. Shallow and deep resistivities are measured by alternating the role of the various guard electrodes and the return location of the bucking current. In shallow measurement mode, A1 and A1' electrodes act as guards, with the current returning to $\mathrm{A} 2$ and $\mathrm{A} 2$ ' electrodes. In deep measurement mode, the pairs $\mathrm{A} 1, \mathrm{~A} 2$ and $\mathrm{A} 1^{\prime}, \mathrm{A} 2{ }^{\prime}$ act as guards, with the current returning to the electrical cable beyond an insulated logging cable. Tool output includes deep (RLLD) and shallow (RLLS) resistivities in ohm.meters $(\Omega \mathrm{m})$. The vertical measurement interval was $0.05 \mathrm{~m}$, acquired at $20-25 \mathrm{~m} / \mathrm{min}$. DLL3 performance is more efficient in high-resistivity formations than in low-resistivity formations.

\section{Magnetic susceptibility (EM51)}

The Geovista EM51 (magnetic susceptibility and conductivity) tool measures formation electrical conductivity and formation magnetic susceptibility using electromagnetic induction. Magnetic susceptibility provides constraints on variations in lithology (composition), whereas conductivity is sensitive to variations in porosity, lithology, and pore fluid content. The sonde includes a set of two coils for conductivity measurement and another set of two coils for magnetic susceptibility measurement. Each pair of coils consists of a transmitter and a receiver. A high-frequency alternating current of constant amplitude is applied to the transmitter coil, which induces an alternating magnetic field around the sonde that in turn induces secondary currents in the formation. These currents create their own alternating magnetic field, which induces currents in the receiver coil of the sonde. The received signal is measured, and its size is proportional to the conductivity of the formation (penetration $<1 \mathrm{~m}$ ). The "in-phase" signal is a measure of susceptibility in formations with magnetic properties. The probe is most effective in high-conductivity geological formations and low-conductivity borehole fluid, including air.

Tool output comprises conductivity (IL) in mmho and magnetic susceptibility (MSUS) in SI units. The measurement window for magnetic susceptibility ranges from $10^{-5}$ to $2 \mathrm{SI}$. The downhole measurement spacing interval selected was $0.05 \mathrm{~m}$, measured at $20-25 \mathrm{~m} / \mathrm{min}$.

\section{Full waveform sonic probe (2PSA-1000)}

The Mount Sopris 2PSA-1000 sonic tool was used to measure the compressional wave velocity of the formation. When bulk density is known (e.g., from core), elastic properties (bulk and shear moduli) and an estimate of porosity can be derived from sonic measurements. These data are also important for core-log-seismic integration (CLSI).

The 2PSA-1000 tool comprises an acoustic transmitter and four receivers. The transmitter emits an acoustic signal that propagates through the borehole fluid to the interface with the borehole wall, where some of the energy is critically refracted. As a result of wavefront spreading (Huygens principle), some of the refracted energy is transmitted back into the borehole and recorded by a receiver. Each receiver picks up the signal and amplifies and digitizes it. Recorded waveforms are then examined, and wave arrival times (acoustic energy transit times) are manually or automatically picked. For Expedition 381, picking was done manually. By measuring the acoustic transit time and knowing the distance between the receivers $(1 \mathrm{ft}$ between each), the fluid velocity, and the nominal borehole diameter, the sonic velocity of the formation is calculated. The interval velocity value is then calculated at each sampling point. In the specific configuration used during this expedition, $P$-waves $(10$ or $15 \mathrm{kHz}$ monopole survey) were recorded, and the log was acquired with a $10 \mathrm{~cm}$ resolution at a speed of $4 \mathrm{~m} / \mathrm{min}$.

\section{Log data quality}

The main factor affecting log data quality is the condition of the borehole (e.g., wall roughness, hole diameter, etc.). Enlarged or bridged sections where borehole diameter is greater or less than the bit size, respectively, cause irregular log results. For Expedition 381, the absence of borehole images or caliper data means that it is not possible to properly assess the borehole quality and how it affects logging data. However, the fact that downward progression of the tools was commonly impeded (and sometimes prevented altogether) by bridges in the formation suggests challenging conditions in at least some parts of the boreholes.

The quality of the wireline depth determination depends on several factors. Logging measurement depth is determined from the length of the cable payed out from the winch. The seafloor is identified on the gamma ray log by the abrupt reduction in gamma ray counts at the sediment/water interface (mudline). Discrepancies between the drilling depth and the wireline log depth may occur. For drilling depth, errors may occur because of core expansion, incomplete core recovery, or incomplete heave compensation. For logging depth, inconsistencies between successive runs may occur because of incomplete heave compensation, incomplete accounting for cable stretch, or cable slip. Tidal changes in sea level affect both drilling and logging depths, although these changes were less than $0.5 \mathrm{~m}$ during all logging operations in the Gulf of Corinth.

\section{Core-log-seismic integration}

The goal of CLSI during the offshore phase was to assess drilling progress with respect to estimated depths of seismic stratigraphic horizons identified before the expedition and for preliminary shipboard interpretation. The onshore CLSI effort built on the preliminary offshore results and aimed at improving the accuracy of the ties between seismic stratigraphic horizons and core units and at integrating new core and logging data into the initial shipboard interpretation. Initial processing and QC of core and logging data was performed with Microsoft Excel and Matlab. Synthetic seismograms were calculated using modules in the Petrel E\&P software platform (version 2015) for comparison with seismic reflection data crossing each site. A Petrel project with the seismic database and structural interpretations for the Gulf of Corinth (Nixon et al., 2016) was used to incorporate new offshore and onshore data.

Synthetic seismograms are generated using borehole and/or core data and are matched to seismic profiles to establish timedepth conversions for seismic traces and to identify the nature of major seismic reflectors. Three pieces of information are needed to produce a synthetic seismogram: source wavelet, velocity, and density. Velocity and density are used to calculate acoustic impedance and from it a reflection coefficient series that is then convolved with the source wavelet to produce a synthetic seismogram. 


\section{Source wavelet}

The source wavelet was estimated in Petrel by averaging autocorrelations for 100 seismic traces closest to the well location that had been truncated at $128 \mathrm{~ms}$ (Figure F17). This approach extracts an estimate of the source wavelet directly from the data rather than assuming a nominal source wavelet (e.g., Ricker, etc.). The estimated source wavelet was also shifted by $21 \mathrm{~ms}$ so that the predicted seafloor reflection matched the observed seafloor reflection, whose onset rather than central peak matched the seafloor, verified by comparing the calculated traveltime to the seafloor using the ship's echo sounder and velocity values from sound velocity profile data at each site with the traveltime of the seafloor reflection in the seismic reflection data.

\section{Velocity}

A pre-expedition linear velocity model, downhole sonic logs, and/or $V_{\mathrm{P}}$ measurements on cores were used to derive compressional $(P-)$ wave velocity $\left(V_{\mathrm{P}}\right)$ for synthetics generation. The preexpedition linear velocity model of $V_{\mathrm{P}}=1.5507+1.5 \Delta \mathrm{T}$ (Figure F18; Nixon et al., 2016) was estimated based on an array of existing velocity data, including tomography (Zelt et al., 2004), poststack depth migrations (Clément, 2000), semblance plots (Bell et al., 2008), and geophysical logging of shallow piston cores (Collier et al., 2000; Moretti et al., 2004). In this velocity model, velocity in the synrift sediments increases linearly by $1.5 \mathrm{~km} / \mathrm{s} / \mathrm{s}$ from the seabed surface, where the shallow sediment velocity has been measured as $1.5507 \mathrm{~km} / \mathrm{s}$ by geophysical logging of shallow piston cores (Moretti et al., 2004), matching a velocity model for calcareous sediment by Hamilton (1985). This velocity function was used to estimate the key horizon depths at each site prior to the expedition. These estimates proved to be very reliable in predicting major boundary depths.

Varying amounts of core and $\log V_{\mathrm{P}}$ data were available at Sites M0078-M0080. Approaches to integrating these data sets were selected based on the data quality and availability and differed at each site. A detailed description and comparison of $V_{\mathrm{P}}$ data are provided in each site chapter. Because of problems with acquiring reliable $V_{\mathrm{P}}$ data on cores, the linear velocity model developed prior to the expedition was used in the absence of logs or physical properties data at Site M0078 and for the deeper part of Site M0079. At Sites M0079 and M0080, discrete $V_{\mathrm{P}}$ measurements were used to evaluate velocity in the shallowest depth interval, followed by borehole logging and MSCL data where available at depth. The logs and/or physical properties data were smoothed, and gaps were filled by linear interpolation as necessary. The smoothing parameters were dictated by the quality and length of each of the available data sets and are described in the Core-log-seismic integration section of each site chapter.

\section{Density}

Because core density was the only downhole information available for building synthetics in Holes M0078A and M0078B and in the lower part of Hole M0079A (no density logs were collected), significant effort went into developing and refining approaches to QC and filtering these data. MSCL density results, which agreed well with MAD density, were used because of continuous coverage and high spatial resolution. However, the results contained significant measurement artifacts, such as abnormally low density values and drilling-related overprints. The drilling-related artifacts were particularly pronounced in the deeper cores from seismic Unit 1 in
Figure F17. Estimated source wavelet, Site M0078.
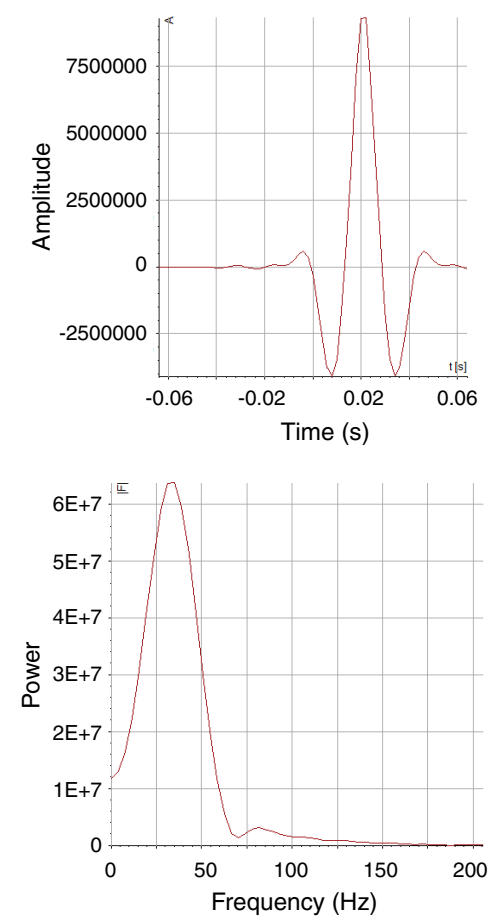

Figure F18. $P$-wave velocity profile estimated from existing data prior to Expedition 381 (Nixon et al., 2016).

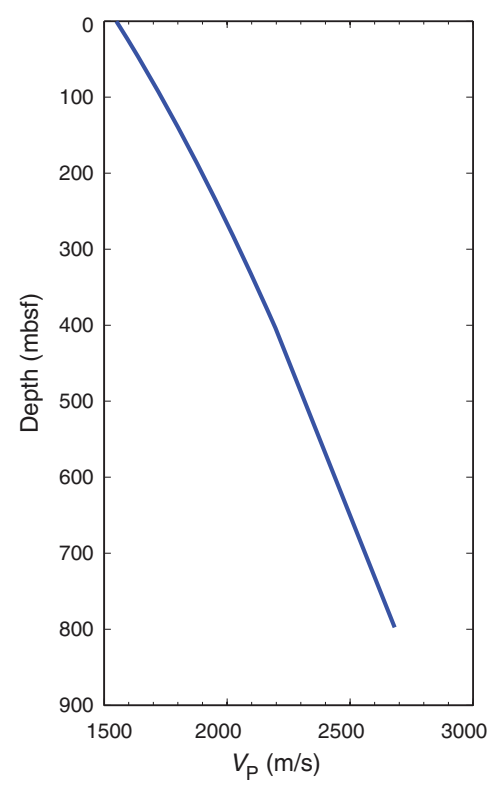

Hole M0078A (roughly below 400 mbsf), where many cores exhibited a systematic gradient from low values at the top of an individual core to much higher values at the bottom of that core (Figure F19). Multiple approaches to data filtering were tested to maximize initial data retention while removing clear artifacts. The approaches included removing abnormally low density values below a certain threshold; using running averages and polynomial fits to smooth the data and to remove outliers defined by a threshold distance from the fit, retaining only the second (middle) section of each core; and/or discarding data from the first section with abnormally low 
Figure F19. Example of initial MSCL density data and a filtered and smoothed density function in the deeper part of Hole M0078A.

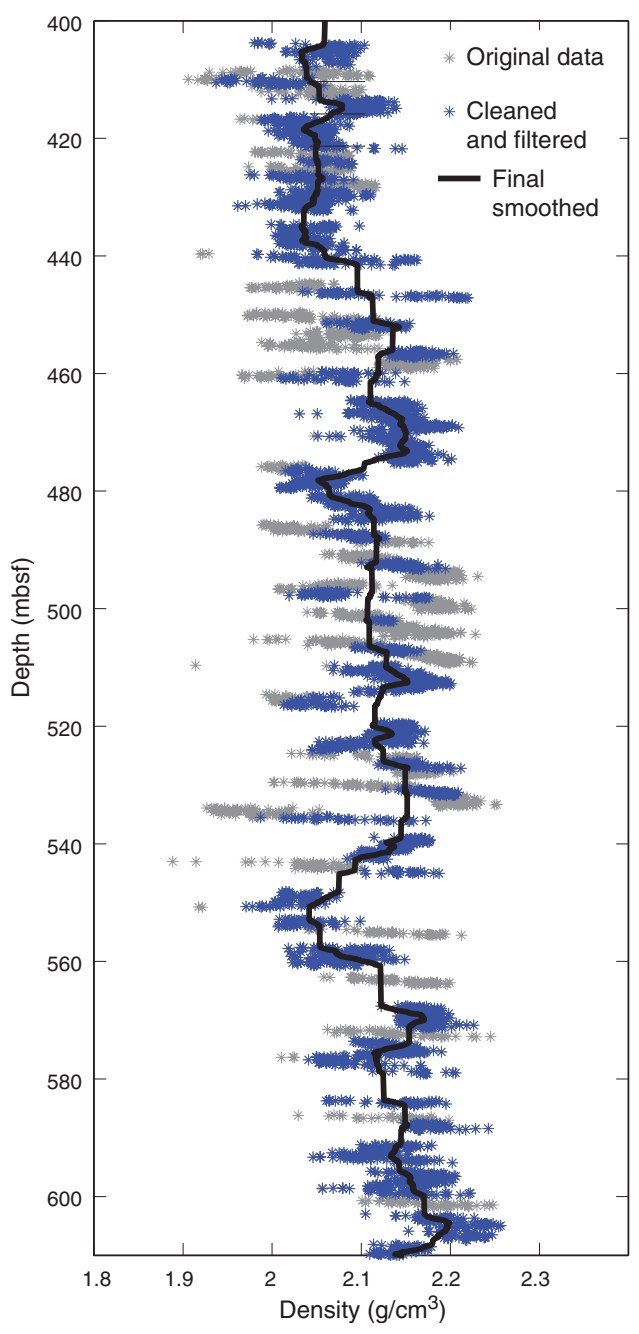

values. As a result, the following approach was developed offshore and worked best for the upper $400 \mathrm{~m}$ of Hole M0078A and the full depth range of Hole M0080A:

- Density values were removed from the upper $\sim 0.5-1 \mathrm{~m}$ of each core. This part of the core often included anomalously low velocity values because of the relatively unconsolidated and disturbed material captured in the uppermost part of the core barrel and the potential for vertical expansion when the $5 \mathrm{~m}$ long core liner was not completely filled. The depth interval of the density values removed from the top of each core was defined manually based on inspection of the data.

- A 25-term polynomial was fit to the remaining data points, and data points with density values less than $0.05 \mathrm{~g} / \mathrm{cm}^{3}$ or greater than $0.1 \mathrm{~g} / \mathrm{cm}^{3}$ from this trend were removed, which eliminated many anomalously low density values due to processes such as expansion/disturbance of the core.

- The remaining data points were filtered with a $5 \mathrm{~m}$ long boxcar to obtain the final density function used for synthetics.

In the lower part of Site M0078, which sampled seismic Unit 1, an interval characterized by low-amplitude reflections and rela- tively uniform density values, more significant cleaning was required to eliminate artifacts with magnitudes greater than the subtle changes creating the low-amplitude reflections. Offshore for this site, more data points were removed from the top and base of each core, which may have been under- or overcompacted during the recovery process. The remaining data were then filtered with a longer $(20 \mathrm{~m})$ boxcar filter. This approach resulted in significant smoothing of the Hole M0078A density profile so that no distinct reflections were produced in the synthetic seismograms below $400 \mathrm{mbsf}$, which was not ideal. Thus, the approach to filtering the density data below 400 mbsf at Site M0078 was further modified onshore to remove drilling artifacts but avoid oversmoothing the data. An automated algorithm was developed to identify cores in which the average density difference between the core top and core bottom exceeded 0.05 $\mathrm{g} / \mathrm{cm}^{3}$. For these cores, only Section 2 data were retained. For the cores in which no significant density gradient was observed, all density data were retained aside from abnormally high and low values defined similarly to the upper $400 \mathrm{mbsf}$. The remaining data points were smoothed with a $3 \mathrm{~m}$ long moving average window (Figure F19). The resulting Site M0078 density log was depth shifted to sea level and imported into the Petrel software for synthetics generation. Water density was assumed to be $1 \mathrm{~g} / \mathrm{cm}^{3}$. The same approach was applied to MSCL density at Site M0079, allowing the achievement of a slightly higher resolution in synthetic seismograms than the methodology used in the upper $400 \mathrm{~m}$ of Hole M0078A. At Site M0080, the same approach as the one utilized for the top of Hole M0078A (manual removal of anomalies at the top of each core, elimination of abnormally high and low values, and calculating moving average with a $5 \mathrm{~m}$ window) was used for the density profile calculation. This approach allowed us to achieve the best balance between data retention and filtering density data artifacts at this site.

\section{Synthetics generation}

The resulting density and velocity data were imported into Petrel and used to calculate synthetic seismograms that generally match the seismic data very well. Modest adjustments were made to the seismic velocity values to match prominent reflections in the synthetic seismogram with those in the observed seismic reflection data. We tried to make as few adjustments as possible to match the overall patterns of reflectivity and ensured that the implied interval velocity values were realistic and not very different from those estimated from available data before the expedition because we gained limited additional velocity information during the expedition. The modified interval velocity values were then used to estimate an updated time-depth relationship, which enabled direct comparison of core observations and data with the seismic reflection data.

An important consideration for tying seismic horizons to core records was the repositioning of the R/V Maurice Ewing lines near Expedition 381 drill sites because of the discovery of an error in geographic referencing of the seismic lines. This error was discovered and correction implemented before the expedition but after the horizon interpretation by Nixon et al. (2016) was developed. It resulted in only a minor horizontal shift in seismic line positions ( 50-100 m). However, it does affect the measurement of two-way traveltime to horizons in the deeper part of Hole M0078A, where layers are tilted (see Figure F8 in the Expedition 381 summary chapter [Expedition 381 Scientists, 2019b]). The CLSI results for each site are reported based on the corrected seismic line navigation. 


\section{References}

Backman, J., Raffi, I., Rio, D., Fornaciari, E., and Pälike, H., 2012. Biozonation and biochronology of Miocene through Pleistocene calcareous nannofossils from low and middle latitudes. Newsletters on Stratigraphy, 45(3):221-244. https://doi.org/10.1127/0078-0421/2012/0022

Bell, R.E, McNeill, L.C., Bull, J.M., and Henstock, T.J., 2008. Evolution of the offshore western Gulf of Corinth. Geological Society of America Bulletin, 120(1-2):156-178. https://doi.org/10.1130/B26212.1

Beug, H.-J., 2004. Leitfaden der Pollenbestimmung für Mitteleuropa und angrenzende Gebiete: München (Verlag Friedrich Pfeil).

Blenkinsop, T.G., and Doyle, M.G., 2010. A method for measuring the orientations of planar structures in cut core. Journal of Structural Geology, 32(6):741-745. https://doi.org/10.1016/j.jsg.2010.04.011

Blum, P., 1997. Technical Note 26: Physical Properties Handbook-A Guide to the Shipboard Measurement of Physical Properties of Deep-Sea Cores. Ocean Drilling Program. https://doi.org/10.2973/odp.tn.26.1997

Bolli, H.M., and Saunders, J.B., 1985. Oligocene to Holocene low latitude planktic foraminifera. In Bolli, H.M., Saunders, J.B., and Perch-Nielsen, K. (Eds.), Plankton Stratigraphy (Volume 1): Planktic Foraminifera, Calcareous Nannofossils and Calpionellids: Cambridge, United Kingdom (Cambridge University Press), 155-262.

Briaud, J.-L., 2013. Geotechnical Engineering: Unsaturated and Saturated Soils: New York (John Wiley \& Sons, Inc.). https://doi.org/10.1002/9781118686195

Bullard, E.C., 1939. Heat flow in South Africa. Proceedings of the Royal Society of London, Series A, 173(955):474-502. https://doi.org/10.1098/rspa.1939.0159

Cande, S.C., and Kent, D.V., 1995. Revised calibration of the geomagnetic polarity timescale for the Late Cretaceous and Cenozoic. Journal of Geophysical Research: Solid Earth, 100(B4):6093-6095. https://doi.org/10.1029/94JB03098

Capotondi, L., Borsetti, A.M., and Morigi, C., 1999. Foraminiferal ecozones, a high resolution proxy for the late Quaternary biochronology in the central Mediterranean Sea. Marine Geology, 153(1-4):253-274. https://doi.org/10.1016/S0025-3227(98)00079-6

Channell, J.E.T., Hodell, D.A., and Curtis, J.H., 2016. Relative paleointensity (RPI) and oxygen isotope stratigraphy at IODP Site U1308: North Atlantic RPI stack for 1.2-2.2 Ma (NARPI-2200) and age of the Olduvai Subchron. Quaternary Science Reviews, 131(A):1-19. https://doi.org/10.1016/j.quascirev.2015.10.011

Channell, J.E.T., Hodell, D.A., Xuan, C., Mazaud, A., and Stoner, J.S., 2008. Age calibrated relative paleointensity for the last 1.5 Myr at IODP Site U1308 (North Atlantic). Earth and Planetary Science Letters, 274(12):59-71. https://doi.org/10.1016/j.epsl.2008.07.005

Channell, J.E.T., Mazaud, A., Sullivan, P., Turner, S., and Raymo, M.E., 2002. Geomagnetic excursions and paleointensities in the Matuyama Chron at Ocean Drilling Program Sites 983 and 984 (Iceland Basin). Journal of Geophysical Research: Solid Earth, 107(B6):2114-2127. https://doi.org/10.1029/2001JB000491

Channell, J.E.T., Wright, J.D., Mazaud, A., and Stoner, J.S., 2014. Age through tandem correlation of Quaternary relative paleointensity (RPI) and oxygen isotope data at IODP Site U1306 (Eirik Drift, SW Greenland). Quaternary Science Reviews, 88:135-146. http://dx.doi.org/10.1016/j.quascirev.2014.01.022

Channell, J.E.T., Xuan, C., and Hodell, D.A., 2009. Stacking paleointensity and oxygen isotope data for the last 1.5 Myr (PISO-1500). Earth and Planetary Science Letters, 283(1-4):14-23. https://doi.org/10.1016/j.epsl.2009.03.012

Chung, F.H., 1974. Quantitative interpretation of X-ray diffraction patterns of mixtures. I. Matrix-flushing method for quantitative multicomponent analysis. Journal of Applied Crystallography, 7(6):519-525. https://doi.org/10.1107/S0021889874010375

Clemens, S.C., Kuhnt, W., LeVay, L.J., Anand, P., Ando, T., Bartol, M., Bolton, C.T., Ding, X., Gariboldi, K., Giosan, L., Hathorne, E.C., Huang, Y., Jaiswal, P., Kim, S., Kirkpatrick, J.B., Littler, K., Marino, G., Martinez, P., Naik, D., Peketi, A., Phillips, S.C., Robinson, M.M., Romero, O.E., Sagar,
N., Taladay, K.B., Taylor, S.N., Thirumalai, K., Uramoto, G., Usui, Y., Wang, J., Yamamoto, M., and Zhou, L., 2016. Expedition 353 methods. In Clemens, S.C., Kuhnt, W., LeVay, L.J., and the Expedition 353 Scientists, Indian Monsoon Rainfall. Proceedings of the International Ocean Discovery Program, 353: College Station, TX (International Ocean Discovery Program). https://doi.org/10.14379/iodp.proc.353.102.2016

Clément, C., 2000. Imagerie sismique crustale de la subduction Hellenique et du Golfe de Corinth [Ph.D. thesis]. Université Paris Diderot, France. http://www.theses.fr/2000PA077043

Collier, R.E.L., Leeder, M.R., Trout, M., Ferentinos, G., Lyberis, E., and Papatheodorou, G., 2000. High sediment yields and cool, wet winters: test of last glacial paleoclimates in the northern Mediterranean. Geology, 28(11):999-1002. https://doi.org/10.1130/0091-

7613(2000)28<999:HSYACW>2.0.CO;2

Cvetkoska, A., Hamilton, P.B., Ognjanova-Rumenova, N., and Levkov, Z., 2014. Observations of the genus Cyclotella (Kützing) Brébisson in ancient lakes Ohrid and Prespa and a description of two new species C. paraocellata sp. nov. and C. prespanensis sp. nov. Nova Hedwigia, 98(3-4):313340. https://doi.org/10.1127/0029-5035/2014/0154

Dickens, G.R., Koelling, M., Smith, D.C., Schneiders, L., and the IODP Expedition 302 Scientists, 2007. Rhizon sampling of pore waters on scientific drilling expeditions: an example from the IODP Expedition 302, Arctic Coring Expedition (ACEX). Scientific Drilling, 4:22-25. https://doi.org/10.2204/iodp.sd.4.08.2007

Economou-Amilli, A., 1987. New fossil taxa of Cyclotella Kützing (Bacillariophyceae) from the Neogene basin of Mytilinii, Samos Island, Greece. Archiv für Hydrobiologie, 47(Supplement):139-156.

Economou-Amilli, A., 1991. Cyclotella elymaea, a new fossil species from the Neogene basin of Kozani-Aeani-Servia, Northern Greece. Diatom Research, 6(2):223-233. https://doi.org/10.1080/0269249X.1991.9705168

Evitt, W.R., Gocht, H., and Netzel, H., 1985. Gonyaulax cysts from Lake Zürich sediments. Review of Palaeobotany and Palynology, 45(1-2):3546. https://doi.org/10.1016/0034-6667(85)90064-8

Expedition 334 Scientists, 2012. Methods. In Vannucchi, P., Ujiie, K., Stroncik, N., Malinverno, A., and the Expedition 334 Scientists, Proceedings of the Integrated Ocean Drilling Program, 334: Tokyo (Integrated Ocean Drilling Program Management International, Inc.). https://doi.org/10.2204/iodp.proc.334.102.2012

Fatela, F., and Taborda, R., 2002. Confidence limits of species proportions in microfossil assemblages. Marine Micropaleontology, 45(2):169-174. https://doi.org/10.1016/S0377-8398(02)00021-X

Folk, R.L., 1980. Petrology of Sedimentary Rocks (2nd edition): Austin, TX (Hemphill's).

Gieskes, J.M., Gamo, T., and Brumsack, H., 1991. Technical Note 15: Chemical Methods for Interstitial Water Analysis Aboard JOIDES Resolution. Ocean Drilling Program. https://doi.org/10.2973/odp.tn.15.1991

Grasshoff, K., Ehrhardt, M., and Kemling, K. (Eds.), 1983. Methods of Seawater Analysis (2nd edition): Weinheim, Germany (Verlag Chemie).

Grimm, E.C., 2004. TGView. Springfield, IL (Illinois State Museum, Research and Collections Center).

Hajós, M., 1973. The Mediterranean diatoms. In Ryan, W.B.F., Hsü, K.J., et al., Initial Reports of the Deep Sea Drilling Project, 13: Washington, DC (U.S. Govt. Printing Office), 944-970. https://doi.org/10.2973/dsdp.proc.13.134-5.1973

Hall, P.O.J., and Aller, R.C., 1992. Rapid, small-volume, flow injection analysis for $\Sigma \mathrm{CO}_{2}$ and $\mathrm{NH}_{4}{ }^{+}$in marine and freshwaters. Limnology and Oceanography, 37(5):1113-1119. https://doi.org/10.4319/lo.1992.37.5.1113

Hamilton, E.L., 1985. Sound velocity as a function of depth in marine sediments. The Journal of the Acoustical Society of America, 78(4):1348-1354. https://doi.org/10.1121/1.392905

Hansbo, S., 1957. A new approach to the determination of the shear strength of clay by the fall-cone test. Royal Swedish Geotechnical Institute Proceedings, 14.

Harris, R.N., Sakaguchi, A., Petronotis, K., Baxter, A.T., Berg, R., Burkett, A., Charpentier, D., Choi, J., Diz Ferreiro, P., Hamahashi, M., Hashimoto, Y., Heydolph, K., Jovane, L., Kastner, M., Kurz, W., Kutterolf, S.O., Li, Y., 
Malinverno, A., Martin, K.M., Millan, C., Nascimento, D.B., Saito, S., Sandoval Gutierrez, M.I., Screaton, E.J., Smith-Duque, C.E., Solomon, E.A., Straub, S.M., Tanikawa, W., Torres, M.E., Uchimura, H., Vannucchi, P., Yamamoto, Y., Yan, Q., and Zhao, X., 2013. Methods. In Harris, R.N., Sakaguchi, A., Petronotis, K., and the Expedition 344 Scientists, Proceedings of the Integrated Ocean Drilling Program, 344: College Station, TX (Integrated Ocean Drilling Program).

https://doi.org/10.2204/iodp.proc.344.102.2013

Hemleben, C., Spindler, M., and Anderson, O.R., 1989. Modern Planktonic Foraminifera: Berlin (Springer-Verlag).

Houk, V., Klee, R., and Tanaka, H., 2010. Atlas of Freshwater Centric Diatoms with a Brief Key and Descriptions: Part 3. Stephanodiscaceae A, Cyclotella, Tertiarius, Discostella: Praha, Czech Republic (Czech Phycological Society).

John, J., and Economou-Amilli, A., 1990. Cyclotella cretica, a new species of diatom from the island of Crete, Greece. Diatom Research, 5(1):43-50. https://doi.org/10.1080/0269249X.1990.9705091

Jutzeler, M., White, J.D.L., Talling, P.J., McCanta, M., Morgan, S., Le Friant, A., and Ishizuka, O., 2014. Coring disturbances in IODP piston cores with implications for offshore record of volcanic events and the Missoula megafloods. Geochemistry, Geophysics, Geosystems, 15(9):3572-3590. https://doi.org/10.1002/2014GC005447

Kennett, J.P., and Srinivasan, M.S., 1983. Neogene Planktonic Foraminifera: A Phylogenetic Atlas: Stroudsburg, PA (Hutchinson Ross).

Kouli, K., Brinkhuis, H., and Dale, B., 2001. Spiniferites cruciformis: a fresh water dinoflagellate cyst? Review of Palaeobotany and Palynology, 113(4):273-286. https://doi.org/10.1016/S0034-6667(00)00064-6

Krammer, K., and Lange-Bertalot, H., 1991. Bacillariophyceae, Part 3. Centrales, Fragilariaceae, Eunotiaceae. In Ettl, H., Gerloff, J., Heynig, H., and Mollenhauer, D. (Eds.), Süßwaserflora von Mitteleuropa (Volume 2/3): Stuttgart, Germany (Gustav Fischer Verlag).

Kulander, B.R., Dean, S.L., and Ward, B.J., Jr., 1990. Fractured Core Analysis: Interpretation, Logging, and Use of Natural and Induced Fractures in Core. Methods in Exploration Series, 8. Tulsa, OK (AAPG).

Leroy, C.C., 1969. Development of simple equations for accurate and more realistic calculation of the speed of sound in seawater. Journal of the Acoustical Society of America, 46(1B):216-226. https://doi.org/10.1121/1.1911673

Lurcock, P.C., and Wilson, G.S., 2012. PuffinPlot: a versatile, user-friendly program for paleomagnetic analysis. Geochemistry, Geophysics, Geosystems, 13(6):Q06Z45. https://doi.org/10.1029/2012GC004098

Mazzullo, J., and Graham, A.G. (Eds.), 1988. Technical Note 8: Handbookfor shipboard sedimentologists. Ocean Drilling Program. https://doi.org/10.2973/odp.tn.8.1988

McNeill, L.C., Dugan, B., Petronotis, K.E., Backman, J., Bourlange, S., Chemale, F., Chen, W., Colson, T.A., Frederik, M.C.G., Guèrin, G., Hamahashi, M., Henstock, T., House, B.M., Hüpers, A., Jeppson, T.N., Kachovich, S., Kenigsberg, A.R., Kuranaga, M., Kutterolf, S., Milliken, K.L., Mitchison, F.L., Mukoyoshi, H., Nair, N., Owari, S., Pickering, K.T., Pouderoux, H.F.A., Yehua, S., Song, I., Torres, M.E., Vannucchi, P., Vrolijk P.J., Yang, T., and Zhao, X., 2017a. Expedition 362 methods. In McNeill, L.C., Dugan, B., Petronotis, K.E., and the Expedition 362 Scientists, Sumatra Subduction Zone. Proceedings of the International Ocean Discovery Program, 362: College Station, TX (International Ocean Discovery Program). https://doi.org/10.14379/iodp.proc.362.102.2017

McNeill, L.C., Dugan, B., Petronotis, K.E., and the Expedition 362 Scientists, 2017b. Supplementary material, https://doi.org/10.14379/iodp.proc.362supp.2017. Supplement to McNeill, L.C., Dugan, B., Petronotis, K.E., and the Expedition 362 Scientists, Sumatra Subduction Zone. Proceedings of the International Ocean Discovery Program, 362: College Station, TX (International Ocean Discovery Program). https://doi.org/10.14379/iodp.proc.362.2017

McNeill, L.C., Shillington, D.J., Carter, G.D.O., Everest, J.D., Le Ber, E., Collier, R.E.Ll., Cvetkoska, A., De Gelder, G., Diz, P., Doan, M.-L., Ford, M., Gawthorpe, R.L., Geraga, M., Gillespie, J., Hemelsdaël, R., Herrero-Bervera, E., Ismaiel, M., Janikian, L., Kouli, K., Li, S., Machlus, M.L., Maffione, M., Mahoney, C., Michas, G., Miller, C., Nixon, C.W., Oflaz, S.A., Omale, A.P.,
Panagiotopoulos, K., Pechlivanidou, S., Phillips, M.P., Sauer, S., Seguin, J., Sergiou, S., and Zakharova, N.V., 2019a. Expedition 381 facies associations. In McNeill, L.C., Shillington, D.J., Carter, G.D.O., and the Expedition 381 Participants, Corinth Active Rift Development. Proceedings of the International Ocean Discovery Program, 381: College Station, TX (International Ocean Discovery Program).

https://doi.org/10.14379/iodp.proc.381.103.2019

McNeill, L.C., Shillington, D.J., Carter, G.D.O., Everest, J.D., Le Ber, E., Collier, R.E.Ll., Cvetkoska, A., De Gelder, G., Diz, P., Doan, M.-L., Ford, M., Gawthorpe, R.L., Geraga, M., Gillespie, J., Hemelsdaël, R., Herrero-Bervera, E., Ismaiel, M., Janikian, L., Kouli, K., Li, S., Machlus, M.L., Maffione, M., Mahoney, C., Michas, G., Miller, C., Nixon, C.W., Oflaz, S.A., Omale, A.P., Panagiotopoulos, K., Pechlivanidou, S., Phillips, M.P., Sauer, S., Seguin, J., Sergiou, S., and Zakharova, N.V., 2019b. Expedition 381 summary. In McNeill, L.C., Shillington, D.J., Carter, G.D.O., and the Expedition 381 Participants, Corinth Active Rift Development. Proceedings of the International Ocean Discovery Program, 381: College Station, TX (International Ocean Discovery Program). https://doi.org/10.14379/iodp.proc.381.101.2019

Mertens, K.N., Rengefors, K., Moestrup, Ø., and Ellegaard, M., 2012. A review of recent freshwater dinoflagellate cysts: taxonomy, phylogeny, ecology and palaeocology. Phycologia, 51(6):612-619. https://doi.org/10.2216/11-89.1

Miller, C.M., Dickens, G.R., Jakobsson, M., Johansson, C., Koshurnikov, A., O'Regan, M., Muschitiello, F., Stranne, C., and Mörth, C.-M., 2017. Pore water geochemistry along continental slopes north of the East Siberian Sea: inference of low methane concentrations. Biogeosciences, 14(12):2929-2953. https://doi.org/10.5194/bg-14-2929-2017

Moore, D.M., and Reynolds, R.C., Jr., 1997. X-ray Diffraction and the Identification and Analysis of Clay Minerals (2nd edition): Oxford, United Kingdom (Oxford University Press).

Moretti, I., Lykousis, V., Sakellariou, D., Reynaud, J.-Y., Benziane, B., and Prinzhoffer, A., 2004. Sedimentation and subsidence rate in the Gulf of Corinth: what we learn from the Marion Dufresne's long-piston coring. Comptes Rendus Geoscience, 336(4-5):291-299. https://doi.org/10.1016/j.crte.2003.11.011

Mudie, P.J., Marret, F., Mertens, K.N., Shumilovskikh, L., and Leroy, S.A.G., 2017. Atlas of modern dinoflagellate cyst distributions in the Black Sea Corridor: from Aegean to Aral Seas, including Marmara, Black, Azov and Caspian Seas. Marine Micropaleontology, 134. https://doi.org/10.1016/j.marmicro.2017.05.004

Nixon, C.W., McNeill, L.C., Bull, J.M., Bell, R.E., Gawthorpe, R.L., Henstock, T.J., Christodoulou, D., et al., 2016. Rapid spatiotemporal variations in rift structure during development of the Corinth Rift, central Greece. Tectonics, 35(5):1225-1248. https://doi.org/10.1002/2015TC004026

Ogg, J.G., Ogg, G., and Gradstein, F.M., 2016. A Concise Geologic Time Scale 2016: Boston (Elsevier).

Pribnow, D., Kinoshita, M., and Stein, C., 2000. Thermal Data Collection and Heat Flow Recalculations for Ocean Drilling Program Legs 101-180: Hanover, Germany (Institute for Joint Geoscientific Research, Institut für Geowissenschaftliche Gemeinschaftsaufgaben [GGA]). http://www-odp.tamu.edu/publications/heatflow/ODPReprt.pdf

Reagan, M.K., Pearce, J.A., Petronotis, K., Almeev, R., Avery, A.A., Carvallo, C., Chapman, T., Christeson, G.L., Ferré, E.C., Godard, M., Heaton, D.E., Kirchenbaur, M., Kurz, W., Kutterolf, S., Li, H.Y., Li, Y., Michibayashi, K., Morgan, S., Nelson, W.R., Prytulak, J., Python, M., Robertson, A.H.F., Ryan, J.G., Sager, W.W., Sakuyama, T., Shervais, J.W., Shimizu, K., and Whattam, S.A., 2015. Expedition 352 methods. In Reagan, M.K., Pearce, J.A., Petronotis, K., and the Expedition 352 Scientists, Izu-Bonin-Mariana Fore Arc. Proceedings of the International Ocean Discovery Program, 352: College Station, TX (International Ocean Discovery Program). https://doi.org/10.14379/iodp.proc.352.102.2015

Reille, M., 1992. Pollen et Spores d'Europe et d'Afrique du Nord: Marseille, France (Laboratoire de Botanique Historique et Palynologie).

Reille, M., 1998. Pollen et Spores d'Europe et d'Afrique du Nord (Supplement 2): Marseille, France (Laboratoire de Botanique Historique et Palynologie). 
Reinholdsson, M., Snowball, I., Zillén, L., Lenz, C., and Conley, D.J., 2013. Magnetic enhancement of Baltic Sea sapropels by greigite magnetofossils. Earth and Planetary Science Letters, 366:137-150. https://doi.org/10.1016/j.eps1.2013.01.029

Rothwell, R.G., 1989. Minerals and Mineraloids in Marine Sediments: An Optical Identification Guide: London (Elsevier). https://doi.org/10.1007/978-94-009-1133-8

Schlumberger, 1989. Log Interpretation Principles/Applications: Houston (Schlumberger Education Services), SMP-7017.

Schmitt, D.R., Currie, C.A., and Zhang, L., 2012. Crustal stress determination from boreholes and rock cores: fundamental principles. Tectonophysics, 580:1-26. https://doi.org/10.1016/j.tecto.2012.08.029

Seeberg-Elverfeldt, J., Schlüter, M., Feseker, T., and Kölling, M., 2005. Rhizon sampling of porewaters near the sediment-water interface of aquatic systems. Limnology and Oceanography: Methods, 3(8):361-371. https://doi.org/10.4319/lom.2005.3.361

Serra, O., 1984. Fundamentals of Well-Log Interpretation (Volume 1): The Acquisition of Logging Data: Amsterdam (Elsevier).

Serra, O., 1986. Fundamentals of Well-Log Interpretation (Volume 2): The Interpretation of Logging Data: Amsterdam (Elsevier).

Singer, B.S., 2014. A Quaternary geomagnetic instability time scale. Quaternary Geochronology, 21:29-52. http://dx.doi.org/10.1016/j.quageo.2013.10.003

Skinner, L.C., and McCave, I.N., 2003. Analysis and modelling of gravity and piston coring based on soil mechanics. Marine Geology, 199(1-2):181204. https://doi.org/10.1016/S0025-3227(03)00127-0

Sohlenius, G., 1996. Mineral magnetic properties of late Weichselian-Holocene sediments from the northwestern Baltic proper. Boreas, 25(2):79-88. https://doi.org/10.1111/j.1502-3885.1996.tb00837.x

Taylor, A.M., and Goldring, R., 1993. Description and analysis of bioturbation and ichnofabric. Journal of the Geological Society, 150(1):141-148. https://doi.org/10.1144/gsjgs.150.1.0141

Terry, R.D., and Chilingar, G.V., 1955. Summary of "Concerning some additional aids in studying sedimentary formations," by M. S. Shvetsov. Jour- nal of Sedimentary Research, 25(3):229-234.

http://jsedres.geoscienceworld.org/cgi/content/abstract/25/3/229

Tucker, M.E., 1988. Techniques in Sedimentology: Oxford, United Kingdom (Blackwell Science Publishing).

Valet, J.-P., and Meynadier, L., 1993. Geomagnetic field intensity and reversals during the past four million years. Nature, 336(6452):234-238. https://doi.org/10.1038/366234a0

Valet, J.-P., Meynadier, L., and Guyodo, Y., 2005. Geomagnetic dipole strength and reversal rate over the past two million years. Nature, 435(7043):802805. https://doi.org/10.1038/nature03674

Von Herzen, R., and Maxwell, A.E., 1959. The measurement of thermal conductivity of deep-sea sediments by a needle-probe method. Journal of Geophysical Research, 64(10):1557-1563. https://doi.org/10.1029/JZ064i010p01557

Wentworth, C.K., 1922. A scale of grade and class terms for clastic sediments. Journal of Geology, 30(5):377-392. https://doi.org/10.1086/622910

Witon, E., and Witkowski, A., 2003. Diatom (Bacillariophyceae) flora of early Holocene freshwater sediments from Skalafjord, Faeroe Islands. Journal of Micropalaeontology, 22:183-208. https://doi.org/10.1144/jm.22.2.183

Wood, D.M., 1985. Some fall-cone tests. Géotechnique, 35(1):64-68. https://doi.org/10.1680/geot.1985.35.1.64

WoRMS Editorial Board, 2018. World Register of Marine Species. https://doi.org/10.14284/170

Zelt, B.C., Taylor, B., Weiss, J.R., Goodliffe, A.M., Sachpazi, M., and Hirn, A., 2004. Streamer tomography velocity models for the Gulf of Corinth and Gulf of Itea, Greece. Geophysical Journal International, 159(1):333-346. https://doi.org/10.1111/j.1365-246X.2004.02388.x

Zonneveld, K.A.F., and Pospelova, V., 2015. A determination key for modern dinoflagellate cysts. Palynology, 39(3):387-409. https://doi.org/10.1080/01916122.2014.990115

Zreik, D.A., Ladd, C.C., and Germaine, J.T., 1995. A new fall cone device for measuring the undrained strength of very weak cohesive soils. Geotechnical Testing Journal, 18(4):472-482. https://doi.org/10.1520/GTJ11022J 